\title{
Comparative Genomic Reconstruction of Transcriptional Regulatory Networks in Bacteria
}

\author{
Dmitry A. Rodionov ${ }^{1,2, *}$ \\ 1 Burnham Institute for Medical Research, La Jolla, California 92037 \\ 2Institute for Information Transmission Problems, Russian Academy of Sciences, Bolshoi Karetny per. 19, \\ Moscow, 127994, Russia
}

\section{Keywords}

bacteria; comparative genomics; transcriptional network; regulons

\section{Introduction}

Microorganisms in most ecological niches are constantly exposed to variations of many environmental factors including temperature, oxygen, nutrient and water availability, presence of toxic compounds, and interaction with other organisms. Changing gene-expression patterns is a major adaptive response to these variations. Expression of genes in bacteria is controlled by a variety of mechanisms based on the level of transcription or translation. In most cases, the switch in gene expression is mediated by the specific regulatory proteins that receive an appropriate intra- or extracellular signal and trigger the specific transcriptional response. ${ }^{1}$

The key components of transcriptional regulatory machinery in prokaryotes are transcription factors (TFs) and transcription factor-binding sites (TFBSs), sigma factors and promoters, antiterminator proteins, and cis- and trans-acting regulatory RNAs. TFs are proteins that recognize specific cis-regulatory DNA sequences (TFBSs) to either stimulate or repress transcription of genes. ${ }^{2}$ Sigma factors are prokaryotic transcription initiation factors that must be a part of RNA polymerase holoenzyme for specific binding to promoter sites encoded in the 5 -untranslated regions (UTR) of genes. ${ }^{3}$ Antiterminator protein factors bind to specific secondary structures in the leader region of mRNA to restart transcription of a gene. ${ }^{4}$ Cellular signals that can modulate TFs include binding of a small molecule (effector), interaction with other proteins (e.g. phosphorylation), changing redox state, temperature, and other conditions. 5 Finally, various regulatory RNA structures including cis-acting metabolite-sensing riboswitches, T-boxes, and attenuators 6,7 and trans-acting small RNAs $^{8}$ control gene expression without involvement of specific proteins.

The operon is a set of adjacent genes that are transcribed as a single polycistronic mRNA. This organization of genes in operons achieves for bacteria a simple solution to the problem of coregulating genes that participate in the same metabolic process. However, the operon strategy has some limitations, e.g., the inability to combine both an independent regulation and a coordinated control. Regulon organization presents a level of control above the operons and permits coordinated control of operons that each have their own unique control. The regulon is a group of operons controlled by a common TF or regulatory RNA. The regulon usually

*Address for correspondence: 10901 N. Torrey Pines Rd., La Jolla, CA 92037, Phone: (858) 646-3100 ext. 3082, Fax: (858) 795-5249, E-mail: rodionov@burnham.org. 
includes genes that are implicated in a common cellular subsystem or a pathway. For example, in most species the regulons for arginine and thiamin biosynthesis genes are controlled by the ArgR repressor and $T H I$ riboswitch, respectively. ${ }^{9}, 10$ However, most responses of bacterial cells to even a simple environmental stimulus are complex. Thus, the operational term stimulon was defined to refer to an ensemble of genes (often involving multiple regulons and independent operons) that respond to a common environmental stimulus, although they may not share a common mechanism of regulation. For example, the heat-shock and phosphatestarvation stimulons include hundreds of genes in Escherichia coli, while only some of them are known members of the $\sigma^{32}$ and PhoB regulons, respectively. ${ }^{11}$ Finally, the term modulon was introduced to define a set of genes that are either directly or indirectly controlled by a certain regulatory system.

Fine-tuned environmental responses require efficient, flexible, and robust transcriptional regulatory networks (TRNs) that contain both internal checkpoints and feedback mechanisms to orchestrate the level of gene expression. To define a particular TRN, we need to specify which TFs bind to the promoter regions of which genes and what is the integrated effect of all these TFs on the expression of all these genes. ${ }^{12}$ Reconstruction of TRNs helps to better understand the metabolism and functions of prokaryotic organisms. ${ }^{13}$ Accumulated amount of information about gene regulation networks was used to define the basic building blocks of complex TRNs, termed network motifs, and to undestand their design principles. ${ }^{14}$

Traditional experimental methods for analysis of transcriptional gene regulation (such as gene cloning, knockout, reporter fusion and in vitro transcription) and characterization of TFBSs (electrophoretic mobility shift, nuclease protection assays) have been very powerful. However, they have certain limitations both in terms of productivity (the scale) and feasibility (e.g. for non-model organisms). Development of high-throughput transcriptome and proteome approaches allows thousands of genes and hundreds of proteins to be studied in a single experiment. DNA microarray technology has revealed the role of many regulatory factors in global regulatory networks in Escherichia coli, Bacillus subtilis, and other model bacteria. ${ }^{15}$ However, in many cases the complexity of the interactions between regulons makes it difficult to distinguish between direct and indirect effects on transcription. Another high-throughput experimental approach, the ChIP-on-chip technique (see section 3.1), is increasingly used for investigation of the genome-wide DNA binding of global TFs in bacteria. ${ }^{16-20}$ Wide-ranging proteomic approach was used to assess phosphate-starvation response in Vibrio cholerae, the iron regulatory network in Rhizobium leguminosarum, and the bacteroid proteins network in Bradyrhizobium japonicum. ${ }^{21-23}$ Finally, recent advances in tandem mass spectrometry and development of the powerful computational algorithms enable de novo shotgun sequencing of protein mixtures, thus provinding another promising approach for high-throughput protein expression analysis. ${ }^{24-25}$

A constantly growing number of complete prokaryotic genomes allows computational biologists to extensively use comparative genomic approaches to predict cis-acting regulatory elements (TFBSs, RNA elements) and to reconstruct TRNs in bacteria. ${ }^{12,13,26-29}$ The major directions of this analysis involve analysis and description of previously known regulons in uncharacterized organisms and ab initio prediction of novel regulons. Finally, the comparative analysis of regulons combined with other techniques of genome context analysis (see section 3.3) helps significantly to improve quality and accuracy of functional gene annotations and predict novel genes in a variety of pathways.

The focus of this review is on novel approaches to the analysis of bacterial regulons, including the methods of identification of TFBSs and RNA regulatory elements based on comparative genomics (Section 2). It provides a summary of several major studies on the computational reconstruction of certain TRNs in bacteria and an overview of Web-accessible databases of 
microbial TFs and their TFBSs (Section 3). Finally, I discuss the likely evolutionary scenarios for bacterial regulons and the balance of conservation and flexibility in the composition of TRNs among species (Section 4).

\section{Computational Methods for Identification of Regulatory Motifs}

\subsection{Structure, Function, and Representation of Transcription Factor Binding Sites}

2.1.1. Position of TFBSs in Promoter Regions-TFs regulate gene expression via specific binding to DNA sequences (or operators) located in promoter regions. The DNAbinding affinity and activity of TFs could be modulated by various signals including interaction with small ligands or covalent modification (e.g., phosphorylation by a specific sensor kinase). When a TF binds to an operator, it can either activate or repress transcription initiation. ${ }^{30}$ In bacteria, there are TFs that act solely as repressors or as activators, whereas some other TFs have a dual regulatory role in gene expression. Positive or negative effects of such dual TFs depend on the position of the operator site within the target promoter region.

Most repressor sites are located between -60 and +60 relative to the transcriptional start site, suggesting that repression by steric hindrance of RNA polymerase binding to the promoter is the most common regulatory mechanism. ${ }^{31-33}$ Alternatively, repressors may act by blocking transcription elongation or by looping DNA in the promoter region (Fig. 1). The degree of repression depends significantly on the operator site position relative to the promoter. ${ }^{34}$ Analysis of the data for various negatively acting regulators shows large variability in the relative positions of operators and promoters for each regulon. This variation in the repressor site position is in contrast to the relatively fixed positions of activator sites. Activators promote gene expression by binding to an operator that is located either upstream of or adjacent to, the promoter -35 element and by recruiting RNA polymerase to the promoter by direct proteinprotein interaction (Fig. 1). For example, the global catabolic activator Crp in E. coli binds operators, which have a preference to be centered at positions $-62.5,-72.5$, or -92.5 at Class I promoters, or at position -41.5 at Class II promoters. ${ }^{35}$ Some activators (e.g., those from the MerR family) bind at or near to the promoter elements and alter the conformation of the promoter to allow its interaction with RNA polymerase. 30

2.1.2. Structure of TFBSs-The size of a single TFBS usually varies between $\sim 12$ to 30 $\mathrm{nt}$, the most common length being 16-20 nt. Since TF proteins often recognize and bind to DNA as homodimers or homo-multimeric protein complexes, the TFBSs usually possess an intrinsic symmetry. Cooperative binding of transcription factors to DNA plays an important role in regulating gene expression, ensuring a sigmoid response to the concentration of effector. Inverted repeats (palindromes) and direct repeats are the most common structures of TFBSs. Some homo-multimeric TFs cooperatively bind more complex TFBSs composed of both inverted and direct repeats (e.g., AraC in E. coli). However, in contrast to eukaryotes, complex regulatory cassettes containing heteromultimeric TFBSs are rare in prokaryotes. On average, TFBSs with dyad symmetry are predominant in bacteria. Although the spacing between two repeats may vary significantly, it is usually a specific value for a given TF. For instance, the distance between two halfsites in direct repeats is often a multiple of the length of one DNA helix turn (10.5 nt). Examples of TFBS structures found in bacteria are given in Table 1.

2.1.3. TFBS Consensus and Logo Sequences-TFs bind to their DNA motifs in regulatory regions in a sequence-specific manner. However, the binding sites of a particular TF located upstream of different genes in the same genome could vary significantly allowing for a more flexible transcriptional control. This degenerate nature of most TFBSs is in contrast with much more strict conservation of recognition sequences for restriction enzymes. Different DNA-binding properties of TFs and restriction enzymes have an impotant biological meaning. Restriction enzymes need to have an all or none activity to protect the cell against phages and 
viruses, whereas TFs may have sites with different sequences and different affinities to regulate gene expression at different levels. ${ }^{36}$

The consensus sequence was commonly used to describe the DNA binding site specificity of TFs and generally refers to a sequence that matches all of the example sites closely, but not necessarily exactly (Fig. 2A). The number of mismatches allowed for the consensus sequence can be decreased by using the degenerate consensus sequence. This description of TFBSs uses an extended alphabet to show variable or degenerate nucleotides. For instanse, $\mathrm{Y}$ stands for $\mathrm{C}$ or T (pYrimidine), R stands for A or G (puRine), W stands for A or T (Weak), and S stands for $\mathrm{C}$ or $\mathrm{G}$ (Strong). Sequence logo is a more precise graphic representation of the patterns within a multiple sequence alignment of TFBSs (Fig. 2B). Logo displays the frequencies of nucleotides at each position, as the relative heights of letters (A, T, G, and C), along with the degree of sequence conservation as the total height of a stack of letters, measured in bits of information. 37,38

2.1.4. Positional Weight Matrices-A nucleotide frequency positional weight matrix (PWM) representation of the sites is an alternative to logo and consensus sequences (Fig. 2C). 39 PWM could be constructed by aligning known TFBS sequences, e.g., by using the program CONSENSUS. ${ }^{40}$ The PWM-based approach is more sensitive and more precise for TFBS recognition than the consensus-based methods. ${ }^{41}$

Several methods have been proposed to determine the positional nucleotide weights for any particular collection of sites. ${ }^{42,43}$ The method introduced by Staden 44 is very similar to current methods. In this method the weights are calculated as the negative logarithms of the frequences of each nucleotide at each position. Thus the sum of weights for any particular site is the negative logarithm of the probability of observing that particular sequence in the collection of known sites. Tom Schneider defined and used "information content" of binding sites on nucleotide sequences to calculate the amount of information that is required to locate the sites, given that they occur with some frequency in the genome. ${ }^{45}$ Using statistical mechanics theory, it was shown that the information content is related to the average binding energy for the collection of sites. ${ }^{46}$

2.1.5. Search for TFBSs in Microbial Genomes-Computational algorithms for searching for potential TFBSs in genomic sequences most often use PWMs to evaluate the resemblance of any DNA sequence to a given TFBS pattern. ${ }^{39}$ The score for a candidate TFBS sequence is calculated as the sum of the respective weights for each position. Any sequence with a score that is higher than the predefined cutoff is considered as a potential TFBS. One limitation of the PWM approach is the assumption that the positions in the site contribute additively to the total activity.

With the constructed PWM one can scan the whole genome and find additional genes that share the same DNA signal within their potential regulatory regions. Various programs, including PATSER $^{40}$ and MAST, ${ }^{47}$ allow scanning sets of DNA sequences to identify potential TFBSs by using the generated PWMs. The Genome Explorer software for bacterial genome analysis provides tools for both genome-wide identification of TFBSs and comparison of gene sets in several genomes. 48

Finally, it is instructively to mention one curious example of genomic identification of TFBSs by experimental biologists that have ignored available TFBS search tools. In this work, the authors used the Microsoft Word 2000 Find tool to identify putative binding sites of the ferric uptake regulator Fur in the genome of Staphylococcus aureus using the consensus sequence and by inserting the "any character" function to enable mismatches. 49 


\subsection{Repertoire of Transcription Factors in Prokaryotic Genomes}

2.2.1. Distribution of TFs in Microbial Genomes-The estimated number of DNAbinding transcription factors varies in different microorganisms depending on their genome size, lifestyle, and habitat. Earlier literature analysis and similarity searches in E. coli K12 suggested that close to $7.5 \%$ of genes (around 300-350) encode TFs. 50 A collection of 237 candidate TFs was identified in another model microorganism, B. subtilis. ${ }^{33}$ The smaller number of TF genes in $B$. subtilis could be explained by the higher number of RNA attenuators, in particular riboswitches, that contribute significantly to the regulation of numerous fundamental metabolic pathways in Gram-positive bacteria. 51

Analyses of other bacterial genomes revealed a reasonable correlation between the number of TFs and the genome size. ${ }^{33,52-55}$ The number of DNA-binding TFs was recently assessed in all sequenced organisms through homology-based prediction using profile hidden Markov models (HMMs) of domains and collected in DBD database. ${ }^{56}$ Thus, it is limited to factors that are homologous to those HMMs. The collection of HMMs was taken from two existing databases (PFAM57 and SUPERFAMILY ${ }^{58}$ ), and is limited to models that include TFs that specifically recognize TFBSs. ${ }^{56}$ Using DBD database we chose 230 prokaryotic organisms and plotted the number of TFs per genome against the total number of open reading frames (ORFs), which serves as an indicator of genome size in prokaryotes (see Supplementary Table 1). Various taxonomic groups of Bacteria and Archaea showed similar trend of a nearly linear increase in the number of TFs starting from $1500 \mathrm{ORFs}$ per genome (Fig. 3A). Obligate pathogens and endosymbionts with a small genome size (less than $\sim 1500$ ORFs, see Supplementary Table 1 and Fig. 3B) have a much lower proportion of TFs (average 1\%) compared to free-living and facultative pathogenic microorganisms (average 4.5\%). The presence of only a few TFs in intracellular parasites (Chlamydia, Rickettsiales), symbiotic $\gamma$ proteobacteria (e.g., Buchnera), and some obligate pathogens (Mycoplasma and Spirochetes) is consistent with a reductive genome evolution that led to the loss of genes not essential for life within the host. ${ }^{59}$

Environmental properties and metabolic capabilities of microorganisms strongly influence the proportion of TFs encoded in their genomes (Supplementary Table 1). Complex lifestyles and metabolic versatility require a higher number of TFs to better coordinate a response to changing conditions. Pathogenic and non-pathogenic bacteria from the same taxonomic group usually have similar proportions of TFs (e.g. see Vibrio cholerae vs. V. fischeri, Bacillus cereus vs. B. subtilis, and Pseudomonas aeruginosa vs. P. fluorescens). Several free-living bacterial species with large genomes (Myxococcus xanthus, Rhodopirellula baltica, Anabaena and Nostoc spp.) have characteristically small proportions of TFs (Fig. 3A). This discrepancy is compensated by the presence of complex regulatory pathways that involve serine-threonine protein kinases and sensor histidine kinases linked to $\sigma^{54}$ activators, as well as many specialized $\sigma$ factors. ${ }^{60-62}$

2.2.2. Families of TFs-Known microbial transcription factors are classified in at least 50 protein families based on the sequence similarity of their DNA-binding domains. $33,52,54$ Major protein families that contain a large number of TF representatives with various regulatory roles are listed in Table 2. The largest known family of TFs is LysR, followed by AraC and TetR. The distribution of TFs by families varies among different species, e.g., the LysR protein family is the most abundant in a- and $\gamma$-proteobacteria, ${ }^{50}$ whereas the MarR family is the largest in B. subtilis, 33 and the IclR family is overrepresented in Bordetella species. 63

Number of TF families detected in archaea is significantly lower than in bacteria: 19 families are shared by bacteria and archaea, wheras 33 families of bacterial TFs were not found in archaea. ${ }^{54}$ Significant divergence of transcription regulatory systems in bacteria and archaea 
could be explained by emergence of novel TF families after divergency of two kingdoms. However, in contrast to a large number of bacteria-specific TF families, there is only one known family of archaea-specific TFs, HTH-10. One possible reason for this fact is the limiting number of experimental studies on transcriptional regulation in archaea.

Almost half of the characterized TF protein families contain regulators with only one characterized functional role/specificity. ${ }^{54}$ Examples of TFs with unique functional roles include ArgR, MetJ, and TrpR for arginine, methionine, and tryptophan metabolism, respectively; BirA and NadR for biotin and NAD biosynthesis; HrcA and LexA for heat shock and SOS responses; ModE and NikR for molybdenum and nickel homeostasis; and NrdR for deoxyribonucleotide synthesis. Some of these protein families are universally distributed among most bacterial species (e.g., NrdR, BirA, ArgR), whereas others are restricted to certain taxonomic groups (e.g., TrpR and MetJ in $\gamma$-proteobacteria, NadR in enterobacteria). Importantly, representatives of these unique TF families are usually present in one copy per genome.

Two-component signal transduction regulatory systems are widely used by prokaryotic cells to transmit and propagate a wide variety of environmental and intracellular signals. These regulatory systems typically comprise a sensory histidine kinase and the cognate response regulator. ${ }^{64}$ Phosphorylation of the Asp residue in the $\mathrm{N}$-terminal receiver domain of the latter regulatory component induces conformational changes, allowing it to form dimers and bind to DNA operators. Most DNA-binding domains in response regulators belong to the OmpR, LuxR/NarL, Fis/NtrC, and LytR families. The large number of paralogous subfamilies of histidine kinases and response regulators includes a repertoire of recently evolved signalling genes, which may reflect selective pressure to adapt new environmental conditions. ${ }^{65}$ Both lineage-specific gene family expansion and horisontal gene transfer play major roles in the appearance of novel two-component regulatory systems.

2.2.3. Domain Architecture of TFs-Structural analysis revealed that the helix-turn-helix (HTH) signature is the most common DNA-binding motif present in all major prokaryotic TF families (Table 2). A "recognition" $\alpha$-helix in the HTH motif forms specific contacts with DNA by fitting into the DNA major groove. Other structural DNA-binding motifs, including zincfinger (e.g., in Ros ${ }^{66}$ ), zinc-ribbon (e.g., in NrdR), and antiparallel $\beta$-sheets (e.g., in MetJ), are much less abundant in prokaryotes. Position of DNA-binding domain within the polypeptide (e.g., N-terminal, C-terminal, or central) is conserved within a TF family but may vary between families (Table 2). Position of DNA-binding domain correlates with a positive or negative mode of regulation by TF: N-terminal DNA-binding domains are consistently present in repressors, whereas activators usually have C-terminal DNA-binding domain. ${ }^{67,68}$

In addition to DNA-binding domains, transcriptional regulators possess domain(s) involved in dimerization and/or sensing of particular environmental stimuli. Most of these non-DNAbinding TF domain families are found exclusively within TFs. However, some of them are shared with proteins of distinct cellular functions, i.e., periplasmic substrate-binding proteins of ABC transporters (LacI family of TFs) or sugar kinases (ROK family of TFs). Interestingly, regulators of the biotin and NAD metabolic pathways in E. coli (BirA and NadR, respectively) are bifunctional proteins with $\mathrm{N}$-terminal HTH domains and $\mathrm{C}$-terminal enzymatic domains, which allows them to contribute to both biochemical transformations and gene expression of the respective metabolic pathways. 69,70

2.2.4. Global and Local TFs-Global transcription factors are defined as regulators that control more than 20 different genes in different transcriptional units and are usually involved in a number of distinct pathways. ${ }^{50}$ Major global regulators in $E$. coli are the cAMP receptor protein Crp; the anaerobic regulators Fnr and ArcA, the leucine-responsive regulator Lrp, the 
histone-like DNA-binding proteins Ihf, Fis, and Hns, the iron-responsive regulator Fur, and the nitrite response regulator NarL. ${ }^{71}$ Global regulators identified in B. subtilis include the growth phase transition factors $\mathrm{AbrB}$ and $\mathrm{CodY}$, the carbon catabolic protein CcpA, the late competence regulator ComK, the regulator of initiation of sporulation Spo0A, and the nitrogen assimilation regulator TnrA. ${ }^{33}$

Local TFs usually regulate one or several transcriptional units encoding proteins from the same metabolic pathway. There is a tendency of genes encoding local TFs to cluster with TFregulated genes on the chromosome (e.g. to form an operon or divergon). ${ }^{72,73}$ It is quite common when a gene cluster involved in the utilization (catabolism) pathway for a specific compound includes also a local TF gene providing a specific transcriptional control of this gene cluster in response to this compound. For example, the sugar-specific repressors from the LacI family in E. coli (e.g., LacI, GalS, GntR, MalI, RbsR, and TreR) are encoded by the same cluster together with target genes involved in utilization of the specific sugar (lactose, galactose, gluconate, maltose, ribose, and trehalose respectively). ${ }^{73}$ Other examples of local TFs include specific regulators of biosynthetic pathways for co-factors (e.g., NadR, BirA in E. coli), amino acids (e.g. MetJ, ArgR, TrpR, TyrR), nucleotides (e.g., PurR), uptake transporters for essential metals (e.g., Zur, ModE, MntR, NikR), and specific stress or drug response pathways (LexA, OxyR, AcrR, MarR).

2.2.5. Alternative Sigma Factors-Bacterial sigma factors are an essential component of RNA polymerase and determine promoter selectivity. ${ }^{74}$ The regulon of a single sigma factor can be comprised of hundreds of genes. The $\sigma^{70}$ subunit of RNA polymerase in $E$. coli specifies transcription from promoters that are responsible for basal gene expression during vegetative growth. Sigma factors can be classified into two structurally unrelated families: the $\sigma^{70}$ and the $\sigma^{54}$ families.

The first family includes primary sigma factors (e.g., E. coli $\sigma^{70}$, B. subtilis $\sigma^{\mathrm{A}}$ ) and related alternative sigma factors that mediate transcription initiation of various sets of genes in bacteria. For instance, $\mathrm{RpoH}\left(\sigma^{\mathrm{H}}\right)$ transcribes the genes of heat shock response regulon. The main regulatory role of FliA $\left(\sigma^{28}\right)$ in many bacterial species is to transcribe genes required for flaggelar synthesis and bacterial motility. The sigma factors $\sigma^{\mathrm{B}}$ in Gram-positive bacteria and $\operatorname{RpoS}\left(\sigma^{S}\right)$ in Gram-negative bacteria are functionally similar to each other in that they are responsible for stationary phase and stress response gene expression. Many alternative sigma factors also play an important role in bacterial pathogenesis by regulating expression of virulence-associated genes (e.g. $\sigma^{\mathrm{S}}$ and $\sigma^{28}$ in Salmonella).

RpoN ( $\sigma^{54}$ or $\sigma^{\mathrm{N}}$ ) has several features that distinguish it from other sigma factors: it is not homologous to other sigma subunits, $\sigma^{54}$-dependent expression absolutely requires an activator, and the activator binding sites can be far from the transcription start site. ${ }^{75} \mathrm{~A}$ physiological theme for $\sigma^{54}$-dependent genes has not yet emerged, as the regulated genes described to date control a wide diversity of processes including nitrogen assimilation, uptake and catabolism of amino acids, secondary metabolism and virulence.

Extracytoplasmic function (ECF) sigma factors is a phylogenetically distinct subfamily within the the $\sigma^{70}$ family. ECF sigma factors are small TFs that, upon receiving a stimulus from the environment, are released and can bind to RNA polymerase to stimulate transcription of a specific group of genes. ${ }^{76}$ The number and functional roles of ECF sigma factors encoded in bacterial genomes are highly variable. For example, FecI in E. coli, and PvdS in $P$. aeruginosa are involved in iron siderophore synthesis and uptake, whereas $\sigma^{\mathrm{W}}$ in $B$. subtilis and the orthologous sigma factor $\sigma^{\mathrm{E}}$ in E. coli control intrinsic resistance to antimicrobial compounds, heavy metals and oxidative stress. 
The number and diversity of sigma factor genes per genome is related to the environmental variation allowing growth for a given species. The distribution of three classes of sigma factors $\left(\sigma^{70}, \sigma^{54}\right.$, and ECF) in bacterial genomes was determined using HMM profiles based on experimentally verified sigma factors (see Supplementary Table 2). ${ }^{77}$ Most bacteria species have either one or no $\sigma^{54}$ genes. However, there is a larger divergence in the number of genes from $\sigma^{70}$ family. For example, the large genomes of Streptomyces species have $14 \sigma^{70}$ genes, while the rest Actinobacteria have far less. In Cyanobacteria, there is quite high number of $\sigma^{70}$ genes (5 to 8), the same is true for the sporulating bacilli and clostridia. ECF sigma factors are generally far more numerous than the other two classes, but since they are not essential, they are missing in many organisms. Streptomyces species have 45 ECF sigma factors that are mainly involved in the control of secondary metabolism. Bacteroides thetaiotaomicron currently holds the record with 48 predicted ECF genes. Other genomes with high amount of ECF sigma factors are M. xanthus (31), R. baltica (29), and Pseudomonas fluorescens (28). Interestingly, the first two species have relatively small proportion of normal TFs in their large genomes.

\subsection{Databases of Microbial TFs and TFBSs}

With the increasing amount of information on transcriptional regulation in bacteria, many public databases specializing in microbial regulation are becoming available (Table 3). These include web-resources specialized on transcriptional regulatory networks in model microorganisms, such as E. coli (RegulonDB78), B. subtilis (DBTBS79), Corynebacteria (CoryneRegNet80) and Mycobacterium tuberculosis (MtbRegList81). These databases compile an arsenal of TFs with their regulated genes as well as their recognition TFBS sequences, which were experimentally characterized. In addition to integration of the published experimental data on gene regulation, these resources provide genome-scale computational predictions of operons, promoters, TFBSs, and regulons. Using of these resources helps to propose new regulatory hypothesis for wet-lab verification.

Several databases provide information about known and predicted TFs in multiple microbial genomes. The DBD database ${ }^{56}$ classifies TFs by DNA-binding domain protein families. The Extra Train database 82 provides the distribution of the 16 largest families of TFs in microbial genomes. The AraC, TetR, and IclR families of TFs were reviewed and analyzed in details, 83-85 and integrated in the BacTregulators database. ${ }^{86}$ The Sentra database ${ }^{87}$ of signal transduction proteins lists manually curated two-component histidine kinases and response regulators encoded in completely sequenced prokaryotic genomes. The cTFbase database classifies TFs identified in 21 cyanobacterial genomes and provides a resource for comparative analysis of putative TFs in Cyanobacteria. ${ }^{88}$

A prokaryotic database of gene regulation, PRODORIC ${ }^{89}$ integrates different types of data including regulators and TFBSs, promoter structures, operon and regulon organization by screening the original literature. Another manually curated database of gene regulation in prokaryotes, Reg TransBase, 90 captures experimental knowledge on regulatory sequences and interactions published for a variety of microorganisms. In addition, these two webresources provide a set of tools to predict and compare TFBSs in multiple genomes. The TRACTOR database ${ }^{91}$ contains comparative genomic predictions of new members of 74 known $E$. coli regulons in the genomes of $\gamma$-proteobacteria.

\subsection{Computational Tools for Discovery of TFBSs in the Genomes}

A number of computational methods have been developed for identification of candidate TFBSs. ${ }^{92,93}$ These methods are subdivided into the consensus-building and PWM-based approaches. The consensus-based approaches including the "word counting" and exhaustive enumeration algorithms are more useful for motif finding in eukaryotic regulatory regions 
which, in contrast to bacteria, mostly include composite regulatory signals. ${ }^{94-97}$ In PWMbased approaches, the specificity of the protein is represented as a matrix rather than the consensus sequence, allowing the binding site pattern to be identified. All these methods identify a common regulatory motif from multiple DNA fragments. The input training set of regulatory regions might be composed based on many sources for possibly co-regulated genes, including microarray experiments, gene knockout experiments, and functional classes of genes that form a common metabolic pathway from the literature. ${ }^{98}$

There are many different implementations of PWM-based algorithms and the most popular of them are outlined below. Detailed operation principles, technical data, and URLs of 13 different PWM-based tools were recently reviewed by Tompa and co-authors. ${ }^{99}$ In this study, the authors conducted comparative assessment of these computational tools and estimated their accuracy and correctness for TFBS discovery in various input settings and data sets. 99

One of the first algorithms builds up a multiple alignment of the sites by adding new sites at each iteration and identifies the best alignment with the highest information content. ${ }^{100}$

Expectation-maximization (EM) methods simultaneously optimize the PWM description of a motif and the binding probabilities for its associated sites. ${ }^{101}$ One popular implementation of EM algorithm, MEME, performs a single iteration for each site in the target sequence, selects the best motif from this set, and then iterates only that one to convergence. ${ }^{102}$ SignalX is another EM-based program that uses an iterative procedure of clustering all weak palindromic sequences in the training set of DNA fragments to identify a palindromic signal of a given length with the highest information content. ${ }^{103}$ A Gibbs-sampling algorithm is a stochastic implementation of the EM method that samples the space of all multiple alignments of small sequence segments in search of the one that is most likely to consist of samples from a common PWM. ${ }^{104}$ The AlignACE program, ${ }^{105}$ the Gibbs Recursive Sampler, 106 and the SeSiMCMC program 107 are variants of the Gibbs sampling algorithm optimized for finding multiple distinct TFBS motifs within a single set of unaligned DNA fragments.

Another modification of PWM-based approach uses the fact that many TFs in bacteria bind to a palindromic motif with intrinsic symmetry. This symmetry-based approach was applied to single bacterial genomes to predict novel regulatory DNA sequence motifs represented by PWMs. ${ }^{108,109}$ The algorithm identifies all statistically significant palindromes in upstream intergenic regions and groups overrepresented sites into clusters of similar patterns. The set of PWMs constructed based on these patterns was used to scan the genome for additional candidate sites and to infer putative regulons. In the model species E. coli and B. subtilis, many derived clusters represent characterized regulatory motifs, whereas the large group of the remaining PWMs is likely to describe uncharacterized TFBSs. 108,109 Similar dimer-based approach was used by a different research group to predict 2497 regulatory motifs (PWMs) in the genome of Streptomyces coelicolor ${ }^{110}$ Functional analysis of genes located downstream of these DNA motifs identified several motifs that may be biologically significant as regulatory elements. These include a DNA motif found preferentially in UTRs immediately upstream of genes involved in polysaccharide degradation and sugar transport. ${ }^{110}$

\subsection{Comparative Genomic Approaches for Identification and Verification of TFBSs}

Identification and recognition of TFBSs in genomic sequences is an old problem in computational molecular biology. Until this section we considered sets of co-regulated genes from one genome and assumed that 5'-UTR regions of these genes contain a common TFBS motif. The problem of identification of additional TFBSs for known TFs was addressed in many studies, conducted mostly in model organisms such as E. coli and B. subtilis. ${ }^{111-118}$ In these studies, either a consensus sequence or a PWM constructed on the experimentally known sites were used to scan the genome of interest in order to predict novel regulon members. However, even for relatively well-studied regulons it is difficult to set thresholds reliably 
distinguishing between true and false sites. Besides, our ability to construct good recognition rules is severely impaired by limited availability of experimental data on TFBSs. The availability of hundreds of bacterial genomes opens opportunities for using comparative genomic approaches to identify conserved functionally important sites (e.g., TFBSs, promoters, RNAs regulatory sites) by genomic comparison of different species.

2.5.1. Consistency Check Approach-The presence of orthologous TFs in the analyzed microbial genomes is a prerequisite to the comparative analysis of their regulons. Furthermore, selection of genomes for the analysis depends on conservation of a TFBS signal between species. Very closely related genomes (e.g., different strains of the same species) usually have almost identical intergenic regions that do not permit getting rid of false positives. On the other hand, regulatory signals are usually poorly conserved, or are at least highly divergent in distant taxonomic groups (e.g., between Gram-positive firmicutes and Gram-negative proteobacteria). Finally, possible changes in operon structures of the co-regulated genes need to be taken into account while comparing the sets of genes with a common regulatory motif. The consistencycheck comparative approach was successfully applied for the prediction and verification of regulatory sites for many TFs in various taxonomic groups of bacteria and archaea. $9,69,70$, 119-127 An overview of these and other comparative studies of microbial regulons on reconstruction of regulatory networks is outlined in the next section of this review.

The consistency-check comparative approach is based on the assumption that regulons (sets of co-regulated genes) have a tendency to be conserved between the genomes that contain orthologous TFs. ${ }^{128,129}$ Therefore, the presence of the same TFBS upstream of orthologous genes is an indication that it is a true regulatory site, whereas TFBSs scattered at random in the genome are considered false positives (Fig. 4A). Simultaneous analysis of multiple phylogenetically related genomes allows one to make reliable predictions of TFBSs even with weak recognition rules. The consistency check sharply increases the specificity of predictions, although it may lose species-specific members of regulons. This technique not only allows the transfer of data on regulatory interactions from well-studied genomes to newly sequenced ones, but also makes it possible to find additional members of regulons and map novel regulons.

2.5.2. Phylogenetic Footprinting Approach-The phylogenetic footprinting approach identifies regulatory elements by finding highly conserved regions in a set of DNA sequences located upstream of orthologous genes from multiple species. ${ }^{130}$ The term "phylogenetic footprint" was first introduced to describe several conserved cis-regulatory elements in primates. ${ }^{131}$ The simple assumption of the method is that functional DNA sequences (such as TFBSs) diverge more slowly than nonfunctional ones (spacers). Identification of conserved regulatory elements by this method requires a certain degree of phylogenetic relatedness of the analyzed upstream regions of orthologous genes (or orthologous UTRs). The standard approach uses a global multiple alignment of the candidate orthologous UTRs to identify a conserved region in the alignment (Fig. 4B). It should be noted that the identification of a novel conserved regulatory element does not automatically reveal a TF that could recognize this site. This important problem of assignment of any identified TFBS to the corresponding TF is discussed in more details in Section 2.5.

The reliability of the phylogenetic footprinting method depends critically on the selection of species for the analysis. If the species are too closely related, the alignment is not informative. On the other hand, if they are too distant, it is difficult or impossible to construct an accurate alignment. The problem of species selection and the number of species required for the phylogenetic footprinting analysis of TFBSs was addressed using a set of $166 \mathrm{E}$. coli genes with experimentally identified TFBSs and genomic data from nine additional $\gamma$-proteobacteria. 132 It was found that just three species were sufficient for accurate motif predictions of TFBSs 
and that an appropriate phylogenetic distance between species is an important factor to consider.

In the case when many closely related genomes are available, one can use various computational tools for multiple alignments of bacterial genomes for mapping of potential TFBSs. Menteric server (http://globin.bx.psu.edu/enterix/) is a visualization tool for bacterial genome alignments designed for $E$. coli and related enterobacteria. ${ }^{133}$ VISTA family of computational tools (http://genome.lbl.gov/vista/) provides pre-computed full scaffold alignments for both microbial and eukaryotic genomes. ${ }^{134}$ Phylogenetic shadowing approach was developed to compute and statistically evaluate conservation profiles of multiple sequence alignments from closely related species. ${ }^{135}$ MicroFootPrinter is a phylogenetic footprinting program for discovering of conserved cis-regulatory elements in prokaryotic genomes. ${ }^{136}$

2.5.3. Genome-wide Application of Comparative Approaches-With the increasing number of sequenced genomes, phylogenetic footprinting approaches are becoming very popular tools of TFBS discovery. The quality of TFBS prediction by phylogenetic footprinting can be substantially improved by combining this approach with the existing motif discovery tools (such as MEME, AlignACE, and Gibbs sampling). Several algorithms based on such combination of phylogenetic footrpinting and motif discovery tools have been developed for eukaryotic genomes, including PhyloGibbs 137 and PhyME. ${ }^{138}$ Here I will outline key studies that use this combined appoach for identification of regulatory elements in bacterial genomes. In these studies, the motif discovery tools are applied to a training set of orthologous UTRs across species. I will illustrate these studies by multiple examples when the predicted TFBSs and regulons became validated in follow-up experiments.

The cross-species comparison of orthologous UTRs in E. coli and eight related $\gamma$-proteobacteria by the Gibbs-sampling algorithm revealed a large set of conserved DNA motifs (for almost 2,000 E. coli genes), many of which coincide with documented TFBSs. ${ }^{139}$ In the follow-up study, application of a Bayesian motif-clustering algorithm to the previously predicted by Gibbs sampling $\gamma$-proteobacterial motifs led to accurate identification of many experimentally reported E. coli regulons (for example, PurR, LexA, MetJ, Crp, TrpR, NtrC, Mlc, and ModE), prediction of their additional members, and identification of novel regulons. ${ }^{140}$ The Bayesian motif-clustering algorithm is based on an explicit statistical model that describes the relationship between the observed motifs and the putative regulons and a Markov chain Monte Carlo computational method. ${ }^{81}$ Several novel regulons identified in $E$. coli by the combined comparative genomic approach 80,81 were later experimentally confirmed. These include fatty acid biosynthesis regulon FabR (previously YijC) ${ }^{141}$ and novel ribonucleotide reductase regulon $\operatorname{NrdR}(\mathrm{YbaD}){ }^{142}$

In genome-wide analysis of eight $\alpha$-proteobacteria, ${ }^{143}$ the recursive Gibbs-sampling algorithm was applied to a set of orthologous upstream regions, and the resulting motifs were filtered and clustered into regulons by the Bayesian motif-clustering algorithm. ${ }^{140}$ The phylogenetic footprinting approach allowed the authors to identify 101 putative regulons in Rhodopseudomonas palustris. Among them are several regulons of particular interest: the FixK, NnrR, NtrC, and RpoN regulons related to nitrogen metabolism; the hydroperoxide stress OhrR regulon; the DNA damage response LexA regulon; the flagellar synthesis FlbD regulon; and the photosynthetic PspR regulon.

Another comparative study of three Bacillus species using a local pairwise alignment program has detected nearly 1,900 phylogenetically conserved elements in the upstream intergenic regions of $\sim 1,500 \mathrm{~B}$. subtilis genes. ${ }^{144}$ Subsequent clustering of these genes according to the motif similarity allowed the authors to predict 154 different DNA motifs, each of those possibly co-regulates a specific set of genes. Many of these motifs correspond to the previously 
described regulatory elements in B. subtilis including various TFBSs (e.g., CtsR, CcpA) and RNA attenuators (e.g., S-box, T-box). The authors tentatively identified several new members of known regulons were (e.g., dnaJ in CtsR), and many potential regulons that were not yet reported. One of these novel regulons, a hypothetical xanthine regulon for the purE, xpt, and $p b u G$ genes, was later described to operate by a novel type of a metabolite-responsive riboswitch, the guanine-responsive G-box. 51

In a comparative genomic study of two related groups of Gram-positive bacteria, lactobacilli and bacilli, clusters of orthologous transcriptional units were first identified, and the conserved DNA motifs were determined for two species sets using the MEME algorithm. ${ }^{145}$ These motifs were subsequently used to scan the upstream regions using the MAST program, and nearly 200 conserved motifs in each set of species were selected. Many of the predicted motifs from bacilli and lactobacilli were very similar, including several well-described regulatory motifs (e.g., T-box, CIRCE, LexA-box). Interestingly, this method revealed 18 lactobacilli-specific candidate regulatory motifs including 13 that had not been described previously. The PhyloScan algorithm was developed to increase the flexibility and sensitivity of scanning for potential TFBSs and to decrease false-positive site predictions using cross-species evidence. 146

The regulon detection by PhyloScan combines the evidence from matching sites found in orthologous data from several related species with the evidence from multiple sites within intergenic regions. The statistical significance of the TFBS predictions is calculated directly, without employing training sets. Application of the PhyloScan algorithm to seven Enterobacteriales genomes allowed authors to identify several novel TFBSs for global transcription factors Crp and PurR in E. coli.

The Regulogger computational approach discriminates true regulon members from falsepositive predictions on the basis of conservation of regulons across multiple genomes. ${ }^{147}$ To quantify the degree of conservation of putative TFBSs, the Regulogger calculates for each predicted regulon member a relative conservation score using the fraction of orthologs that are preceded by the same candidate TFBS. Regulon members that have orthologs with conserved candidate TFBSs are considered true-positive predictions and such a set is defined as a regulog. Application of Regulogger to the genome of Staphylococcus aureus and six related Grampositive bacteria identified 125 high-scoring regulogs, many of which are consistent with previously characterized regulons (e.g. TnrA, Fnr, Fur, CtsR, LexA). Some of these regulogs correspond to the highly conserved regions within the known RNA regulatory elements (e.g., T-box, $T H I$ riboswitch). The regulog approach also predicted novel members of known regulons and revealed novel potential regulons. One of the predicted regulogs containing various ribonucleotide reductase genes was later investigated in detail and shown to operate by the novel transcription regulatory system $\mathrm{NrdR}$ for the ribonucleotide reductase genes in most bacterial lineages. $87,142,148$

\subsection{Interconnection of Transcription Factors and Their DNA Motifs}

Many putative TFs in prokaryotes have been identified only on the basis of their homologies and are still uncharacterized with regard to their cognate DNA-binding motifs, sets of target genes (regulons) and effectors. New candidate TFBSs discovered by computational approaches such as phylogenetic footprinting and clustering 139,140 may be connected to particular TFs using a combination of different types of evidence such as (i) positional clustering of TFBS and TF on the chromosome; ${ }^{72}$ (ii) correlation in the phylogenetic pattern of co-occurrence of TFBSs (the presence or absence of a regulon) and TFs (the presence or absence of a candidate TF gene) in the genomes; ${ }^{148}$ and (iii) binding specificity constraints for TFs having structurally similar DNA-binding domains. ${ }^{149,150}$ Tan et al. ${ }^{151}$ combined these types of information to calculate the probability of a given TF-TFBS pair and predicted many new connections 
between uncharacterized TFs and candidate DNA motifs in E. coli. Positional evidence of the first type provides the strongest impact on the assignment of a TF to its DNA sites. This is not surprising, since bacterial TFs are often autoregulated ${ }^{71}$ and the genes encoding TFs tend to co-localize on the chromosome with the genes they regulate. ${ }^{151}$ For instance, in many local sugar utilization regulons, the target genes preceded by upstream TFBSs are located adjacent to the regulatory gene encoding corresponding TF.

Conservation of the gene neighborhood is very useful not only for functional annotation of enzymes and transporters, ${ }^{152}$ but also to predict the cellular and biological processes that TFs potentially regulate. ${ }^{72}$ However, some known TF genes, mostly those whose products has more than one target TFBS in the genome, are located remotely from their target genes (e.g., FruR and PurR in E.coli). Another limitation of the positional approach (especially if applied to a small group of species) is illustrated in the example of the NrdR regulatory system for ribonucleotide reductase genes. Based on the conserved positional clustering with riboflavin biosynthesis genes in most proteobacteria, the hypothetical gene ybaD in E. coli was originally annotated as a regulator of riboflavin biosynthesis. 72,153 However, a subsequent comparative genomic study 148 using phylogenetic co-occurrence patterns of TFs and TFBSs in combination with the phylogenetic footprinting approach assigned a different role of a universal regulator of the deoxyribonucleotide metabolism (named $\mathrm{NrdR}$ ) to the YbaD protein family. An extended positional analysis of NrdR sites allowed identifying several cases of colocalization of $n r d R$ genes with target ribonucleotide reductase genes in other bacterial lineages, e.g., in Actinobacteria. ${ }^{148}$ The predicted regulatory role of NrdR was finally confirmed in experiments conducted in Streptomyces species. 154

\subsection{Analysis of RNA Regulatory Elements}

Various RNA regulatory systems including riboswitches, translational attenuators, T-boxes, and RNA-binding proteins have been described in bacteria. ${ }^{7}$ The main mechanisms involved in regulation by cis-regulatory RNAs are based on the formation of alternative mRNA structures that either terminate transcription (terminators) or inhibit initiation of translation (sequestors). Different classes of RNA elements use different mechanisms to sense the concentration of a metabolite. Typically, an effector-responsive protein factor specifically binds the cis-regulatory RNA that is rather small and simple in structure (e.g., the tryptophanresponsive TRAP protein in B. subtilis). A unique class of RNA elements, T-boxes in Grampositive bacteria, interacts directly with specific uncharged tRNAs to promote expression of target genes in response to amino acid concentrations. Riboswitches are widespread RNA elements with a complex structure that directly sense metabolites and control gene expression of related metabolic pathways. ${ }^{155,156}$ Each riboswitch class is defined by a core of conserved base-paired elements and consensus nucleotides at specific positions and is highly specific to its cognate effector metabolite. Among various metabolites detected by known classes of riboswitches are vitamins (coenzyme $\mathrm{B}_{12}$, thiamin pyrophosphate, and flavin mononucleotide), amino acids (lysine, glycine, and S-adenosylmethionine) and nucleotides (adenine, guanine and queuosine).

A high level of conservation of primary and secondary structures of riboswitches and T-boxes is remarkable and very useful for their identification by comparative genome analysis. Various classes of riboswitches that regulate the cobalamin, thiamin, riboflavin, lysine, methionine and quesosine biosynthesis pathways were discovered by comparative genomic analysis $10,157-$ 162 and experimentally characterized by in-line probing assays. ${ }^{162-168}$ Representatives of 13 known classes of riboswitches identified in prokaryotic genomes are available within the Rfam database. ${ }^{169}$ RibEx, ${ }^{170}$ RegRNA, ${ }^{171}$ and Riboswitch finder, ${ }^{172}$ web-tools were designed to search any input sequence for the presence of known regulatory RNA elements. 
Discovery of new classes of RNA motifs and riboswitches in orthologous UTRs of genes is an interesting computational challenge. Comparison of UTRs between species resulted in identification of many novel RNA motifs with extensive sequence and secondary-structure conservation. ${ }^{173-176}$ Some of these RNA motifs were experimentally validated (e.g., two novel S-adenosylmethioinine riboswitches, queuosine riboswitch). ${ }^{162,174-177}$ Since the target genes for several other classes of new RNA motifs are mostly hypothetical, the effector molecules and the mechanism of regulation for these putative RNA regulatory elements remain unknown.

\section{Reconstruction and Comparison of Regulatory Networks that Control Central Metabolism in Bacteria}

During the last decade, the number of studies that use integrative genomic approaches for the analysis of regulons and metabolic pathways has substantially increased. Various techniques of genome context analysis, including chromosomal gene clustering, protein fusions and occurrence profiles are extremely useful for metabolic reconstruction and functional gene annotation (see152 for a review). In this section, the key principles and practical steps of genomic-based reconstruction of regulatory networks in bacteria are outlined. In the first part, single-microorganism studies of TF regulons that combine both high-throughput experimental approaches (such as expression profiling) with the genomic identification of TFBSs are outlined. The second part of this section summarizes comparative genomic studies describing TFBSs identification and reconstruction of TF regulons in complete microbial genomes. Finally, the last part illustrates the power of the comparative analysis of regulons for metabolic reconstruction and functional predictions including novel functional roles in metabolic pathways, candidates for missing genes, and specificities of transporters.

\subsection{Combining Experimental and Genomic Data to Predict TFBS Motifs}

DNA microarray technology detects changes in mRNA levels in different conditions and is extensively used for the analysis of transcriptional responses in bacteria. ${ }^{13}$ Expression profiling allows thousands of genes in the cell to be studied simultaneously in a single experiment. By comparing gene expression in different conditions or between different genetic backgrounds (e.g., a gene knockout mutant vs. a wild-type strain), one can identify a set of genes with the same pattern of expression, which could be potentially controlled by the same TF. However, because of experimental and biological variability, the interpretation of DNA microarray data is often ambiguous. ${ }^{178}$ Technical imperfections of the method include random biological variations, sample handling errors, and measuring errors. Furthermore, co-variation of expression level alone does not automatically imply that the corresponding genes form a single regulon (i.e., a set of genes directly controlled by a single TF). More accurately, such genes may be considered as a part of a so-called modulon (i.e., a set of genes either directly or indirectly controlled by a certain regulatory system).

The combination of chromatine immunoprecipitation (ChIP) and high-density microarrays, also known as the ChIP-on-chip technique, has been widely exploited to investigate interactions between eukaryotic proteins and their DNA targets in vivo. ${ }^{179,180}$ The method is based on capturing of protein-DNA interactions by chemical crosslinking and filtering them out using antibodies specific to the protein of interest. The enriched DNA population is then labeled and applied to DNA microarrays to detect enriched signals. In bacteria, ChIP-on-chip was successfully used for whole-genome identification TFBSs for global TFs, such as CtrA in Caulobacter crescentus, Crp and Fnr in E. coli, and Spo0A in B. subtilis. ${ }^{16-20}$ In comparison with DNA microarray appoach, ChIP-on-chip avoids complications due to genes indirectly controlled by a TF or genes that are regulated by multiple TFs. However, it also has an important limitation due to its inability to detect all TF-DNA interactions, which may be caused by 
inefficient cross-linking at some location. For example, ChIP-on-chip analysis of the Fnr regulon in E. coli identified 63 binding target sites, including several novel targets and missing many previously validated targets. ${ }^{17}$

The development of high-throughput experimental techniques has allowed the generation of vast amounts of data related to TRNs. These data combined with the information on known TRN structures from databases and literature have opened the way for genome-scale reconstruction of microbial TRNs. ${ }^{12}$ The matrix formalism was introduced to represent a series of regulatory rules for the individual genes of a TRN in a matrix form. ${ }^{181}$ In this form, the state of a gene is represented as either transcribed or not transcribed in response to regulatory signals. The matrix formalism allows for the systematic characterization of functional states of transcriptional regulatory systems and facilitates the computation of the transcriptional state of the genome under given environmental condition. ${ }^{181}$ The consistency between known TRNs and gene-expression data in E. coli is influenced by both the structural features of the network and the functional classes of genes involved in TRNs. ${ }^{182}$

The increased availability of high-throughput data will further improve the prospects of TRN reconstruction, and additional data types can be used to resolve inconsistencies. For instance, a large-scale mapping of $E$. coli TRNs inferred from a compendium of $445 E$. coli Affimetrix expression arrays and 3,216 known E. coli regulatory interactions from RegulonDB 78 was performed by the context likelihood of relatedness algorithm, allowing prediction of 1,079 regulatory interactions (with a $60 \%$ true positive rate), of which one-third were in the previously known TRN and two-thirds were novel predictions. 183

Computational identification of TFBSs in the genomes, combined with the gene expression data, improve the determination of bacterial regulons and allow one to distinguish between direct and indirect effects of a certain TF on the gene regulation. Many specific regulons were analyzed using high-throughput transcriptome comparisons between wild-type and TFknockout strains of a single bacterial species and supported by the genomic identification of candidate binding sites for the respective TFs. These include many global regulatory systems, such as Crp, ArcA, NarL, Fnr, and Fur in E. coli; $113,114,184,185$ CcpA, Fnr, and TnrA in $B$. subtilis; $115,117,186$ and Fur in Shewanella oneidensis ${ }^{187}$ and Yersinia pestis $188_{-}$as well as some specific regulons - such as the SOS response system LexA in B. subtilis ${ }^{189}$, the ironresponsive systems DtxR in Corynebacterium glutamicum, ${ }^{146,190}$ and Irr in

Bradyrhizobium japonicum. 191

Comparison of gene expression between TF knockout mutant and wild-type strains, subsequent selection of differentially regulated genes, and comparative analysis of the corresponding upstream gene regions help to accurately predict candidate TFBSs. For example, analysis of the CodY regulon in Lactococcus lactis revealed a novel overrepresented motif in the upstream regions of genes derepressed in the $\operatorname{cod} Y$ mutant strain. This motif was confirmed to function as a high-affinity CodY-binding site using electrophoretic mobility shift and nuclease protection assays. ${ }^{192}$ In another example, the $C$. glutamicum sulfur metabolism regulon McbR was analyzed by the same approach, resulting in the identification and experimental verification of a consensus McbR binding site. ${ }^{193}$ Whereas the DNA microarray detected 86 genes with enhanced transcription in the $m c b R$ mutant strain, the genomic analysis identified candidate McbR-binding sites upstream of 22 genes and operons, suggesting that the transcription of at least 45 genes involved in the sulfur metabolism is directly controlled by the McbR repressor. The remaining genes, which showed an enhanced expression in the $m c b R$ mutant but which are not part of the McbR regulon, are likely the subject of an indirect co-regulation. 
Similar conclusions were obtained by comparing the ArcA and Fnr modulons and regulons in $E$. coli that are involved in global anaerobic respiration control. ${ }^{194}$ The data about modulon composition were taken from two microarray studies of $\operatorname{arcA}$ and fnr mutants of E. coli, 195 , 196 whereas regulons were predicted by TFBS search and comparison between $E$. coli and related enterobacteria. ${ }^{194,197}$ The Fnr and ArcA modulons were defined as sets of genes with at least a two-fold change in expression and included 151 and 135 operons, respectively. However, in these groups of $E$. coli operons, candidate Fnr- and ArcA-binding sites were determined in the regulatory regions of 38 and 23 operons, respectively. It was concluded that the Fnr-ArcA regulatory cascade and additional regulatory systems significantly expand the respiratory modulons in comparison with the respective regulons. 194

Another novel technique, which combines in vitro run-off transcription with macroarray analysis (ROMA), was used to analyse the $\sigma^{\mathrm{W}}$ regulon in B. subtilis. ${ }^{198}$ Comparison of in vivo transcriptional profiling, ROMA, and consensus search approaches showed that these methods are complementary to each other and that each tends to miss some sites. Maximal coverage in the definition of a bacterial regulon was obtained by combining all three approaches. In a similar study of the $E$. coli Crp regulon, 35 the in vivo and in vitro transcription profiling methods were combined with Crp-binding site determination. Comparison of the ability of each of these methods to identify known members of the Crp regulon demonstrates that the site-search approach prevails over in vivo transcription profiling. The main reason of the failure to identify many Crp-regulated genes using microarrays is the complexity of the Crp regulon, where the Crp-activated promoters are dependent on the presence of additional regulators in response to a specific substrate.

In contrast to $E$. coli and $B$. subtilis, specific regulatory mutants are rarely available for many other species. Nevertheless, the combination of both hierarchical clustering of microarray data in different conditions and TFBS-finding approaches is an efficient approach for describing novel regulons. Mao et al. ${ }^{199}$ investigated the photosynthetic regulons PrA, and PpsR and the anaerobic regulon FnrL in Rhodobacter sphaeroides by detection of genes that share similar expression patterns in photosynthetic and/or anaerobic conditions and by identification of possible TFBS motifs that may be involved in their co-regulation. This approach allowed the authors to find and improve FnrL- and PpsR-binding motifs and to predict a candidate TFBS motif for the photosynthetic response regulator PrrA.

Finally, integration of in silico genomic approaches with in vitro and in vivo experimental methods helps identify novel regulatory systems in poorly characterized microorganisms. For instance, transcriptional regulation of the glycolytic genes in the hyperthermophilic archaea Pyrococcus and Thermococcus was elucidated by experimental determination of the transcription initiation sites and computational comparison of the promoter regions. ${ }^{200}$ This analysis of thermococcal archaea revealed a potential TFBS motif within 20 glycolytic promoters and a candidate regulator from the TrmB family, which is likely involved in recognition of this DNA motif. Only a limited number of regulons have been characterized experimentally in Archaea. ${ }^{201}$ The described above and other in silico genomic studies 103 demonstrated an importance of the genomic approaches for analysis of archaeal regulons.

\subsection{Comparative Genomic Reconstruction of Regulatory and Metabolic Networks}

A general strategy to analyse known regulons consists of the following steps: i) search for orthologous TFs to reveal phylogenetic distribution of the regulon, ii) obtain binding-site models from known sites in a model genome(s), iii) obtain sets of orthologous upstream gene sequences from genomes at the appropriate phylogenetic distance, iv) apply pattern recognition programs, v) construct PWMs and search for additional sites in the genomes of interest, and vi) perform consistency check or cross-species comparison of the predicted members of the regulon (see Fig. 5A). The last step schematically represented in Fig. 4A is very important for 
the comparative approach, which is based on the assumption that regulatory events tend to be conserved in closely related species with orthologous regulators. Thus, conservation of a candidate regulatory site upstream of orthologous genes in a group of genomes is used to eliminate false-positive site predictions. The consistency-check stage requires special attention to the selection of a group of genomes for comparison and to a threshold for TFBS search. Also, to account for possible differences in the operon structures of orthologous genes, it needs an accurate operon prediction for the candidate regulon members.

Depending on the availability of experimental data, the training set for signal identification may be obtained in different ways. In the simplest situation, the training set is composed of experimentally known TFBSs that have been defined in model species, such as $E$. coli or $B$. subtilis (Strategy Ia). In the absence of such knowledge, the training set may be composed of candidate regulatory regions of genes that are known to be controlled by a given TF in model species (Strategy Ib). Accuracy of de novo identification of a regulatory signal depends on the number of sequences in the training set and may be improved by inclusion of orthologous upstream regions from related species.

To identify novel regulons in the absence of any experimental data about regulation of specific genes, two alternative comparative genomic strategies could be used (see Fig. 5B). The subsystem-oriented approach (Strategy IIa) is based on the assumption that the genes from the same metabolic pathway may be co-regulated by one TF. This approach starts with the identification of a set of functionally linked genes within the taxonomic group of interest (e.g., genes from the same metabolic pathway). First, all possible operons including the genes of interest are defined and the corresponding upstream UTRs are collected. Then, the collection of candidate regulatory regions is used by signal-recognition programs to predict a common DNA pattern allowing a limited number of input sequences to be excluded from the pattern. On the next step the genomes of interest are scanned with the constructed DNA pattern to reveal the distribution of similar sites, which are verified by the consistency-check procedure.

An alternative approach for discovery of novel regulons is based on the phylogenetic footprinting method (Strategy IIb). Orthologous upstream UTRs of a gene of interest are collected from a group of closely related genomes and used to construct a multiple alignment. The group of genomes is selected based on the presence of orthologous target genes and on the extent of conservation of UTRs. In an ideal case, the multiple sequence alignment contain several highly conserved regions that are broken by relatively unconserved regions. These islands of conservation in UTRs are obvious candidates to serve as promoters or cis-regulatory sites. Since most prokaryotic TFs bind DNA as homodimers recognizing symmetrical sites, the analyzed conserved regions might be inspected for the presence of either inverted or direct repeats with allowable mismatches. Candidate TFBS regions are used to construct search profiles. On the next stage, these TFBS regions are verified by genome-wide searches for similar sites in intergenic regions of analyzed species. Combination of phylogenetic footprinting approach with clustering of predicted TFBSs can help to identify novel regulons. For example, the fatty acid biosynthesis regulon FabR in E. coli was first identified by this combined in silico approach ${ }^{139}$ and then experimentally validated. ${ }^{141}$ Finally, a novel predicted TFBS motif could be connected to a specific TF using positional genomic evidences, phylogenetic co-occurrence profiles and binding specificity constraints (see Section 2.6).

The above strategies of identification of TFBSs were successfully applied to analyse many regulons involved in the central metabolism of sugars, amino acids, nucleotides, metals, and co-factors as well as important regulons controlling respiration, nitrogen metabolism, and stress response (Table 4). The combination of metabolic maps and regulatory networks shows many species- and taxon-specific differences in the structure of metabolic pathways and regulons in bacteria. Several representative examples that illustrate the powers of these comparative 
genomic approaches for discovery and characterization of microbial regulons are outlined in Table 5 and are briefly discussed below.

3.2.1. $\mathrm{N}$-acetylglucosamine and Chitin Utilization-The NagC regulon for $\mathrm{N}$ acetylglucosamine and chitin utilization was initially characterized in E. coli ${ }^{202}$ and further identified by comparative genomics in other species from two taxonomic groups, the Enterobacteriales and Vibrionales. ${ }^{203}$ The NagC-binding motif was constructed using upstream regions of known NagC-controlled genes in E. coli and their orthologs in related genomes. Scanning of the $n a g C$-containing genomes using the constructed motif identified additional candidate $\mathrm{NagC}$-regulated genes that are involved in the degradation and uptake of chitin and its $\mathrm{N}$-acetylglucosamine derivatives. In Vibrio cholerae, the predicted $\mathrm{NagC}$ regulon was in agreement with microarray data on the induction of gene expression by $\mathrm{N}$ acetylglucosamine. $^{204}$

In contrast to Enterobacteriales and Vibrionales, many species from other taxonomic groups contain genes for $\mathrm{N}$-acetylglucosamine utilization but lack orthologs of NagC. Analysis of conserved nag gene clusters in other groups of proteobacteria (Altermonadales,

Pseudomonadales, Xanthomonadales, $\beta$ - and $\alpha$-proteobacteria) identified two previously uncharacterized regulators from the LacI and GntR protein families. These two TFs, called respectively NagR and NagQ, were tentatively predicted to control the nag genes in a subset of species based on positional genomic evidences and phylogenetic co-occurrence profiles.

203 For each group of species containing one of these TFs, a conserved DNA binding motif was identified in the training set of potentially co-regulated genes from the chitin and $\mathrm{N}$ acetylglucosamine pathways. The constructed recognition profiles were then used to scan against a subset of genomes of proteobacteria having a respective Nag regulator and to identify additional conserved regulon members. The results of this study suggested that at least three non-orthologous types of TFs control expression of the $\mathrm{N}$-acetylglucosamine and chitin utilization genes in various groups of proteobacteria (Table 5).

3.2.2. Sugar Acids Utilization-E. coli is capable of using various sugar acids (e.g., gluconate, hexuronates) as a source of carbon and energy. The respective sugar acid catabolic pathways converge to the common Entner-Doudoroff glycolytic pathway and are controlled by three different sugar acid-responsive TFs, GntR, UxuR and KdgR. Comparative analysis of these sugar acid regulons in $\gamma$-proteobacteria predicted novel regulons members and TFBS motifs. ${ }^{119}$ Combination of metabolic maps with regulatory networks showed the differences in the structure of the sugar acid catabolic pathways and regulons in different species.

The E. coli gluconate repressor GntR controls operons involved in the gluconate catabolism (gntT, gntKU) and the Entner-Doudoroff pathway (edd-eda). A GntR-binding site search profile was constructed by application of the signal detection procedure SignalX to the training set of upstream regions of the GntR-regulated genes and their orthologs in enterobacteria. 119 The GntR consensus site obtained by this procedure coincides with the experimentally mapped GntR sites at gntT (Table 5). Reconstruction of the GntR regulons by a genomic search with the GntR motif profile revealed some differences in the regulon content of various $\gamma$ proteobacteria. For instance, the GntR regulon in Yersinia pestis consists of only gntK and gnt $U$ genes, whereas $e d d$ and $e d a$ are in different operons that have no candidate GntR sites. In many cases, the candidate GntR sites occur in pairs, suggesting possible co-operative interactions of GntR dimer pairs.

The UxuR repressor in E. coli regulates the glucuronate utilization genes but its DNA binding site was unknown. Using of signal-detection procedure and a sample of upstream regions of UxuR-regulated genes and their orthologs, a candidate UxuR-binding motif was identified and used to locate additional UxuR target genes (e.g., gntP) in the genomes of enterobacteria. 
119 These comparartive genomic predictions were later confirmed in experiments, where the UxuR repressor was proved to bind its candidate operator sites in $E$. coli and control the expression of gntP in response to fructuronate concentrations. ${ }^{205}$

Utilization of pectin and its derivatives, oligogalacturonates and 2-keto-3-deoxygluconate (KDG), is controlled by the KDG-responsive repressor KdgR. All previously characterized KdgR-binding sites in the plant pathogen Erwinia chrysanthemi were collected from the literature and used to construct a search profile. 119,206 Comparative genomic analysis of the KdgR regulon in other enterobacteria and Vibrio species helped identify many new KdgRregulated genes. For example, the predicted oligogalacturonide transporter OgtABCD ${ }^{119}$ was confirmed in an independent study to have the proposed function (renamed TogMNAB) and to be regulated by KdgR in E. chrysanthemi. ${ }^{207}$ Regulation of most other regulon members predicted in E. chrysanthemi was experimentally validated using in vivo transcriptional fusions, and for the first time a new phenomenon of positive regulation by KdgR was described. 206 Complete reconstruction of the KdgR regulons in various $\gamma$-proteobacteria yielded a metabolic map reflecting a globally conserved pathway for the catabolism of pectin and its derivatives, but with significant variability in transport and enzymatic capabilities among species. ${ }^{206}$

3.2.3. Biotin Metabolism-Biotin is an obligate co-factor of numerous biotin-dependent carboxylases in a variety of microorganisms. The strict control of biotin biosynthesis in $E$. coli is mediated by the bifunctional BirA protein, which acts both as a biotin-protein ligase and as a transcriptional repressor of the bio operon. A comparative genomic approach was used to reconstruct the biotin biosynthesis pathways and regulatory networks in a wide range of prokaryotic organisms. ${ }^{70}$ Although birA is a widely distributed gene, only a fraction of BirA orthologs possess the N-terminal DNA-binding domain with the HTH motif (D-b-BirA). Based on phylogenetic analysis of DNA-binding domains, all D-b-BirA proteins were divided into two major groups, proteobacterial and nonproteobacterial. Accordingly, two partially similar recognition profiles for the BirA binding sites were constructed using the sets of upstream regions of the bio genes from various genomes (Table 5). The constructed profiles successfully detected new candidate members of the biotin regulon bacteria that contain D-b-BirA. In particular, the previously uncharacterized hypothetical transmembrane protein BioY was predicted to encode a transporter for biotin. Additional scanning of microbial genomes showed that the occurrence of potential BirA-binding sites upstream of biotin-related genes coincides with the presence of D-b-BirA in a genome. ${ }^{70}$

BirA represents a rare example of a TF in which the binding signal is conserved in various bacteria and archaea. However, the mode(s) of biotin-dependent regulation in the bacteria that lack D-b-BirA is still not known. This gap in our knowledge was partially filled by comparative genomic analysis using the Strategy IIa, which allowed us to identify a novel GntR-type TF for the bio genes (named BioR) and its binding signal in 8 out of 19 species of $\alpha$-proteobacteria. 208

Here I report, for the first time, the application of a similar approach (Strategy IIa) to a set of the biotion biosynthesis and transport bio genes in Actinobacteria, another lineage that lacks D-b-BirA. In 11 out of 27 genomes of Actinobacteria, there is a novel palindromic DNA motif associated with the bio genes (Fig. 6). In many cases, these novel candidate sites occur in tandem, suggesting cooperative binding of an unknown TF to DNA. A candidate regulatory gene that encodes a TetR-type TF (named BioQ) is co-localized with the biotin synthase gene bioB in 5 genomes (Nocardia, Rhodococcus and Propionibacterium and two Mycobacteria species) and with the biotin transport operon bioYMN in 2 genomes (Leifsonia and Clavibacter species). Orthologs of the bio $Q$ gene are also present in 4 Corynebacterium species but not in other Actinobacteria. In Corynebacterium species, the bio $Q$ and bio genes are not clustered on the chromosome. Phyletic distribution and genomic localization of novel 
candidate TFBS motifs and bio $Q$ genes strongly suggest that BioQ mediates the biotindependent transcriptional regulation of the bio genes in the 11 species of Actinobacteria. However, the mode of control of bio genes in other Actinobacteria (including Streptomyces and pathogenic Mycobacterium species) is yet unknown.

These observations demonstrate that the biotin metabolism in bacteria is regulated by at least three distinct systems, including the bifunctional enzyme/repressor D-b-BirA, and two specialized TFs from the GntR and TetR protein families, BioR and BioQ (Table 5).

3.2.4. Nitrogen Metabolism-Expression of nitrogen assimilation genes in bacteria is under the control of many regulatory systems including the RpoN sigma factor and a set of lineage-specific TFs. In proteobacteria, this metabolic pathway is regulated by the twocomponent Ntr system, whose response regulator belongs to the Fis family of TFs. 209 Regulators from different protein families mediate the control of nitrogen assimilation genes in other bacterial lineages: MerR-type regulators TnrA and GlnR in the Bacillus/Clostridium group, ${ }^{210}$ Fnr-type regulator NtcA in Cyanobacteria, ${ }^{211}$ and TetR-type regulator AmtR in Actinobacteria. 212 These and other regulons were analyzed by various comparative genomic techniques.

The NtcA regulon in Cyanobacteria was analyzed using the comparative genomic algorithm that combines information about co-occurrence of candidate NtcA and sigma-factor binding sites and the presence of similar motifs in the regulatory regions of orthologous genes in other related genomes. ${ }^{213}$ Using the phylogenetic footprinting approach, the authors were able to predict new members of the NtcA regulons in the genomes of nine Cyanobacteria. In addition to multiple nitrogen assimilation genes, high-scoring NtcA sites were found for many genes involved in the various stages of the photosynthesis process, suggesting tight coordination of these metabolic processes in Cyanobacteria. 213

Comparative analysis of the homologous TnrA and GlnR regulons in the Bacillus/

Clostridium group revealed their significant plasticity in different bacteria. ${ }^{127}$ The TnrA and GlnR orthologs were distinguished using the constructed phylogenetic tree for the MerR family of transcription factors. Streptococcus, Listeria, and Staphylococcus species lack TnrA but have the highly conserved GlnR regulon, which mainly contains genes of glutamine transport and utilization. In Bacillus species, the duplicated regulators TnrA and GlnR control many genes for utilization of glutamine and other nitrogen-containing compounds.

Genes involved in the nitrogen fixation are under control of the $\sigma^{\mathrm{N}}$-dependent transcriptional activator NifA in bacteria, 214 whereas in the nitrogen-fixing species of archaea these genes are regulated by the transcriptional repressor NrpR that represents a new family of regulators unique to the Euryarchaeota. ${ }^{215}$ Accordingly, these two different regulatory systems operate by different binding motifs (Table 5). The NifA regulon in $\alpha$-proteobacteria was analyzed in conjunction with identification of $\mathrm{RpoN}\left(\sigma^{54}\right)$ binding sites using the training sets of experimentally characterized sites of both factors (Natalia A. Doroshchuk, D.A.R., unpublished observation). Simultaneous comparative analysis of upstream NifA binding sites and downstream $\sigma^{54}$-dependent promoters decreases the rate of false-positive site predictions, allowing for more-accurate reconstruction of the nitrogen fixation regulons in the sequenced genomes of $\alpha$-proteobacteria. Finally, the archaeal nitrogen fixation regulon $\mathrm{NrpR}$ was analyzed using the consistency-check approach and the training set of nitrogen fixation genes. 103

Two dissimilatory processes in the bacterial inorganic nitrogen cycle, denitrification and detoxification of nitrogen oxides, are controlled by an evolutionary variable transcriptional network that involves Fnr-like transcription factors HcpR, Dnr, and NnrR; two-component 
systems NarXL and NarPQ; nitric oxide-responsive $\sigma^{54}$-dependent activator NorR, and nitritesensitive repressor NsrR. ${ }^{126,216}$ Comparative reconstruction of the nitrogen oxides regulatory network has revealed multiple interconnections between the regulons, conservation of some regulatory interactions, and changing of other regulatory interaction, as well as extensions, reductions, or even loss of some regulons. ${ }^{216}$ For instance, the nitrogen oxides detoxification genes $h c p$ and $h m p$ are regulated by various TFs (NsrR, NorR, Dnr, and HcpR) in various bacterial species.

3.2.5. NAD Metabolism-Transcriptional regulation of NAD biosynthesis genes has been extensively studied in enterobacteria, where at high NAD levels the multifunctional protein NadR represses the de novo NAD synthesis and salvage genes. ${ }^{217}$ In addition to the N-terminal DNA-binding domain, NadR has two enzymatic domains involved in the salvage of nicotinamide riboside. 218 The application of the comparative genomic approach to the analysis of the NadR regulon in the Enterobacteriales revealed similar patterns of NadR binding sites in this lineage and predicted the autoregulation of the $n a d R$ gene. ${ }^{69}$ In contrast to enterobacteria, an N-terminal DNA-binding domain of NadR is absent in other bacterial lineages and the mechanism of regulation of the NAD metabolism in these species is unclear. Different taxonomic groups of bacteria may have a variety of regulatory strategies for control of the same pathway. Application of the signal-detection procedure and the subsystem-oriented Strategy IIa of comparative genomics allowed us to identify and reconstruct three other novel NAD regulons in different bacterial lineages (D.A.R., Nadia Raffaelli, Andrei Osterman, unpublished observations).

A different nicotinate-responsive transcriptional repressor encoded by $y r x A$ gene was later identified in Bacillus subtilis where it controls the NAD biosynthesis operon, however its DNAbinding site was unknown. ${ }^{219}$ We applied the comparative approach to the genomes of other Firmicutes that have $y r x A$ orthologs and identified a conserved palindromic motif in upstream regions of NAD biosynthesis and salvage operons from the Bacillus/Clostridium group (Table 5). Based on co-occurence and co-localization with yrxA genes in the genomes, this novel DNA motif was tentatively attributed to the YrxA-like NAD regulator. A search for additional YrxA sites, complemented by genome context analysis and cross-species comparisons, led to identification of new candidate members of the YrxA regulon, in particular, different types of candidate transporters for NAD metabolic precursors (D.A.R., Andrei Osterman, manuscript in preparation).

Comparative analysis of potential regulatory regions of NAD biosynthesis operons in $\alpha$ - and $\beta$-proteobacteria revealed a conserved DNA motif (Table 5) and a connected hypothetical TF, named NadQ, which is encoded by an adjacent gene immediately upstream of the nad operon (D.A.R., unpublished observation). Similar analysis of the NAD metabolic genes in the genomes of Cyanobacteria and Actinobacteria identified another DNA motif and a hypothetical $\mathrm{TF}$, named NrtR, which is encoded in close proximity to the NAD biosynthesis and salvage genes and has this candidate motif upstream. Although the predicted NAD regulators NrtR and NadQ belong to different protein families, they share similar HTH domains on their C-terminal parts. The candidate binding sites for NadQ and NrtR have some resemblance to each other, consistent with the similarity of their DNA-binding domains. Recently, the novel predicted NAD regulator NrtR was purified from Synechocystis sp. and confirmed in electrophoretic mobility shift assays to bind specifically the candidate NrtR sites upstream of nadE, nadMV, and nadA genes (Nadia Raffaelli and D.A.R., manuscript in preparation).

Apart from these taxonomic groups, the mode of regulation of NAD metabolism in other prokaryotic lineages remains unclear and requires further study. 


\subsection{Analysis of Regulons to Support Metabolic Reconstruction and Functional Predictions}

Comparative analysis of regulons based on the identification and cross-genome comparison of shared regulatory sites (e.g., TFBSs, RNA regulatory elements) is an important technique for functional annotation of hypothetical genes. It predicts co-regulation of a set of genes, providing evidence that these genes may be functionally coupled. First, the identification of novel members of metabolic regulons helps to locate candidates for so-called missing genes in metabolic pathways, attempting to connect known functional roles to genes that have not yet been characterized. ${ }^{152}$ From the other hand, the metabolic regulon reconstruction allows one to identify novel metabolic enzymes and to predict novel enzymatic reactions that were not known before. Finally, the analysis of bacterial regulons promotes a substantial progress in functional annotation of hypothetical transporter genes that could be tentatively attributed to the regulated metabolic pathway (D.A.R., Mikhail Gelfand, in preparation).

Integration of the comparative genomic analysis of microbial regulons with traditional approaches of genome context analysis is an efficient method for functional gene annotation and metabolic pathway reconstruction. The traditional approaches of genome context analysis largely fall into one of the following three categories: ${ }^{152}$

- Clustering of genes on the chromosome (or gene neighborhood) approaches are based on the known tendency that proteins, whose corresponding genes are located "close" to each other in multiple genomes, are expected to be "functionally coupled" and form the same metabolic pathway. 220,221

- Gene fusion-based approaches attempt to discover pairs or sets of genes in one genome that are merged to form a single gene in another genome, providing further evidence of potential functional coupling. 222,223

- Phylogenetic profiling approach is based on the assumption that functionally associated proteins are expected to have very similar occurrence profiles across various organisms. ${ }^{224}$

Several examples below illustrate how the comparative analysis of regulons helps in metabolic recontruction and, in particular, how useful is it to predict novel functional roles, missing genes and transporters in microbial metabolic pathways.

3.3.1. L-rhamnose Utilization-The first example, presented here for the first time, describes in detail the general strategy for reconstruction of a metabolic pathway and associated regulatory mechanisms. To reconstruct the L-rhamnose utilization system in bacteria, we used a subsystem-based approach combining a number of comparative genomic techniques as implemented in the SEED platform. ${ }^{203,225,226}$ The utilization of L-rhamnose in E. coli is catalyzed via L-rhamnose mutarotase (RhaM), L-rhamnose isomerase (RhaA), L-rhamnulose kinase (RhaB), and L-rhamnulose-1-phosphate aldolase (RhaD). The detailed results of this analysis are captured in the SEED subsystem available online (http://theseed.uchicago.edu/FIG/subsys.cgi) and in Figure 7.

The transcriptional activator RhaS in E. coli belongs to the AraC family and controls the Lrhamnose transporter rhaT and the catabolic operon rhaBADM. 227,228 Orthologs of rhaS and these L-rhamnose catabolic genes are present in some other $\gamma$-proteobacterial genomes. The analysis of upstream regions of $r$ ha genes in this taxonomic group results in construction of the RhaS search profile and identification of additional RhaS targets (Fig. 7). For example, Salmonella typhimurium and Erwinia carotovora are predicted to possess a RhaS-regulated hypothetical transport system (named rhiABC), which is similar to the C4-dicarboxylate transport system Dcu. Candidate RhaS regulons in two Erwinia species and Klebsiella pneumoniae also include the rhiT-rhiN operons involved in the uptake and catabolism of 
rhamnogalacturonides, L-rhamnose-containing oligosaccharides. ${ }^{229}$ Based on the geneoccurrence pattern and candidate co-regulation, RhiABC is tentatively predicted to encode an alternative transporter for rhamnogalacturonides, which replaces RhiT in S. typhimurium.

The RhaS regulon in $\gamma$-proteobacteria is also predicted to include various genes that are likely involved in utilization of L-lactaldehyde, a final product of the L-rhamnose catabolism. The rhamnose operons in K. pneumoniae and S. typhimurium include an additional gene (named rhaZ) encoding the hypothetical iron-containing alcohol dehydrogenase (PF00465 protein family in PFAM ${ }^{57}$ ). E. carotovora has a single RhaS-regulated gene aldA encoding alcohol dehydrogenase from another protein family (PF00171). In contrast, the RhaS regulons in Erwinia chrysanthemi and Mannheimia succiniproducens include the lactaldehyde reductase fucO, whereas aldA and rhaZ are absent from their genomes. These observations suggest that $\gamma$-proteobacteria use three different enzymes and two different pathways for the final stage of the L-rhamnose pathway.

Analysis of other taxonomic groups outside the $\gamma$-proteobacteria tentatively identifies previously uncharacterized members of the LacI, DeoR, and AraC families as alternative transcriptional regulators of the L-rhamnose pathway (Fig. 7). In Actinobacteria, a LacI-type regulator (named here R2) is identified in a chromosomal cluster with the rha genes. The predicted palindromic R2-binding signal is characteristic of DNA-binding sites of LacI family regulators. Two TFs from the DeoR family (R3 and R3', 28\% similar to each other) are inferred based on chromosomal clustering with rha genes in the Bacillaceae and $\alpha$-proteobacteria groups, respectively. The deduced binding motifs consist of two or three imperfect direct repeats (AACAAAA for R3 and TGATTGA for R3') separated by $3 \mathrm{bp}$. Finally, another potential regulator from the AraC family with a very weak similarity to RhaS (named R1) is identified in some species from the Bacillus/Clostridium group. Thus, at least five nonorthologous types of TFs appear to regulate the L-rhamnose utilization genes in bacteria.

In addition to TFs, a high level of variation is also observed for the components of transport machinery. The L-rhamnose-specific transporter RhaT is a conserved member of $r h a$ operons and RhaS regulons in $\gamma$-proteobacteria. An alternative system of L-rhamnose transport via a committed ABC cassette (named RhaFGHJ) is predicted to substitute RhaT in $\alpha$-proteobacteria and Streptomyces spp., whereas K. pneumoniae has both of them encoded in the rha gene cluster. Another novel transporter for L-rhamnose (named RhaY) is tentatively identified in Actinobacteria and in the Bacillus/Clostridium group (Fig. 7). RhaY has no similarity to RhaT and belongs to the PF00083 family of sugar transporters from the MFS superfamily.

The reconstruction of bacterial L-rhamnose utilization pathways reveals that all but one enzymatic pathway component occur in many alternative forms, with the L-rhamnulose kinase RhaB being the only invariant component of the pathway. A non-orthologous isomerase (named RhaI) is inferred by the genome context analysis in Actinobacteria, $\alpha$-proteobacteria, and $B$. licheniformis. Instead of the canonical form of aldolase (RhaD), the rha clusters in Actinobacteria, Bacilli, and $\alpha$-proteobacteria contain a chimeric gene (e.g., $y u x G$ in $B$. subtilis), which encodes a two-domain protein with $\mathrm{N}$-terminal class II aldolase domain and C-terminal short chain dehydrogenase domain (named RhaE and RhaW, respectively). The phylogenetic occurrence profile suggests that RhaW may encode the missing L-lactaldehyde dehydrogenase. Thus, this bifunctional protein is tentatively predicted to catalyze two final reactions in the L-rhamnose utilization pathway.

3.3.2. Other Catabolic Pathways-A similar approach was applied for the comparative genomic analysis of other sugar catabolic pathways in bacteria. ${ }^{119-121,203,206}$ In the Nacetylglucosamine utilization subsystem, a similarly high level of variations and nonorthologous gene displacements was observed for specific TFs and transport systems. Most 
notably, the PTS-mediated transport of $\mathrm{N}$-acetylglucosamine in Enterobacteriales and Vibrionales appears to be functionally replaced by a specific MFS-type permease in Altermonadales and Xanthomonadales or an $\mathrm{ABC}$ cassette in $\alpha$-proteobacteria in conjunction with a novel bacterial $\mathrm{N}$-acetylglucosamine kinase enzyme. In addition to that, two nonorthologous versions of the N-acetylglucosamine-6-phosphate deaminase NagB were found and experimentally verified. 203

Analysis of the arabinose utilization subsystem identified a novel non-orthologous variant of L-ribulokinase in a number of Gram-positive bacteria. ${ }^{121}$ Reconstruction of the xylose regulon XylR in Enterobacteriales resulted in identification of operons comprising putative transporters and hydrolases for utilization of xylose oligosaccharides. ${ }^{120}$ Analysis of the KdgR regulon revealed several novel transport systems and enzymes (e.g., sugar isomerase SpiX) involved in the utilization of products of pectin degradation such as galacturonate, glucuronate and KDG. 119,206

The comparative analysis of the fatty acid degradation regulon FadR revealed new members of this regulon in the E. coli genome (fadIJ, formerly b2342-41) and demonstrated that the candidate FadR-regulated gene yafH encoding acyl-CoA dehydrogenase is identical to the gene fadE previously identified by genetic techniques. ${ }^{230}$ The identity of $y$ afH and $f a d E$ in $E$. coli was then experimentally confirmed by targeted gene disruption and the FadR-dependent regulation of its transcription was further confirmed. 231

3.3.3. Biosynthesis of Coenzyme $\mathbf{B}_{\mathbf{1 2}}$-Biosynthesis of adenosylcobalamin (coenzyme $\mathrm{B}_{12}$ ) requires about 25 enzymes encoded by $c b i$ and $c o b$ genes that catalyze the de novo synthesis of a tetrapyrrole-derived corrin ring, insertion of a cobalt ion, adenosylation and attachment of an aminopropanol arm to the corrin ring, and assembly of the nucleotide loop that bridges the lower ligand dimethybenzimidazole and the corrin ring. ${ }^{232}$ Most $c b i$ and $c o b$ genes in bacteria are organized in extended operons and controlled by $\mathrm{B}_{12}$ riboswitch elements, conserved mRNA leader sequences that directly bind an effector molecule, adenosylcobalamin. 159,165 The genomic identification and comparative analysis of $\mathrm{B}_{12}$ riboswitches combined with other genome context techniques identified a large number of new candidate $\mathrm{B}_{12}$-regulated genes with tentatively assigned functional roles in the $\mathrm{B}_{12}$ biosynthesis pathway. ${ }^{233}$ For example, nine different types of candidate cobalt transporters were identified within the bacterial $\mathrm{B}_{12}$ regulons in different lineages, emphasizing the importance of cobalt uptake for the de novo coenzyme $\mathrm{B}_{12}$ biosynthesis. ${ }^{198}$ Experimental analysis confirmed cobalt transport activity for several representatives of two families of metal uptake transporters, CbiMNQO and NiCoT. ${ }^{234,235}$

Metabolic reconstruction of the $\mathrm{B}_{12}$ biosynthesis pathway revealed a large number of missing genes, most of which were identified as non-orthologous displacements. ${ }^{233}$ Most remarkably, various non-orthologous gene displacements for the $c o b C$ gene involved in the nucleotide loop assembly were identified in archaea, $\alpha$-proteobacteria, and Actinobacteria (named cobZ, $c b l X Y$, and $c b l Z$, respectively). Later, the cobZ gene of Methanosarcina mazei was confirmed to encode a non-orthologous replacement of the $\alpha$-ribasole-5-phosphate phosphatase (CobC) enzyme of enterobacteria. 236

A novel functional role of the L-threonine kinase PduX has been proposed for the pathway of synthesis of lower ligand of coenzyme $\mathrm{B}_{12}$. In some Gram-positive bacteria, the $p d u X$ gene of unknown function was found within the $\mathrm{B}_{12}$ biosynthesis gene clusters adjacent to the $\operatorname{cobD}$ gene. In Streptomyces coelicolor, the single $p d u X$ gene is predicted to be regulated by a $\mathrm{B}_{12}$ riboswitch. The PduX proteins belong to the GHMP kinase superfamily and are weakly similar to L-homoserine and mevalonate kinases. The lower ligand of $\mathrm{B}_{12}$ is synthesized by the CobD aminotransferase, which requires L-threonine-3-phosphate as a substrate. Based on these facts, 
the novel $\mathrm{B}_{12}$-regulated gene $p d u X$ was proposed to encode $\mathrm{L}$-threonine kinase involved in $\mathrm{B}_{12}$ biosynthesis, ${ }^{233}$ and experimental verification of PduX function is currently underway (Aaron Best, personal communication).

3.3.4. New Mechanisms for Alternative Cofactor Adaptation-Comparative analyses of several cofactor-specific regulons revealed several cases where distinct isofunctional genes appear to be regulated according to the availability of respective cofactors (Table 6).

$\mathrm{B}_{12}$ riboswitches were detected upstream of the $m e t E, n r d A B$, and $n r d D G$ genes encoding the $\mathrm{B}_{12}$-independent isozymes of methionine synthase and ribonucleotide reductase in various genomes from diverse taxonomic groups of bacteria (e.g., $\alpha$-proteobacteria and Actinobacteria). These microbial genomes also encode the MetH and NrdJ isozymes that perform the same functional roles but require $B_{12}$ as a cofactor. Thus, it was proposed that when vitamin $B_{12}$ is present in the cell, expression of $B_{12}$-independent isozymes is inhibited, and only relatively more-efficient $B_{12}$-dependent isozymes are used. ${ }^{233}$ Although the repression of $\mathrm{B}_{12}$-independent isozymes by the excess of coenzyme $\mathrm{B}_{12}$ looks rational, this regulatory strategy was not known before the comparative genomic identification of $\mathrm{B}_{12}$ riboswitches upstream of the $n r d$ and $m e t E$ genes. Recently, this hypothesis about regulation by $\mathrm{B}_{12}$ riboswitches was experimentally confirmed for $m e t E$ in Bacillus clausii 237 and $n r d A B$ in Streptomyces coelicolor. ${ }^{238}$ Interestingly, the methionine synthetase metE in $B$. clausii is subject to dual regulation by tandem riboswitches that respond to $\mathrm{S}$ adenosylmethionine and coenzyme $\mathrm{B}_{12} .{ }^{237}$

Several genes encoding iron-containing enzymes (e.g., $s d h, a c n A, f u m A, \operatorname{sodB}$ ) are positively regulated in high iron concentrations by Fur in $E$. coli through repression of synthesis of a small antisense RNA. ${ }^{239}$ Another regulatory strategy for iron metabolism, where an alternative iron-independent enzyme is negatively regulated by high iron concentrations, was reported for the non-iron fumarate hydratase FumC and [Mn] superoxide dismutase SodA in $\gamma$ - and $\alpha$ proteobacteria. ${ }^{123,240}$ In addition, [Fe]-Fur was predicted to repress a flavodoxin gene in Desulfovibrio species, which may be used in an electron transfer chain as an alternative to ferredoxins present in the genomes. ${ }^{241}$ Finally, the nickel repressor NikR was predicted to regulate the hyd operon encoding [ $\mathrm{Fe}]$ hydrogenase in Desulfovibrio desulfuricans, whose genome also encodes [NiFe] hydrogenase. ${ }^{241}$

A similar regulatory strategy has been proposed for ribosomal proteins in the comparative genomic study of bacterial zinc regulons. ${ }^{124}$ Repression by the zinc repressor Zur was predicted for genes encoding paralogs of L36, L33, L31, and S14 ribosomal proteins. The original copies of these proteins contain zinc-ribbon motifs and thus likely bind $\mathrm{Zn}$, whereas these motifs are not present in zinc-regulated paralogs that substitute the main proteins during zinc starvation. Since ribosomes are highly abundant in the cell, this alternation may lead to increased concentration of zinc ions available for other zinc-binding proteins in the cell. Therefore, this regulatory system would contribute to the zinc homeostasis in the cell under zinc starvation. This regulatory model of zinc-dependent regulation of ribosomal proteins by Zur was experimentally confirmed in B. subtilis 242,243 in S. coelicolor. ${ }^{244,245}$

Taken together, these data suggest that a flexible strategy of transcriptional regulation of isozymes and other isofunctional proteins with different cofactor requirements may represent a common theme in the environmental adaptation of bacteria.

3.3.5. Prediction of Transporter Specificities-Transport systems are essential components of the cell. ${ }^{246}$ They are involved in uptake of all nutrients into the cytoplasm supporting the utilization of exogenous sources of carbon and nitrogen and also providing the source of essential microelements (e.g., vitamins, metal ions). Classification of enzymes and 
reconstruction of metabolic pathways from genomic data has led to the development of metabolic databases such as MetaCyc ${ }^{247}$ and KEGG. ${ }^{248}$ In contrast to metabolic pathways, much less effort has been expended on genomic reconstruction of transport systems. The Transport DB collects known and predicted transport systems encoded in complete microbial genomes and annotated based on a series of experimental and bioinformatic evidence. ${ }^{249}$ However, most potential transport systems are still annotated as hypothetical and need to be characterized.

Projection of transporter annotations by homology only is not reliable in many cases, as, in comparison with enzymes, the substrate specificity of transporters is much more changeable during evolution. The use of reporter gene fusions in a high-throughput platform offers the possibility of screening hundreds of compounds against all candidate transporter operons to identify specific inducers for transport systems and predict their solute specificity. 250 Particular genome context evidences (chromosomal clustering, co-regulation and cooccurrence profiles) and careful phylogenetic analysis of transport protein families contribute significantly to functional annotation of hypothetical transporters (D.A.R., Mikhail Gelfand, in preparation).

Comparative genomic analysis of specific metabolic regulons has led to substantial progress in functional annotation of hypothetical transporter genes. For instance, candidate uptake transporters for amino acids arginine, lysine, methionine, and glycine in Shewanella oneidensis (ArgP, LysW, MetT, and GlyP, respectively), and for vitamins riboflavin, biotin, and thiamin in B. subtilis (YpaA, BioY, and YuaJ, respectively) were predicted based on coregulation with the respective amino acid/vitamin biosynthetic genes by a specific metaboliteresponsive riboswitch or TF regulon. ${ }^{10,70,157,158,160,174,208,251}$ The predicted specificities of YpaA (re-named RibU) and BioY transporters were later confirmed by direct measurements of riboflavin and biotin uptake, respectively. ${ }^{252-255}$

\section{Patterns and Mechanisms in Evolution of Transcriptional Regulatory Networks}

Although the comparative genomics of microbial regulons is an emerging field of research, a substantial amount of data have already been accumulated for the description of the most common and important types of events associated with the evolution of TRNs in bacteria. ${ }^{26}$, 73 Duplications and losses of TFs and their TFBSs result in regulon expansions, shrinkages, mergers, and split-ups. New regulons could be introduced by duplication and specialization of a TF paralog. Similar to metabolic enzymes, microbial TFs are subject to horizontal gene transfer and non-orthologous gene displacement events leading to considerable rewiring of TRNs. The inference of these evolutionary events is strongly supported by the observation of multiple cases when non-orthologous TFs control equivalent pathways or, vice versa, orthologous regulators control distinct pathways in different species.

In this section, several approaches for analysis of evolutionary dynamics of TRNs are described and illustrated by examples of how the inferred evolutionary events could contribute to the flexibility and interchangeability of regulons in bacteria.

The best-characterized TRN currently available, that of the model bacterium E. coli (documented in RegulonDB ${ }^{78}$ ), was used in a number of studies to analyze the conservation patterns of this network across completely sequenced prokaryotic genomes. A high level of conservation of co-regulation between two well-characterized model bacteria was first reported by the comparison of the operon map of $B$. subtilis with the regulon map of E. coli. ${ }^{256}$ In three other studies, the conservation of individual components of TRNs in E. coli was analyzed by identification of orthologs of TFs and their target genes. ${ }^{53,257,258}$ All three investigations 
reported an extreme flexibility of TRNs in bacteria. TFs are typically less conserved than the target genes and appear to evolve independently. The majority of $E$. coli regulons get rapidly lost over the increase of phylogenetic distance, as other microorganisms tend to have their own sets of TFs. ${ }^{53,257}$ Despite a generally poor conservation of the regulatory interactions across genomes, certain regulons (e.g., ArgR, Fur, BirA, LexA) have been conserved across different taxonomic groups. 257

However, the above approach does not take into account the presence and distribution of TFBSs in the genomes, limiting its ability to predict the loss and gain of regulatory interactions, novel regulon members and the rewiring of regulons.

Combining identification of orthologous TFs with the genome-scale search for their cognate TFBSs is a powerful approach to the analysis of co-evolution of TFs and TFBSs. This integrated approach allows us to describe divergence and adaptation of regulons in conjunction with duplication, birth or loss of TFBSs. ${ }^{70,124,215,240,259-261}$ Several examples below illustrate a remarkable variability of TRNs associated with a particular metabolic pathway, that allow us to make first steps towards the reconstruction of possible evolutionary scenarios for these TRNs.

\subsection{Methionine Metabolism}

Methionine metabolism in bacteria is regulated by a variety of RNA and DNA regulatory systems (Table 7A). Analysis of distribution of these regulatory systems in bacterial species helps to elucidate possible evolutionary scenario(s) for regulation of this metabolic pathway.

In $\gamma$-proteobacteria, two TFs, MetJ and MetR, are implicated in the control of methionine metabolism. The S-adenosylmethionine repressor MetJ in E. coli controls all methionine biosynthesis and transport genes by binding to operators that contain two to five tandem repeats of an 8-bp sequence. ${ }^{262}$ The homocysteine-responsive activator MetR controls the expression of $m e t E$, $m e t H, m e t A$, and $m e t F$ genes, which are under dual control of MetJ and MetR. ${ }^{263}$ Computational analysis of the distribution of MetJ-binding sites in bacteria whose genomes have a metJ ortholog revealed significant conservation of the MetJ regulon in $\gamma$-proteobacteria (D.A.R., unpublished observation). In a limited number of species (e.g., in 3 out of 11 Shewanella species), the MetJ regulon is extended to include the methionine degradation and salvage genes $(m d e A, m h t)$. The MetR regulon possibly has emerged earlier than MetJ since it is present also in various $\beta$-proteobacteria.

In contrast, in the actinobacterium C. glutamicum, the McbR repressor responds to Sadenosylhomocysteine and co-regulates the methionine biosynthesis, sulfur assimilation, and cysteine biosynthesis genes. ${ }^{193}$ Comparative analysis confirmed major conservation of the McbR regulon in three other Corynebacterium species. ${ }^{264}$ Although two other species from the Corynebacteriaceae group, Nocardia farcinica and Mycobacterium smegmatis, have a $m c b R$ ortholog preceded by a candidate McbR binding site, the McbR regulon was not identified in other Actinobacteria. Thus, it is tempting to speculate that the global sulfur metabolism regulon McbR was only recently evolved in the common ancestor of Corynebacteria.

Three different classes of S-adenosylmethionine-responsive RNA regulatory elements regulate the methionine metabolism in various taxonomic groups. The SAM-I riboswitch (or the S-box system) is widely distributed in the Bacillus/Clostridium group and is also present in some additional diverse bacterial lineages. ${ }^{251}$ Most SAM-II riboswitches were found in $\alpha$ proteobacteria and the CFB group. 175 Thus, it is likely that SAM-I and SAM-II were already present in the last common ancestors of firmicutes and $\alpha$-proteobacteria, respectively. However, among firmicutes, SAM-I riboswitches were only identified in the Bacillales and 
Clostridiales lineages but not in the Lactobacillales and Streptococcaceae, where they were likely substituted by other methionine-specific regulatory systems. ${ }^{251}$

The loss of the SAM-I regulatory system in the Streptococcaceae group is correlated with the emergence of two novel LysR-type TFs that control the methionine and cysteine metabolism in Streptococcus and Lactococcus species (Table 7A). MtaR was first identified as a regulator of methionine transport in the group B streptococci, but its binding site was unknown. 265 Comparative genomic analysis of the Streptococcus genomes allowed us to identify a potential binding motif (MET-box) in the regulatory regions of methionine biosynthesis and transport genes. ${ }^{251}$ The co-occurence of MET-boxes and $m t a R$ orthologs suggests that MET-boxes are likely MtaR-binding sites. The O-acetylserine-responsive TF CmbR in L. lactis was characterized as a master regulator of the sulfur amino acid metabolism that controls all genes likely involved in methionine and cysteine synthesis and transport except $c y s E$ and $m e t E F$. 266 Interestingly, the latter operon is the only potential target of MtaR in L. lactis. ${ }^{251}$ Further comparative analysis of the $\mathrm{CmbR}$ regulon suggests that it mostly controls the cysteine metabolism in Streptococcus species and also has some overlap with the MtaR regulon (Galina Kovaleva, personal communication). Consensus binding sites of CmbR (CYS-box) and MtaR (MET-box) differ from each other but follow the general symmetry for LysR-type regulators.

In the Clostridiales and Bacillales groups, the methionine-specific T-box RNA elements regulate expression of only one gene, the methionyl-tRNA synthetase metS. In contrast, the Met-T-box regulation is extensively used only in the Lactobacillales group, where it exclusively controls methionine genes in the absence of the SAM-I riboswitch regulon. This suggests that the family of Met-T-boxes initially associated with the met $S$ genes have been likely expanded in the Lactobacillales lineage to include most of the methionine metabolism genes. ${ }^{251}$ Indeed, the phylogenetic analysis of T-box families suggests that these RNA regulatory elements are subject to frequent duplications, deletions, and horizontal transfer between species (Alexei G. Vitreschak, personal communication).

The S-adenosylmethionine synthetase gene $m e t K$ is regulated by the SAM-I riboswitch in Bacillales and Clostridiales; however, this gene is not a member of the MtaR and Met-T-box regulons in the Lactobacillales (including the Streptococcaceae family), probably because they don't use S-adenosylmethionine as an effector. ${ }^{251}$ This gap was recently filled by identification of a novel S-adenosylmethionine-responsive riboswitch (SAM-III) for translational regulation of $m e t K$ in the Lactobacillales. ${ }^{176}$ Limited phylogenetic distribution of SAM-III riboswitch and its limited appearance in the genomes (it was found only upstream of $m e t K$ ) suggest that this regulatory element has been emerged relatively recent in the common ancestor of the Lactobacillales.

\subsection{Aromatic Amino Acid Metabolism}

A similar variability in regulatory mechanisms was identified for the aromatic amino acid (ARO) biosynthesis pathway (Table 7B). Biosynthesis of tyrosine, phenylalanine, and tryptophan starts from the common chorismate biosynthesis pathway encoded by the aro genes and then divides into the terminal pathways that are specific for each aromatic amino acid.

In $\gamma$-proteobacteria, the control of this pathway is mediated by two aromatic amino acidresponsive TFs, the tyrosine/phenylalanine-specific regulator TyrR and the tryptophan repressor TrpR. ${ }^{125}$ In addition, the phenylalanine and tryptophan operons are controlled by Phe- and Trp-specific transcriptional attenuators, respectively. ${ }^{267}$ Although the TFs and their cognate DNA signals are conserved in $\gamma$-proteobacteria, the content of TrpR and TyrR regulons varies widely. In the Enterobacteriales, Pasteurellales and Vibrionales lineages, TrpR and TyrR control the biosynthesis and transport of tryptophan and tyrosine/phenylalanine, respectively. Some genes are under dual control of two different regulatory systems, for instance, aroL and 
$m t r$ are regulated by both TyrR and TrpR, whereas the trp operon is controlled by the TrpR repressor and tryptophan attenuator. ${ }^{125}$ An ortholog of TyrR in the Pseudomonadales was characterized as PhhR, an activator of the phenylalanine degradation operon, which binds to a TyrR-box-like motif in the presence of phenylalanine or tyrosine. ${ }^{268}$ The comparative genomic analysis of TyrR- and TrpR-like regulons in Shewanella species that belong to the Altermonadales group of $\gamma$-proteobacteria revealed large-scale shifts in the metabolic content of regulons (D.A.R., unpublished observation). In Shewanella, TyrR is predicted to regulate degradation and transport of various amino acids (e.g., branch chain amino acids, proline, phenylalanine), whereas TrpR likely controls the tyrosine biosynthesis and transport. Finally, the tryptophan-responsive TrpR repressor was experimentally characterized in Chlamydia species, where it regulates the tryptophan synthase operon. 269

Tryptophan biosynthesis and transport genes in the Bacillus/Clostridium group are regulated at the RNA level by two different mechanisms, the Trp-specific T-box RNA elements and the RNA-binding TRAP protein. ${ }^{269,270}$ The TRAP-mediated regulation is used in all Bacillus species except the B. cereus group. In contrast, other lineages in the Bacillus/Clostridium group (including B. cereus) use Trp-T-boxes for tryptophan control. The common pathway of aromatic amino acid biosynthesis (encoded by aro genes) is likely regulated by two different conserved DNA elements, termed PCE in the Bacillus species and ARO-box in the Streptococcales. ${ }^{144,259}$ Note, though, that B. cereus group does not have PCE elements and uses tyrosine-specific T-boxes to control aro genes. In other firmicutes Tyr-T-boxes mostly regulate tyrosine-specific aminoacyl-tRNA synthetase (Alexei G. Vitreschak, personal communication). These observations suggest that T-boxes in some gram-positive species have undergone multiple duplications leading the expansion of respective amino acid regulons from aminoacyl-tRNA synthetases to the biosynthesis and transport.

\subsection{Fructose Regulon in $\mathrm{y}$-Proteobacteria}

The fructose repressor FruR, which belongs to the LacI family of TFs demonstrates a noteworthy example of regulon expansion. This TF has a pleiotropic regulatory role in $E$. coli and closely related Salmonella species. ${ }^{271}$ It responds to the level of fructose-6-phosphate (Fru-6P) repressing the fructose utilization operon fruBKA. Therefore it was initially named FruR. Later, it was also implicated in global regulation of more than 20 operons involved in the central carbohydrate pathways (e.g., glycolysis, gluconeogenesis, the Entner-Doudoroff pathway, and the TCA cycle), which led to an alternative name Cra, for catabolite repressoractivator protein. ${ }^{272}$ Comparative analysis of the FruR regulons in other species of the Enterobacteriales revealed an intermediate situation, with a smaller number of genes being controlled by FruR compared to E. coli. ${ }^{73}$ For example, the FruR regulon in Erwinia and Yersinia species does not include the $m t l A D R, p c k A, f b p$, and $a c e B A K$ operons that are FurR regulated in Escherichia and Salmonella spp. In other groups of $\gamma$-proteobacteria (e.g., Vibrionales and Pseudomonadales), FruR appears to be just a local regulator of the fruBKA operon. ${ }^{73}$ These observations suggest a possible evolutionary scenario for FruR. The initially local fructose uptake regulon was expanded in various species of the Enterobacteriales at the different extent to become a global TF mediating Fru-6P-dependent catabolic regulation of the central carbon metabolism genes.

\subsection{Iron and Manganese Regulatory Networks}

Global control of iron and manganese homeostasis including uptake, storage, and usage of these metals is mediated by TFs from at least three major protein families, Fur, DtxR, and Rrf2. 273 The DtxR family of metalloregulators includes the manganese repressor MntR in proteobacteria and firmicutes and the iron-responsive regulators IdeR and DtxR in Actinobacteria. TFs of the Rrf2 family are widespread in bacteria where they regulate diverse metabolic processes, such as metabolism of nitrogen oxides (NsrR), Fe-S cluster biogenesis 
(IscR), and iron homeostasis (RirA). Metalloregulators from the Fur superfamily respond to specific metal ions (iron, zinc, manganese, nickel) and regulate respective metabolic pathways.

Fur, the global iron-responsive TF, is the most widely distributed regulator of iron homeostasis since it is present both in gram-negative proteobacteria $(\gamma-, \beta-, \varepsilon-$, and $\delta$-subdivisions), grampositive bacteria, and cyanobacteria. Some lineages of $\alpha$-proteobacteria (e.g. Caulobacter, Magnetospirillum) are predicted to have a similar regulon, suggesting that the last common ancestor of $\alpha$-proteobacteria used a Fur-like protein to control iron metabolism. ${ }^{240}$ However, recent experimental 274,275 and comparative genomic 240 analyses demonstrated that the iron and manganese regulons in the Rhizobiales and Rhodobacterales groups of $\alpha$-proteobacteria are significantly different from other microbial lineages (Table 8).

An evolutionary scenario suggested for the Rhizobiales and Rhodobacterales lineages uncludes the following events (Table 8): 240 i) change of the effector molecule (from $\mathrm{Fe}^{2+}$ to $\mathrm{Mn}^{2+}$ ) and the regulon content (from the iron metabolism genes to the manganese uptake genes) for the Fur proteins, which were therefore re-named "Mur"; ii) recruitment of two novel TFs to control of the iron metabolism, the [Fe-S]-responsive repressor RirA and the heme-responsive regulator Irr, that sense the physiological consequence of the iron availability rather than iron concentration per se; iii) the secondary loss of Mur and its substitution by MntR in at least two species, Mesorhizobium loti and Rhodobacter capsulatus (possibly achieved by horizontal gene transfer).

Interestingly, the candidate consensus DNA-binding sites of Fur and Mur in $\alpha$-proteobacteria still resemble each other and show a similarity to the classical Fur-box consensus from $\gamma$ proteobacteria and firmicutes. Futhermore, the Fur/Mur-sites show faint similarity to RirAbinding sites (consensus TG-N11-CA), suggesting that iron-regulatory signals in $\alpha$ proteobacteria may have evolved from canonical Fur-sites. Indeed, theoretical calculations of bacterial TFBSs demonstrate that TFBSs even weakly conforming to the requirements of cognate TF may provide a selective advantage for the regulon to function and further positive selection may perfect a TFBS to a higher-affinity state. ${ }^{276}$

Comparative genomic reconstruction of the iron and manganese regulatory networks based on the identification of several classes of TFBS motifs in $\alpha$-proteobacteria revealed the significant variability and cross-connectivity of these TRNs as follows: i) the proposed mechanisms of regulation are different between various lineages and species (Table 8); ii) the functional content of regulons is variable due to lineage-specific regulon extensions and reductions; iii) there is an overlap between regulons and potential regulatory cascades involving the two different iron-responsive TFs, Irr and RirA. 240

\section{Directions for Future Studies}

This review illustrates major advances in comparative genomic reconstruction of regulons associated with metabolic pathways in microorganisms. This area is still very young and many unresolved questions and open problems listed below have to be addressed in the coming years.

1. Development of new powerful comparative genomics tools for in silico analysis, annotation and computational prediction of TRNs in the multitude of sequenced microbial genomes. Key components of prokaryotic TRNs, TFs and their TFBSs, need to be systematically classified and captured in specialized databases.

2. Further accumulation of high-quality expression data generated by transcriptomics and proteomics techniques, and protein-DNA interaction (ChIP-on-chip) in a broad range of species and experimental conditions. 
3. Capture experimental and computational data about TRNs within a framework of genomic integrations supporting reconstruction and comparative analysis of regulatory and metabolic networks. Such a broad integration will strongly impact annotation and reconstruction of both, TRNs and metabolic pathways including prediction of previously uncharacterized genes (regulators, enzymes, transporters).

4. Systematic comparison and cross-evaluation of high-throughput experimental data and in silico reconstructed microbial regulons. Assessment of advantages and limitations for each of these techniques.

5. Development of theoretical models for the evolution of TRNs in prokaryotes. Incorporation of horisontal transfer and duplication into evolutionary models. Systematic analysis of co-evolution of TFs and their TFBSs.

\section{Supplementary Material}

Refer to Web version on PubMed Central for supplementary material.

\section{Abbreviations}

TRN, transcription regulatory network

$\mathrm{TF}$, transcription factor

TFBS, transcription factor binding site

UTR, untranslated region

ChIP, chromatine immunoprecipitation

PWM, positional weight matrix

ORF, open reading frame

$\mathrm{HTH}$, helix-turn helix

$\mathrm{ABC}$, ATP binding cassette

NAD, Nicotinamide adenine dinucleotide

$\mathrm{ECF}$, extracytoplasmic function sigma factors

HMM, hidden Markov model

EM, expectation-maximization method

\section{Acknowledgements}

I thank Andrei Osterman and Mikhail Gelfand for useful discussions, careful reading and comments during the preparation of this manuscript. I am grateful to Aaron Best, Nadia Raffaelli, Galina Kovaleva, Alexei Vitreschak, Dmitry Ravcheev, and Natalia Doroshchuk for sharing unpublished data. I am indebted to Andrey Mironov, who designed and wrote the Genome Explorer program that was used in many comparative genomic studies of microbial regulation, and Ross Overbeek and the SEED development team for providing access to integrated genomes and tools for their comparative analysis. This work has been partially supported by the National Institute of Health (1R01AI066244-01A2), the Department of Energy (DE-FG02-ER64384), the Howard Hughes Medical Institute (grant 55005610, "Comparative genomics and evolution of regulatory systems"), and the Russian Academy of Sciences (Program "Molecular and Cellular Biology").

\section{References}

1. Baumberg, S. Prokaryotic Gene Expression. Oxford: Oxford University Press; 1999.

2. Lloyd G, Landini P, Busby S. Essays Biochem 2001;37:17. [PubMed: 11758454]

3. Kazmierczak MJ, Wiedmann M, Boor KJ. Microbiol. Mol. Biol. Rev 2005;69:527. [PubMed: 16339734]

4. Gollnick P, Babitzke P. Biochim. Biophys. Acta 2002;1577:240. [PubMed: 12213655]

5. Hodgson, DA. Signals, Switches, Regulons, and Cascades. Cambridge: Cambridge University Press; 2002.

6. Winkler WC, Breaker RR. Annu. Rev. Microbiol 2005;59:487. [PubMed: 16153177] 
7. Gelfand MS. Mol Biol 2006;40:609.

8. Gottesman S. Annu. Rev. Microbiol 2004;58:303. [PubMed: 15487940]

9. Makarova KS, Mironov AA, Gelfand MS. Genome Biol 2001:2.Research0013

10. Rodionov DA, Vitreschak AG, Mironov AA, Gelfand MS. J. Biol. Chem 2002;277:48949. [PubMed: 12376536]

11. Neidhardt, FC.; Savageau, MF. Escherichia coli and Salmonella: cellular and molecular biology. Neidhardt, FC., editor. Vol. Vol. 2. Washington, D.C.: ASM Press; 1996. p. 1310

12. Herrgard MJ, Covert MW, Palsson BO. Curr. Opin. Biotechnol 2004;15:70. [PubMed: 15102470]

13. Zhou D, Yang R. Cell. Mol. Life Sci 2006;63:2260. [PubMed: 16927028]

14. Shen-Orr SS, Milo R, Mangan S, Alon U. Nat. Genet 2002;31:64. [PubMed: 11967538]

15. Dharmadi Y, Gonzalez R. Biotechnol. Prog 2004;20:1309. [PubMed: 15458312]

16. Grainger DC, Aiba H, Hurd D, Browning DF, Busby SJ. Nucleic Acids Res 2007;35:269. [PubMed: 17164287]

17. Grainger DC, Hurd D, Harrison M, Holdstock J, Busby SJ. Proc. Natl. Acad. Sci. U S A 2005;102:17693. [PubMed: 16301522]

18. Laub MT, Chen SL, Shapiro L, McAdams HH. Proc. Natl. Acad. Sci. U S A 2002;99:4632. [PubMed: 11930012]

19. Breier AM, Grossman AD. Mol. Microbiol 2007;64:703. [PubMed: 17462018]

20. Molle V, Fujita M, Jensen ST, Eichenberger P, Gonzalez-Pastor JE, Liu JS, Losick R. Mol. Microbiol 2003;50:1683. [PubMed: 14651647]

21. von Kruger WM, Lery LM, Soares MR, de Neves-Manta FS, Batista e Silva CM, Neves-Ferreira AG, Perales J, Bisch PM. Proteomics 2006;6:1495. [PubMed: 16447160]

22. Sarma AD, Emerich DW. Proteomics 2005;5:4170. [PubMed: 16254929]

23. Todd JD, Sawers G, Johnston AW. Mol. Genet. Genomics 2005;273:197. [PubMed: 15856304]

24. Sadygov RG, Cociorva D, Yates JR 3rd. Nat. Methods 2004;1:195. [PubMed: 15789030]

25. Yates JR 3rd. Annu. Rev. Biophys. Biomol. Struct 2004;33:297. [PubMed: 15139815]

26. Gelfand MS. Curr. Opin. Struct. Biol 2006;16:420. [PubMed: 16650982]

27. Gelfand MS, Novichkov PS, Novichkova ES, Mironov AA. Brief. Bioinform 2000;1:357. [PubMed: 11465053]

28. Gelfand MS. Res. Microbiol 1999;150:755. [PubMed: 10673013]

29. Stormo GD, Tan K. Curr. Opin. Microbiol 2002;5:149. [PubMed: 11934610]

30. Browning DF, Busby SJ. Nat. Rev. Microbiol 2004;2:57. [PubMed: 15035009]

31. Collado-Vides J, Magasanik B, Gralla JD. Microbiol. Rev 1991;55:371. [PubMed: 1943993]

32. Espinosa V, Gonzalez AD, Vasconcelos AT, Huerta AM, Collado-Vides J. J. Mol. Biol 2005;354:184. [PubMed: 16236313]

33. Moreno-Campuzano S, Janga SC, Perez-Rueda E. BMC Genomics 2006;7:147. [PubMed: 16772031]

34. Lanzer M, Bujard H. Proc. Natl. Acad. Sci. U S A 1988;85:8973. [PubMed: 3057497]

35. Zheng D, Constantinidou C, Hobman JL, Minchin SD. Nucleic Acids Res 2004;32:5874. [PubMed: 15520470]

36. von Hippel PH. Annu. Rev. Biophys. Biomol. Struct 2007;36:79. [PubMed: 17477836]

37. Schneider TD, Stephens RM. Nucleic Acids Res 1990;18:6097. [PubMed: 2172928]

38. Crooks GE, Hon G, Chandonia JM, Brenner SE. Genome Res 2004;14:1188. [PubMed: 15173120]

39. Stormo GD. Bioinformatics 2000;16:16. [PubMed: 10812473]

40. Hertz GZ, Stormo GD. Bioinformatics 1999;15:563. [PubMed: 10487864]

41. Stormo GD, Schneider TD, Gold L, Ehrenfeucht A. Nucleic Acids Res 1982;10:2997. [PubMed: 7048259]

42. Staden R. Comput. Appl. Biosci 1989;5:89. [PubMed: 2720468]

43. Claverie JM, Audic S. Comput. Appl. Biosci 1996;12:431. [PubMed: 8996792]

44. Staden R. Nucleic Acids Res 1984;12:505. [PubMed: 6364039]

45. Schneider TD, Stormo GD, Gold L, Ehrenfeucht A. J. Mol. Biol 1986;188:415. [PubMed: 3525846]

Chem Rev. Author manuscript; available in PMC 2009 February 16. 
46. Berg OG, von Hippel PH. J. Mol. Biol 1987;193:723. [PubMed: 3612791]

47. Bailey TL, Gribskov M. Bioinformatics 1998;14:48. [PubMed: 9520501]

48. Mironov AA, Vinokurova NP, Gelfand MS. Mol. Biol 2000;34:253.

49. Horsburgh MJ, Ingham E, Foster SJ. J. Bacteriol 2001;183:468. [PubMed: 11133939]

50. Perez-Rueda E, Collado-Vides J. Nucleic Acids Res 2000;28:1838. [PubMed: 10734204]

51. Mandal M, Boese B, Barrick JE, Winkler WC, Breaker RR. Cell 2003;113:577. [PubMed: 12787499]

52. Perez-Rueda E, Collado-Vides J, Segovia L. Comput. Biol. Chem 2004;28:341 . [PubMed: 15556475]

53. Madan Babu M, Teichmann SA, Aravind L. J. Mol. Biol 2006;358:614. [PubMed: 16530225]

54. Minezaki Y, Homma K, Nishikawa K. DNA Res 2005;12:269. [PubMed: 16769689]

55. van Nimwegen E. Trends Genet 2003;19:479. [PubMed: 12957540]

56. Kummerfeld SK, Teichmann SA. Nucleic Acids Res 2006;34:D74. [PubMed: 16381970]

57. Finn RD, Mistry J, Schuster-Bockler B, Griffiths-Jones S, Hollich V, Lassmann T, Moxon S, Marshall M, Khanna A, Durbin R, Eddy SR, Sonnhammer EL, Bateman A. Nucleic Acids Res 2006;34:D247. [PubMed: 16381856]

58. Wilson D, Madera M, Vogel C, Chothia C, Gough J. Nucleic Acids Res 2007;35:D308. [PubMed: 17098927]

59. Dobrindt U, Hacker J. Curr. Opin. Microbiol 2001;4:550. [PubMed: 11587932]

60. Studholme DJ, Dixon R. FEMS Microbiol. Lett 2004;230:215. [PubMed: 14757243]

61. Wang L, Sun YP, Chen WL, Li JH, Zhang CC. FEMS Microbiol. Lett 2002;217:155. [PubMed: 12480098]

62. Goldman BS, Nierman WC, Kaiser D, Slater SC, Durkin AS, Eisen JA, Ronning CM, Barbazuk WB, Blanchard M, Field C, Halling C, Hinkle G, Iartchuk O, Kim HS, Mackenzie C, Madupu R, Miller N, Shvartsbeyn A, Sullivan SA, Vaudin M, Wiegand R, Kaplan HB. Proc. Natl. Acad. Sci. U S A 2006;103:15200. [PubMed: 17015832]

63. Molina-Henares AJ, Krell T, Eugenia GuazzaroniM, Segura A, Ramos JL. FEMS Microbiol. Rev 2006;30:157. [PubMed: 16472303]

64. Galperin MY. J. Bacteriol 2006;188:4169. [PubMed: 16740923]

65. Alm E, Huang K, Arkin A. PLoS Comput. Biol 2006;2:e143. [PubMed: 17083272]

66. Bouhouche N, Syvanen M, Kado CI. Trends Microbiol 2000;8:77. [PubMed: 10664601]

67. Perez-Rueda E, Gralla JD, Collado-Vides J. J. Mol. Biol 1998;275:165. [PubMed: 9466899]

68. Madan Babu M, Teichmann SA. Trends Genet 2003;19:75. [PubMed: 12547514]

69. Gerasimova AV, Gelfand MS. J. Bioinform. Comput. Biol 2005;3:1007. [PubMed: 16078372]

70. Rodionov DA, Mironov AA, Gelfand MS. Genome Res 2002;12:1507. [PubMed: 12368242]

71. Martinez-Antonio A, Collado-Vides J. Curr. Opin. Microbiol 2003;6:482. [PubMed: 14572541]

72. Doerks T, Andrade MA, Lathe W 3rd, von Mering C, Bork P. Trends Genet 2004;20:126. [PubMed: 15049306]

73. Gelfand, MS.; Laikova, ON. Frontiers in Computational Genomics. Galperin, MY.; Koonin, EV., editors. Vol. 195. Wymondham: Caister Academic Press; 2003.

74. Kazmierczak MJ, Wiedmann M, Boor KJ. Microbiol. Mol. Biol. Rev 2005;69:527. [PubMed: 16339734]

75. Reitzer L, Schneider BL. Microbiol. Mol. Biol. Rev 2001;65:422. [PubMed: 11528004]

76. Helmann JD. Adv. Microb. Physiol 2002;46:47. [PubMed: 12073657]

77. Kiil K, Ferchaud JB, David C, Binnewies TT, Wu H, Sicheritz-Ponten T, Willenbrock H, Ussery DW. Microbiology 2005;151:3447. [PubMed: 16272367]

78. Salgado H, Gama-Castro S, Peralta-Gil M, Diaz-Peredo E, Sanchez-Solano F, Santos-Zavaleta A, Martinez-Flores I, Jimenez-Jacinto V, Bonavides-Martinez C, Segura-Salazar J, Martinez-Antonio A, Collado-Vides J. Nucleic Acids Res 2006;34:D394. [PubMed: 16381895]

79. Makita Y, Nakao M, Ogasawara N, Nakai K. Nucleic Acids Res 2004;32:D75. [PubMed: 14681362]

80. Baumbach J, Brinkrolf K, Czaja LF, Rahmann S, Tauch A. BMC Genomics 2006;7:24. [PubMed: 16478536]

Chem Rev. Author manuscript; available in PMC 2009 February 16. 
81. Jacques PE, Gervais AL, Cantin M, Lucier JF, Dallaire G, Drouin G, Gaudreau L, Goule J, Brzezinsk R. Bioinformatics 2005;21:2563. [PubMed: 15722376]

82. Pareja E, Pareja-Tobes P, Manrique M, Pareja-Tobes E, Bonal J, Tobes R. BMC Microbiol 2006;6:29. [PubMed: 16539733]

83. Tobes R, Ramos JL. Nucleic Acids Res 2002;30:318. [PubMed: 11752325]

84. Krell T, Molina-Henares AJ, Ramos JL. Protein Sci 2006;15:1207. [PubMed: 16597823]

85. Ramos JL, Martinez-Bueno M, Molina-Henares AJ, Teran W, Watanabe K, Zhang X, Gallegos MT, Brennan R, Tobes R. Microbiol. Mol. Biol. Rev 2005;69:326. [PubMed: 15944459]

86. Martinez-Bueno M, Molina-Henares AJ, Pareja E, Ramos JL, Tobes R. Bioinformatics 2004;20:2787. [PubMed: 15166024]

87. D'Souza M, Glass EM, Syed MH, Zhang Y, Rodriguez A, Maltsev N, Galperin MY. Nucleic Acids Res 2007;35:D271. [PubMed: 17135204]

88. Wu J, Zhao F, Wang S, Deng G, Wang J, Bai J, Lu J, Qu J, Bao Q. BMC Genomics 2007;8:104. [PubMed: 17439663]

89. Munch R, Hiller K, Grote A, Scheer M, Klein J, Schobert M, Jahn D. Bioinformatics 2005;21:4187. [PubMed: 16109747]

9. Kazakov AE, Cipriano MJ, Novichkov PS, Minovitsky S, Vinogradov DV, Arkin A, Mironov AA, Gelfand MS, Dubchak I. Nucleic Acids Res 2007;35:D407. [PubMed: 17142223]

91. Perez AG, Angarica VE, Vasconcelos AT, Collado-Vides J. Nucleic Acids Res 2007;35:D132. [PubMed: 17088283]

92. Brazma A, Jonassen I, Eidhammer I, Gilbert D. J. Comput. Biol 1998;5:279. [PubMed: 9672833]

93. D'Haeseleer P. Nat. Biotechnol 2006;24:959. [PubMed: 16900144]

94. Sinha S, Tompa M. Nucleic Acids Res 2002;30:5549. [PubMed: 12490723]

95. Eskin E, Pevzner PA. Bioinformatics 2002;18:S354. [PubMed: 12169566]

96. Pavesi G, Mauri G, Pesole G. Bioinformatics 2001;17:S207. [PubMed: 11473011]

97. Marsan L, Sagot MF. J. Comput. Biol 2000;7:345. [PubMed: 11108467]

98. McGuire AM, Hughes JD, Church GM. Genome Res 2000;10:744. [PubMed: 10854408]

99. Tompa M, Li N, Bailey TL, Church GM, De Moor B, Eskin E, Favorov AV, Frith MC, Fu Y, Kent WJ, Makeev VJ, Mironov AA, Noble WS, Pavesi G, Pesole G, Regnier M, Simonis N, Sinha S, Thijs G, van Helden J, Vandenbogaert M, Weng Z, Workman C, Ye C, Zhu Z. Nat. Biotechnol 2005;23:137. [PubMed: 15637633]

100. Stormo GD, Hartzell GW. Proc Natl. Acad. Sci. U S A 1989;86:1183. [PubMed: 2919167]

101. Lawrence CE, Reilly AA. Proteins 1990;7:41. [PubMed: 2184437]

102. Bailey TL, Elkan C. Proc. Int. Conf. Intell. Syst. Mol. Biol 1994;2:28. [PubMed: 7584402]

103. Gelfand MS, Koonin EV, Mironov AA. Nucleic Acids Res 2000;28:695. [PubMed: 10637320]

104. Lawrence CE, Altschul SF, Boguski MS, Liu JS, Neuwald AF, Wootton JC. Science 1993;262:208. [PubMed: 8211139]

105. Roth FP, Hughes JD, Estep PW, Church GM. Nat. Biotechnol 1998;16:939. [PubMed: 9788350]

106. Thompson W, Rouchka EC, Lawrence CE. Nucleic Acids Res 2003;31:3580. [PubMed: 12824370]

107. Favorov AV, Gelfand MS, Gerasimova AV, Ravcheev DA, Mironov AA, Makeev VJ. Bioinformatics 2005;21:2240. [PubMed: 15728117]

108. Mwangi MM, Siggia ED. BMC Bioinformatics 2003;4:18. [PubMed: 12749771]

109. Li H, Rhodius V, Gross C, Siggia ED. Proc. Natl. Acad. Sci. U S A 2002;99:11772. [PubMed: 12181488]

110. Studholme DJ, Bentley SD, Kormanec J. BMC Microbiol 2004;4:14. [PubMed: 15072583]

111. Djordjevic M, Sengupta AM, Shraiman BI. Genome Res 2003;13:2381. [PubMed: 14597652]

112. Thieffry D, Salgado H, Huerta AM, Collado-Vides J. Bioinformatics 1998;14:391. [PubMed: 9682052]

113. Constantinidou C, Hobman JL, Griffiths L, Patel MD, Penn CW, Cole JA, Overton TW. J. Biol. Chem 2006;281:4802. [PubMed: 16377617]

114. Liu X, De Wulf P. J. Biol. Chem 2004;279:12588. [PubMed: 14711822] 
115. Yoshida K, Yamaguchi H, Kinehara M, Ohki YH, Nakaura Y, Fujita Y. Mol. Microbiol 2003;49:157. [PubMed: 12823818]

116. Brune I, Werner H, Huser AT, Kalinowski J, Puhler A, Tauch A. BMC Genomics 2006;7:21. [PubMed: 16469103]

117. Reents H, Munch R, Dammeyer T, Jahn D, Hartig E. J. Bacteriol 2006;188:1103. [PubMed: 16428414]

118. Zheng M, Wang X, Doan B, Lewis KA, Schneider TD, Storz G. J. Bacteriol 2001;183:4571. [PubMed: 11443092]

119. Rodionov DA, Mironov AA, Rakhmaninova AB, Gelfand MS. Mol. Microbiol 2000;38:673. [PubMed: 11115104]

120. Laikova ON, Mironov AA, Gelfand MS. FEMS Microbiol. Lett 2001;205:315. [PubMed: 11750821]

121. Rodionov DA, Mironov AA, Gelfand MS. FEMS Microbiol. Lett 2001;205:305. [PubMed: 11750820]

122. Permina EA, Gelfand MS. J. Mol. Microbiol. Biotechnol 2003;6:174. [PubMed: 15153770]

123. Panina EM, Mironov AA, Gelfand MS. Nucleic Acids Res 2001;29:5195. [PubMed: 11812853]

124. Panina EM, Mironov AA, Gelfand MS. Proc. Natl. Acad. Sci. U S A 2003;100:9912. [PubMed: 12904577]

125. Panina EM, Vitreschak AG, Mironov AA, Gelfand MS. J. Mol. Microbiol. Biotechnol 2001;3:529. [PubMed: 11545272]

126. Ravcheev DA, Rakhmaninova AB, Mironov AA, Gelfand MS. Mol. Biol 2005;39:832.

127. Doroshchuk NA, Gelfand MS, Rodionov DA. Mol. Biol 2006;40:919.

128. Tan K, Moreno-Hagelsieb G, Collado-Vides J, Stormo GD. Genome Res 2001;11:566. [PubMed: 11282972]

129. Mironov AA, Koonin EV, Roytberg MA, Gelfand MS. Nucleic Acids Res 1999;27:2981. [PubMed: 10390542]

130. Blanchette M, Tompa M. Genome Res 2002;12:739. [PubMed: 11997340]

131. Tagle DA, Koop BF, Goodman M, Slightom JL, Hess DL, Jones RT. J. Mol. Biol 1988;203:439. [PubMed: 3199442]

132. McCue LA, Thompson W, Carmack CS, Lawrence CE. Genome Res 2002;12:1523. [PubMed: 12368244]

133. Florea L, McClelland M, Riemer C, Schwartz S, Miller W. Nucleic Acids Res 2003;31:3527. [PubMed: 12824359]

134. Dubchak I, Ryaboy DV. Methods Mol. Biol 2006;338:69. [PubMed: 16888351]

135. Boffelli D, McAuliffe J, Ovcharenko D, Lewis KD, Ovcharenko I, Pachter L, Rubin EM. Science 2003;299:1391. [PubMed: 12610304]

136. Neph S, Tompa M. Nucleic Acids Res 2006;34:W366. [PubMed: 16845027]

137. Siddharthan R, Siggia ED, van Nimwegen E. PLoS Comput. Biol 2005;1:e67. [PubMed: 16477324]

138. Sinha S, Blanchette M, Tompa M. BMC Bioinformatics 2004;5:170. [PubMed: 15511292]

139. McCue L, Thompson W, Carmack C, Ryan MP, Liu JS, Derbyshire V, Lawrence CE. Nucleic Acids Res 2001;29:774. [PubMed: 11160901]

140. Qin ZS, McCue LA, Thompson W, Mayerhofer L, Lawrence CE, Liu JS. Nat. Biotechnol 2003;21:435. [PubMed: 12627170]

141. Zhang YM, Marrakchi H, Rock CO. J. Biol. Chem 2002;277:15558. [PubMed: 11859088]

142. Torrents E, Grinberg I, Gorovitz-Harris B, Lundström H, Borovok I, Aharonowitz YB, Sjöberg B, Cohen G. J. Bacteriol 2007 May 11;189

143. Conlan S, Lawrence C, McCue LA. Appl. Environ. Microbiol 2005;71:7442. [PubMed: 16269786]

144. Terai G, Takagi T, Nakai K. Genome Biol 2001;2Research0048

145. Wels M, Francke C, Kerkhoven R, Kleerebezem M, Siezen RJ. Nucleic Acids Res 2006;34:1947. [PubMed: 16614445]

146. Carmack CS, McCue LA, Newberg LA, Lawrence CE. Algorithms Mol. Biol 2007;2:1. [PubMed: 17244358]

147. Alkema WB, Lenhard B, Wasserman WW. Genome Res 2004;14:1362. [PubMed: 15231752] 
148. Rodionov DA, Gelfand MS. Trends Genet 2005;21:385. [PubMed: 15949864]

149. Morozov AV, Siggia ED. Proc. Natl. Acad. Sci. U S A 2007;104:7068. [PubMed: 17438293]

150. Sandelin A, Wasserman WW. J. Mol. Biol 2004;338:207. [PubMed: 15066426]

151. Tan K, McCue LA, Stormo GD. Genome Res 2005;15:312. [PubMed: 15653829]

152. Osterman A, Overbeek R. Curr. Opin. Chem. Biol 2003;7:238. [PubMed: 12714058]

153. Wolf YI, Rogozin IB, Kondrashov AS, Koonin EV. Genome Res 2001;11:356. [PubMed: 11230160]

154. Grinberg I, Shteinberg T, Gorovitz B, Aharonowitz Y, Cohen G, Borovok I. J. Bacteriol 2006;188:7635. [PubMed: 16950922]

155. Winkler WC, Breaker RR. Annu. Rev. Microbiol 2005;59:487. [PubMed: 16153177]

156. Vitreschak AG, Rodionov DA, Mironov AA, Gelfand MS. Trends Genet 2004;20:44. [PubMed: 14698618]

157. Gelfand MS, Mironov AA, Jomantas J, Kozlov YI, Perumov DA. Trends Genet 1999;15:439. [PubMed: 10529804]

158. Vitreschak AG, Rodionov DA, Mironov AA, Gelfand MS. Nucleic Acids Res 2002;30:3141. [PubMed: 12136096]

159. Vitreschak V, Rodionov DA, Mironov AA, Gelfand MS. RNA 2003;9:1084. [PubMed: 12923257]

160. Rodionov DA, Vitreschak AG, Mironov AA, Gelfand MS. Nucleic Acids Res 2003;31:6748. [PubMed: 14627808]

161. Grundy FJ, Henkin TM. Mol. Microbiol 1998;30:737. [PubMed: 10094622]

162. Roth A, Winkler WC, Regulski EE, Lee BW, Lim J, Jona I, Barrick JE, Ritwik A, Kim JN, Welz R, Iwata-Reuyl D, Breaker RR. Nat. Struct. Mol. Biol 2007;14:308. [PubMed: 17384645]

163. Winkler WC, Cohen-Chalamish S, Breaker RR. Proc. Natl. Acad. Sci. U S A 2002;99:15908. [PubMed: 12456892]

164. Mironov AS, Gusarov I, Rafikov R, Lopez LE, Shatalin K, Kreneva RA, Perumov DA, Nudler E. Cell 2002;111:747. [PubMed: 12464185]

165. Nahvi A, Barrick JE, Breaker RR. Nucleic Acids Res 2004;32:143. [PubMed: 14704351]

166. Winkler W, Nahvi A, Breaker RR. Nature 2002;419:952. [PubMed: 12410317]

167. Sudarsan N, Wickiser JK, Nakamura S, Ebert MS, Breaker RR. Genes Dev 2003;17:2688. [PubMed: 14597663]

168. McDaniel BA, Grundy FJ, Artsimovitch I, Henkin TM. Proc. Natl. Acad. Sci. U S A 2003;100:3083. [PubMed: 12626738]

169. Griffiths-Jones S, Moxon S, Marshall M, Khanna A, Eddy SR, Bateman A. Nucleic Acids Res 2005;33:D121. [PubMed: 15608160]

170. Abreu-Goodger C, Merino E. Nucleic Acids Res 2005;33:W690. [PubMed: 15980564]

171. Huang HY, Chien CH, Jen KH, Huang HD. Nucleic Acids Res 2006;34:W429. [PubMed: 16845041]

172. Bengert P, Dandekar T. Nucleic Acids Res 2004;32:W154. [PubMed: 15215370]

173. Abreu-Goodger C, Ontiveros-Palacios N, Ciria R, Merino E. Trends Genet 2004;20:475. [PubMed: 15363900]

174. Barrick JE, Corbino KA, Winkler WC, Nahvi A, Mandal M, Collins J, Lee M, Roth A, Sudarsan N, Jona I, Wickiser JK, Breaker RR. Proc. Natl. Acad. Sci. U S A 2004;101:6421. [PubMed: 15096624]

175. Corbino KA, Barrick JE, Lim J, Welz R, Tucker BJ, Puskarz I, Mandal M, Rudnick ND, Breaker RR. Genome Biol 2005;6:R70. [PubMed: 16086852]

176. Fuchs RT, Grundy FJ, Henkin TM. Nat. Struct. Mol. Biol 2006;13:226. [PubMed: 16491091]

177. Mandal M, Lee M, Barrick JE, Weinberg Z, Emilsson GM, Ruzzo WL, Breaker RR. Science 2004;306:275. [PubMed: 15472076]

178. Hatfield GW, Hung SP, Baldi P. Mol. Microbiol 2003;47:871. [PubMed: 12581345]

179. Hudson ME, Snyder M. Biotechniques 2006;41:673. [PubMed: 17191608]

180. Lee TI, Johnstone SE, Young RA. Nat. Protoc 2006;1:729. [PubMed: 17406303]

181. Gianchandani EP, Papin JA, Price ND, Joyce AR, Palsson BO. PLoS Comput. Biol 2006;2:e101. [PubMed: 16895435]

182. Herrgard MJ, Covert MW, Palsson BO. Genome Res 2003;13:2423. [PubMed: 14559784] 
183. Faith JJ, Hayete B, Thaden JT, Mogno I, Wierzbowski J, Cottarel G, Kasif S, Collins JJ, Gardner TS. PLoS Biol 2007;5:e8. [PubMed: 17214507]

184. Gosset G, Zhang Z, Nayyar S, Cuevas WA, Saier MH Jr. J. Bacteriol 2004;186:3516. [PubMed: 15150239]

185. McHugh JP, Rodriguez-Quinones F, Abdul-Tehrani H, Svistunenko DA, Poole RK, Cooper CE, Andrews SC. J. Biol. Chem 2003;278:29478. [PubMed: 12746439]

186. Lorca GL, Chung YJ, Barabote RD, Weyler W, Schilling CH, Saier MH Jr. J. Bacteriol 2005;187:7826. [PubMed: 16267306]

187. Wan XF, Verberkmoes NC, McCue LA, Stanek D, Connelly H, Hauser LJ, Wu L, Liu X, Yan T, Leaphart A, Hettich RL, Zhou J, Thompson DK. J. Bacteriol 2004;186:8385. [PubMed: 15576789]

188. Zhou D, Qin L, Han Y, Qiu J, Chen Z, Li B, Song Y, Wang J, Guo Z, Zhai J, Du Z, Wang X, Yang R. FEMS Microbiol. Lett 2006;258:9. [PubMed: 16630248]

189. Au N, Kuester-Schoeck E, Mandava V, Bothwell LE, Canny SP, Chachu K, Colavito SA, Fuller SN, Groban ES, Hensley LA, O'Brien TC, Shah A, Tierney JT, Tomm LL, O'Gara TM, Goranov AI, Grossman AD, Lovett CM. J. Bacteriol 2005;187:7655. [PubMed: 16267290]

190. Wennerhold J, Bott M. J. Bacteriol 2006;188:2907. [PubMed: 16585752]

191. Rudolph G, Semini G, Hauser F, Lindemann A, Friberg M, Hennecke H, Fischer HM. J. Bacteriol 2006;188:733. [PubMed: 16385063]

192. den Hengst CD, van Hijum SA, Geurts JM, Nauta A, Kok J, Kuipers OP. J. Biol. Chem 2005;280:34332. [PubMed: 16040604]

193. Rey DA, Nentwich SS, Koch DJ, Ruckert C, Puhler A, Tauch A, Kalinowski J. Mol. Microbiol 2005;56:871. [PubMed: 15853877]

194. Tsyganova MO, Gelfand MS, Ravcheev DA. Mol. Biol 2007;41in press

195. Salmon KA, Hung SP, Steffen NR, Krupp R, Baldi P, Hatfield GW, Gunsalus RP. J. Biol. Chem 2005;280:15084. [PubMed: 15699038]

196. Salmon K, Hung SP, Mekjian K, Baldi P, Hatfield GW, Gunsalus RP. J. Biol. Chem 2003;278:29837. [PubMed: 12754220]

197. Gerasimova AV, Rodionov DA, Mironov AA, Gelfand MS. Mol. Biol 2001;35:853.

198. Cao M, Kobel PA, Morshedi MM, Wu MF, Paddon C, Helmann JD. J. Mol. Biol 2002;316:443. [PubMed: 11866510]

199. Mao L, Mackenzie C, Roh JH, Eraso JM, Kaplan S, Resat H. Microbiology 2005;151:3197. [PubMed: 16207904]

200. van de Werken HJ, Verhees CH, Akerboom J, de Vos WM, van der Oost J. FEMS Microbiol. Lett 2006;260:69. [PubMed: 16790020]

201. Geiduschek EP, Ouhammouch M. Mol. Microbiol 2005;56:1397. [PubMed: 15916593]

202. Plumbridge J. Nucleic Acids Res 2001;29:506. [PubMed: 11139621]

203. Yang C, Rodionov DA, Li X, Laikova ON, Gelfand MS, Zagnitko OP, Romine MF, Obraztsova AY, Nealson KH, Osterman AL. J. Biol. Chem 2006;281:29872. [PubMed: 16857666]

204. Meibom KL, Li XB, Nielsen AT, Wu CY, Roseman S, Schoolnik GK. Proc. Natl. Acad. Sci. U S A 2004;101:2524. [PubMed: 14983042]

205. Bates, UtzC; Nguyen, AB.; Smalley, DJ.; Anderson, AB.; Conway, T. J. Bacteriol 2004;186:7690. [PubMed: 15516583]

206. Rodionov DA, Gelfand MS, Hugouvieux-Cotte-Pattat N. Microbiology 2004;150:3571. [PubMed: 15528647]

207. Hugouvieux-Cotte-Pattat N, Blot N, Reverchon S. Mol. Microbiol 2001;41:1113. [PubMed: 11555291]

208. Rodionov DA, Gelfand MS. FEMS Microbiol. Lett 2006;255:102. [PubMed: 16436068]

209. Reitzer L. Annu. Rev. Microbiol 2003;57:155. [PubMed: 12730324]

210. Yoshida K, Yamaguchi H, Kinehara M, Ohki YH, Nakaura Y, Fujita Y. Mol. Microbiol 2003;49:157. [PubMed: 12823818]

211. Su Z, Mao F, Dam P, Wu H, Olman V, Paulsen IT, Palenik B, Xu Y. Nucleic Acids Res 2006;34:1050. [PubMed: 16473855] 
212. Silberbach M, Burkovski A. J. Biotechnol 2006;126:101. [PubMed: 16698104]

213. Su Z, Olman V, Mao F, Xu Y. Nucleic Acids Res 2005;33:5156. [PubMed: 16157864]

214. Dixon R, Kahn D. Nat. Rev. Microbiol 2004;2:621. [PubMed: 15263897]

215. Lie TJ, Wood GE, Leigh JA. J. Biol. Chem 2005;280:5236. [PubMed: 15590692]

216. Rodionov DA, Dubchak IL, Arkin AP, Alm EJ, Gelfand MS. PLoS Comput. Biol 2005;1:e55. [PubMed: 16261196]

217. Grose JH, Bergthorsson U, Roth JR. J. Bacteriol 2005;187:2774. [PubMed: 15805524]

218. Kurnasov OV, Polanuyer BM, Ananta S, Sloutsky R, Tam A, Gerdes SY, Osterman AL. J. Bacteriol 2002;184:6906. [PubMed: 12446641]

219. Rossolillo P, Marinoni I, Galli E, Colosimo A, Albertini AM. J. Bacteriol 2005; 187:7155. [PubMed: 16199587]

220. Overbeek R, Fonstein M, D'Souza M, Pusch GD, Maltsev N. Proc. Natl. Acad. Sci. U S A 1999;96:2896. [PubMed: 10077608]

221. Galperin MY, Koonin EV. Nat. Biotechnol 2000;18:609. [PubMed: 10835597]

222. Marcotte EM, Pellegrini M, Ng HL, Rice DW, Yeates TO, Eisenberg D. Science 1999;285:751. [PubMed: 10427000]

223. Enright AJ, Ouzounis CA. Genome Biol 2001;2Research0034

224. Pellegrini M, Marcotte EM, Thompson MJ, Eisenberg D, Yeates TO. Proc. Natl. Acad. Sci. U S A 1999;96:4285. [PubMed: 10200254]

225. Overbeek R, Begley T, Butler RM, Choudhuri JV, Chuang HY, Cohoon M, de Crecy-Lagard V, Diaz N, Disz T, Edwards R, Fonstein M, Frank ED, Gerdes S, Glass EM, Goesmann A, Hanson A, Iwata-Reuyl D, Jensen R, Jamshidi N, Krause L, Kubal M, Larsen N, Linke B, McHardy AC, Meyer F, Neuweger H, Olsen G, Olson R, Osterman A, Portnoy V, Pusch GD, Rodionov DA, Ruckert C, Steiner J, Stevens R, Thiele I, Vassieva O, Ye Y, Zagnitko O, Vonstein V. Nucleic Acids Res 2005;33:5691. [PubMed: 16214803]

226. Gerdes SY, Kurnasov OV, Shatalin K, Polanuyer B, Sloutsky R, Vonstein V, Overbeek R, Osterman AL. J. Bacteriol 2006;188:3012. [PubMed: 16585762]

227. Via P, Badia J, Baldoma L, Obradors N, Aguilar J. Microbiology 1996;142:1833. [PubMed: 8757746]

228. Egan SM, Schleif RF. J. Mol. Biol 1994;243:821. [PubMed: 7966303]

229. Hugouvieux-Cotte-Pattat N. Mol. Microbiol 2004;51:1361. [PubMed: 14982630]

230. Sadovskaya NS, Laikova ON, Mironov AA, Gelfand MS. Mol. Biol 2001;35:862.

231. Campbell JW, Cronan JE Jr. J. Bacteriol 2002;184:3759. [PubMed: 12057976]

232. Warren MJ, Raux E, Schubert HL, Escalante-Semerena JC. Nat. Prod. Rep 2002;19:390. [PubMed: 12195810]

233. Rodionov DA, Vitreschak AG, Mironov AA, Gelfand MS. J. Biol. Chem 2003;278:41148. [PubMed: 12869542]

234. Rodionov DA, Hebbeln P, Gelfand MS, Eitinger T. J. Bacteriol 2006;188:317. [PubMed: 16352848]

235. Hebbeln P, Eitinger T. FEMS Microbiol. Lett 2004;230:129. [PubMed: 14734175]

236. Zayas CL, Woodson JD, Escalante-Semerena JC. J. Bacteriol 2006;188:2740. [PubMed: 16547066]

237. Sudarsan N, Hammond MC, Block KF, Welz V, Barrick JE, Roth A, Breaker RR. Science 2006;314:300. [PubMed: 17038623]

238. Borovok I, Gorovitz B, Schreiber R, Aharonowitz Y, Cohen G. J. Bacteriol 2006;188:2512. [PubMed: 16547038]

239. Masse E, Gottesman S. Proc. Natl. Acad. Sci. U S A 2002;99:4620. [PubMed: 11917098]

240. Rodionov DA, Gelfand MS, Todd JD, Curson AR, Johnston AW. PLoS Comput. Biol 2006;2:e163. [PubMed: 17173478]

241. Rodionov DA, Dubchak I, Arkin A, Alm E, Gelfand MS. Genome Biol 2004;5:R90. [PubMed: 15535866]

242. Akanuma G, Nanamiya H, Natori Y, Nomura N, Kawamura F. J. Bacteriol 2006;188:2715. [PubMed: 16547061] 
243. Nanamiya H, Akanuma G, Natori Y, Murayama R, Kosono S, Kudo T, Kobayashi K, Ogasawara N, Park SM, Ochi K, Kawamura F. Mol. Microbiol 2004;52:273. [PubMed: 15049826]

244. Owen GA, Pascoe B, Kallifidas D, Paget MS. J. Bacteriol 2007;189:4078. [PubMed: 17400736]

245. Shin JH, Oh SY, Kim SJ, Roe JH. J. Bacteriol 2007;189:4070. [PubMed: 17416659]

246. Paulsen IT, Sliwinski MK, Saier MH Jr. J. Mol Biol 1998;277:573. [PubMed: 9533881]

247. Caspi R, Foerster H, Fulcher CA, Hopkinson R, Ingraham J, Kaipa P, Krummenacker M, Paley S, Pick J, Rhee SY, Tissier C, Zhang P, Karp PD. Nucleic Acids Res 2006;34:D511. [PubMed: 16381923]

248. Kanehisa M, Goto S, Hattori M, Aoki-Kinoshita KF, Itoh M, Kawashima S, Katayama T, Araki M, Hirakawa M. Nucleic Acids Res 2006;34:D354. [PubMed: 16381885]

249. Ren Q, Chen K, Paulsen IT. Nucleic Acids Res 2007;35:D274. [PubMed: 17135193]

250. Mauchline TH, Fowler JE, East AK, Sartor AL, Zaheer R, Hosie AH, Poole PS, Finan TM. Proc. Natl. Acad. Sci. U S A 2006;103:17933. [PubMed: 17101990]

251. Rodionov DA, Vitreschak AG, Mironov AA, Gelfand MS. Nucleic Acids Res 2004;32:3340. [PubMed: 15215334]

252. Guillen-Navarro K, Araiza G, Garcia-de Los Santos A, Mora Y, Dunn MF. FEMS Microbiol. Lett 2005;250:209. [PubMed: 16099603]

253. Hebbeln P, Rodionov DA, Alfandega A, Eitinger T. Proc. Natl. Acad. Sci. U S A 2007;104:2909. [PubMed: 17301237]

254. Kreneva RA, Gelfand MS, Mironov AA, Iomantas IuA, Kozlov IuI, Mironov AS, Perumov DA. Genetika 2000;36:1166. [PubMed: 11033791]

255. Burgess CM, Slotboom DJ, Geertsma ER, Duurkens RH, Poolman B, van Sinderen D. J. Bacteriol 2006;188:2752. [PubMed: 16585736]

256. Snel B, van Noort V, Huynen MA. Nucleic Acids Res 2004;32:4725. [PubMed: 15353560]

257. Lozada-Chavez I, Janga SC, Collado-Vides J. Nucleic Acids Res 2006;34:3434. [PubMed: 16840530]

258. Hershberg R, Margalit H. Genome Biol 2006;7:R62. [PubMed: 16859509]

259. Panina EM, Vitreschak AG, Mironov AA, Gelfand MS. FEMS Microbiol. Lett 2003;222:211. [PubMed: 12770710]

260. Permina EA, Kazakov AE, Kalinina OV, Gelfand MS. BMC Microbiol 2006;6:49. [PubMed: 16753059]

261. Ravcheev DA, Gerasimova AV, Mironov AA, Gelfand MS. BMC Genomics 2007;8:54. [PubMed: 17313674]

262. Marincs F, Manfield IW, Stead JA, McDowall KJ, Stockley PG. Biochem. J 2006;396:227. [PubMed: 16515535]

263. LaMonte BL, Hughes JA. Microbiology 2006;152:1451. [PubMed: 16622061]

264. Kovaleva, GYu; Gelfand, MS. Mol. Biol 2007;41:126.

265. Shelver D, Rajagopal L, Harris TO, Rubens CE. J. Bacteriol 2003;185:6592. [PubMed: 14594832]

266. Sperandio B, Polard P, Ehrlich DS, Renault P, Guedon E. J. Bacteriol 2005;187:3762. [PubMed: 15901700]

267. Vitreschak AG, Lyubetskaya EV, Shirshin MA, Gelfand MS, Lyubetsky VA. FEMS Microbiol. Lett 2004;234:357. [PubMed: 15135544]

268. Herrera MC, Ramos JL. J. Mol. Biol 2007;366:1374. [PubMed: 17217960]

269. Akers JC, Tan M. J. Bacteriol 2006;188:4236. [PubMed: 16740930]

270. Gollnick P, Babitzke P, Antson A, Yanofsky C. Annu. Rev. Genet 2005;39:47. [PubMed: 16285852]

271. Ramseier TM. Res. Microbiol 1996;147:489. [PubMed: 9084760]

272. Saier MH Jr. FEMS Microbiol. Lett 1996;138:97. [PubMed: 9026456]

273. Hantke K. Curr. Opin. Microbiol 2001;4:172. [PubMed: 11282473]

274. Rudolph G, Hennecke H, Fischer HM. FEMS Microbiol. Rev 2006;30:631. [PubMed: 16774589]

275. Johnston AW, Todd JD, Curson AR, Lei S, Nikolaidou-Katsaridou N, Gelfand MS, Rodionov DA. Biometals 2007;20:501. [PubMed: 17310401] 
276. Mustonen V, Lassig M. Proc. Natl. Acad. Sci. U S A 2005;102:15936. [PubMed: 16236723]

277. Danilova LV, Lyubetsky VA, Gelfand MS, Laikova ON. Mol. Biol 2003;37:716.

278. Yellaboina S, Ranjan S, Vindal V, Ranjan A. FEBS Lett 2006;580:2567. [PubMed: 16631750]

279. Studholme DJ, Pau RN. BMC Microbiol 2003;3:24. [PubMed: 14641908]

280. Su Z, Olman V, Mao F, Xu Y. Nucleic Acids Res 2005;33:5156. [PubMed: 16157864]

281. Erill I, Jara M, Salvador N, Escribano M, Campoy S, Barbe J. Nucleic Acids Res 2004;32:6617. [PubMed: 15604457]

282. Permina EA, Mironov AA, Gelfand MS. Gene 2002;293:133. [PubMed: 12137951]

283. Ravcheev DA, Gelfand MS, Mironov AA, Rakhmaninova AB. Genetika 2002;38:1203. [PubMed: 12391881]

284. Yuan ZC, Zaheer R, Morton R, Finan TM. Nucleic Acids Res 2006;34:2686. [PubMed: 16717279]

285. Liu J, Tan K, Stormo GD. Nucleic Acids Res 2003;31:6891. [PubMed: 14627822]

286. Hallin PF, Ussery D. Bioinformatics 2004;20:3682. [PubMed: 15256401] 
A.

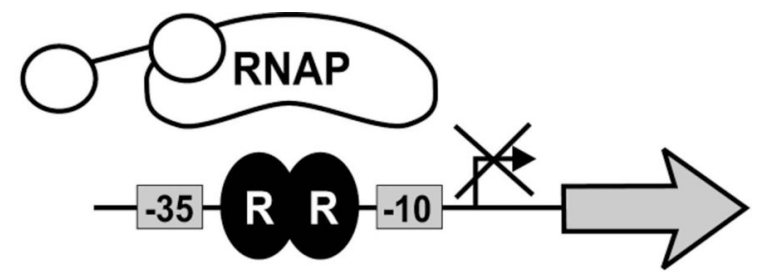

B.

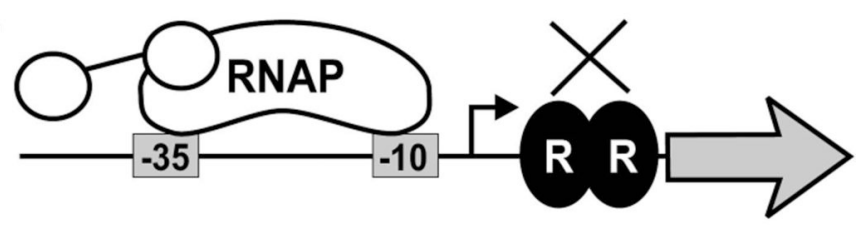

C.
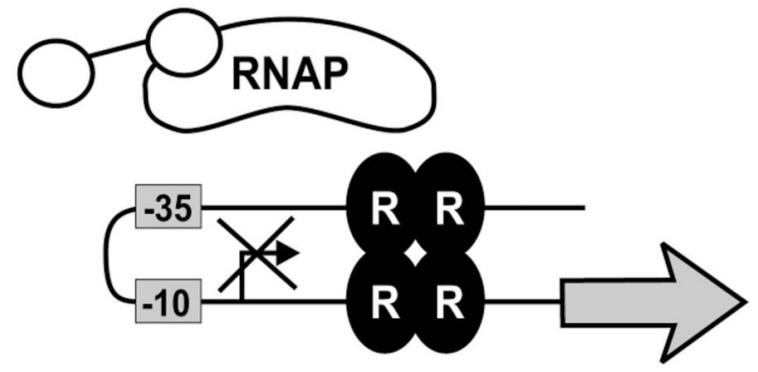

D.

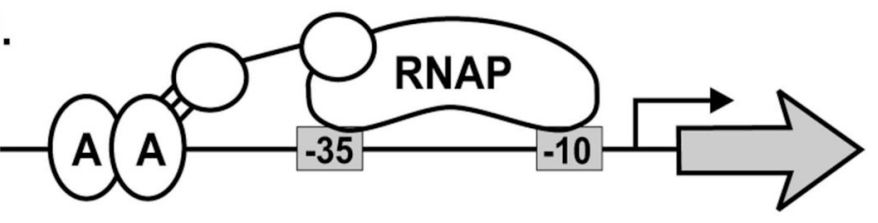

E.

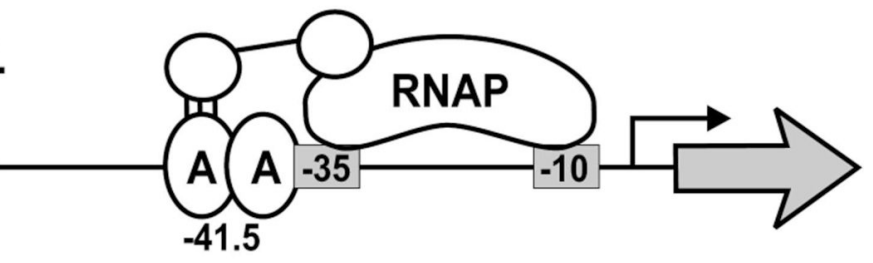

F.

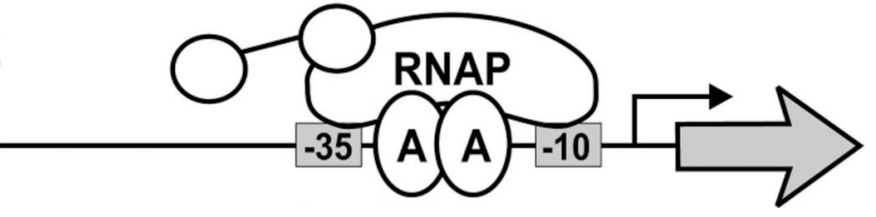

Figure 1. Mechanisms of regulation by transcription factors in prokaryotes

$\mathrm{A}$, repression by steric hindrance; $\mathrm{B}$, repression by blocking of the transcription elongation; $\mathrm{C}$, repression by DNA looping; D, Class I activation; E, Class II activation; F, activation by conformation change. 'RNAP', 'A', and 'R' indicate RNA polymerase, activator and repressor proteins, respectively. Promoter elements are shown by ' -35 ' and ' -10 ' boxes. Thin and thick arrows indicate transcription start sites and target genes, respectively. At Class I promoters, the activator is bound to an upstream site and contacts $\alpha$ subunit of RNAP, thereby recruiting the polymerase to the promoter. At Class II promoters, the activator binds to a target that is adjacent to promoter (in most cases at position -41.5 relative to transcription start site), and the bound activator interacts with $\sigma 70$ subunit of RNAP. 
A. Consensus sequence, multiple site alignment

\begin{tabular}{|ll|}
\hline >nagB & CTTATTTTATCATTCAAAAAATC \\
>nagE & TTTAATTTGCGATACGAATAAA \\
>yhcK & GTGATTTTTCATTAAAAAATATG \\
>b1498 & CTTATTTCTCTTCGTAAAATTAC \\
>ybfM & GATAATTCGCGTCGCGAAAAATA \\
>manX1 & ATTTTTTCGATATCTAAAATAAA \\
>manX2 & GATATTTTACCTTTCGAAATTTC \\
>glmU1 & GTTTATTCATTGATCGAAATAAG \\
>glmU2 & TCCATTTCACGATGAAAAAAATG \\
>ptsH & ATTATTTTGATGCGCGAAATTAA \\
>yheB & GTTATTTTCGATGGCAAAATTTA \\
>celA & CTTAATTATCTTCGCGAATATT \\
Consensus & nWTWWTTYnnnnnnMRAAWWWWn
\end{tabular}

\section{B. Sequence logo}

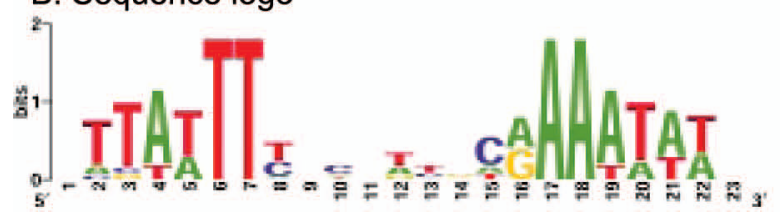

C. Positional Weight Matrix (PWM)

\begin{tabular}{|rrrr|}
\hline \multicolumn{1}{|c}{$\mathbf{a}$} & \multicolumn{1}{c}{$\mathrm{c}$} & \multicolumn{1}{c|}{$\mathrm{t}$} \\
-0.05 & 0.01 & 0.10 & -0.05 \\
0.04 & -0.06 & -0.28 & 0.30 \\
-0.26 & -0.04 & -0.04 & 0.34 \\
0.37 & -0.23 & -0.23 & 0.09 \\
0.18 & -0.25 & -0.25 & 0.31 \\
-0.16 & -0.16 & -0.16 & 0.47 \\
-0.16 & -0.16 & -0.16 & 0.47 \\
-0.08 & 0.17 & -0.30 & 0.20 \\
0.07 & -0.15 & 0.07 & 0.02 \\
-0.03 & 0.19 & -0.13 & -0.03 \\
-0.05 & -0.05 & 0.01 & 0.10 \\
0.12 & -0.31 & 0.00 & 0.19 \\
-0.13 & 0.09 & -0.13 & 0.16 \\
-0.04 & -0.14 & 0.15 & 0.03 \\
0.02 & 0.26 & -0.30 & 0.02 \\
0.25 & -0.25 & 0.25 & -0.25 \\
0.47 & -0.16 & -0.16 & -0.16 \\
0.47 & -0.16 & -0.16 & -0.16 \\
0.37 & -0.23 & -0.23 & 0.09 \\
0.14 & -0.24 & -0.24 & 0.34 \\
0.31 & -0.25 & -0.25 & 0.18 \\
0.22 & -0.25 & -0.25 & 0.28 \\
0.11 & 0.02 & 0.02 & -0.15 \\
\hline
\end{tabular}

Figure 2. Representation of transcription factor binding sites

A, Alignment of NagC binding sites in E. coli ${ }^{203}$ and the derived consensus sequence.

B. Sequence logo representation generated by the WebLogo tool (http://weblogo.berkeley.edu). The relative height of letters represents the frequencies of nucleotides at each position measured in bits of information.

C. PWM for the NagC binding motif, where the repective positional weights were calculated using the following formula: ${ }^{64} W_{b, k}=\log \left(N_{b, k}+0.5\right)-0.25 \Sigma_{\mathrm{i}=\mathrm{A}, \mathrm{T}, \mathrm{G}, \mathrm{C}} \log \left(N_{i, k}+0.5\right)$, where $N_{b, k}$ is the count of nucleotide $b$ in position $k$. 
A.

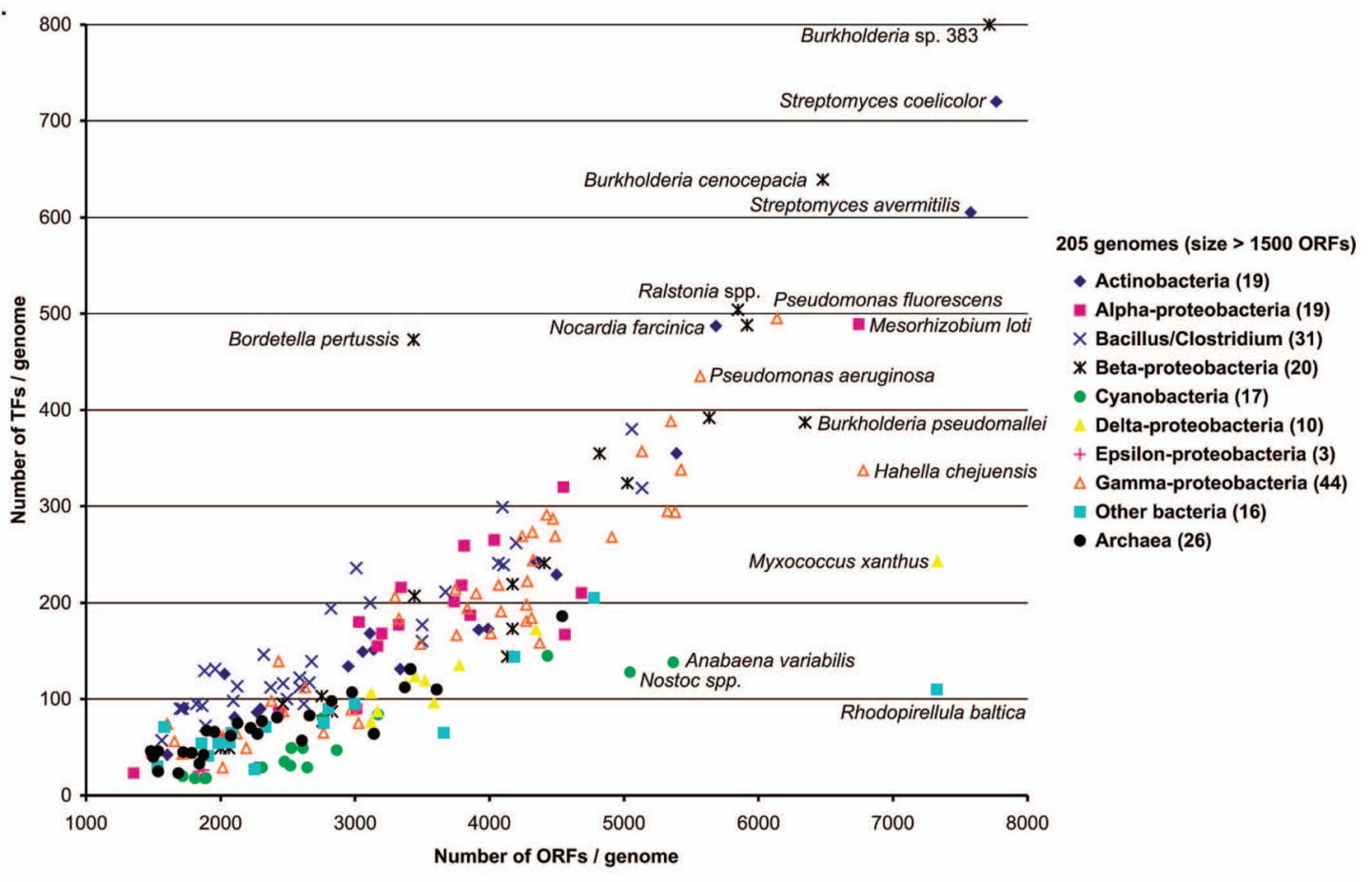

B.

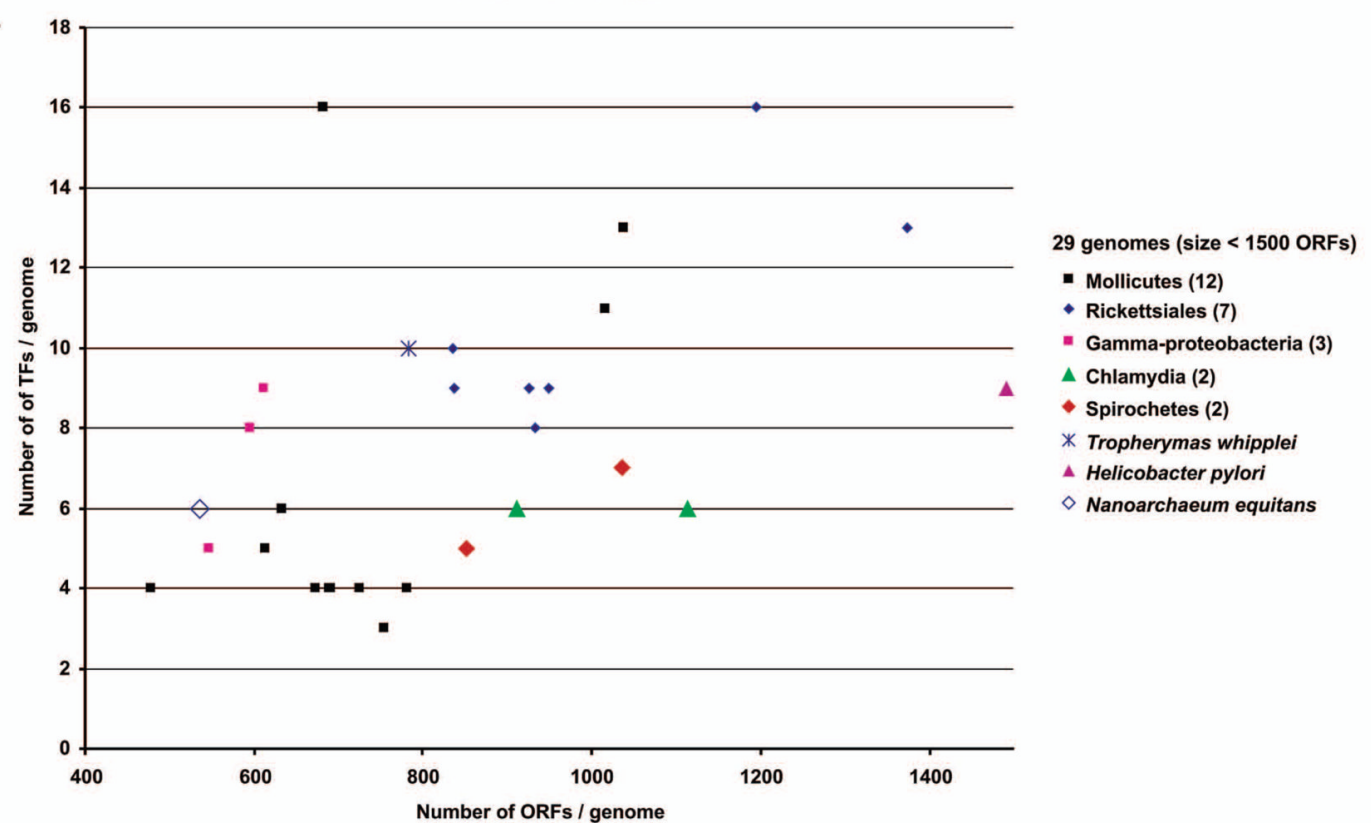

Figure 3. Number of TFs in prokaryotic genomes against the total number of ORFs per genome Predicted TFs are from DBD database. ${ }^{56}$ Different taxonomic groups listed in the right insert are represented by dots of different form and color. Number of genomes in each taxonomic group is given in parenthesis. A. Plot for 205 prokaryotic genomes with size more than 1500 ORFs. B. Plot for 29 genomes of obligate pathogens and symbionts with size less than 1500 ORFs. 


\section{A. Consistency check}

\section{Genome 1}

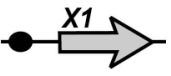

Genes $X, Y$, and $Z$
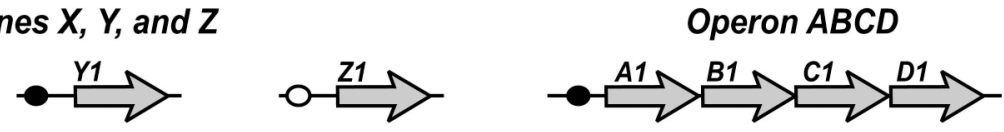

Genome 2
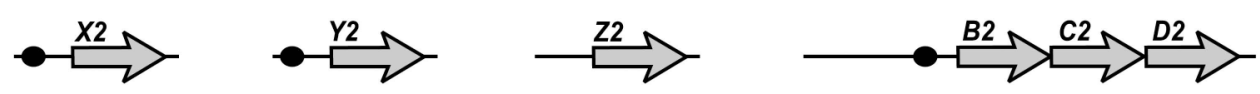

Genome 3
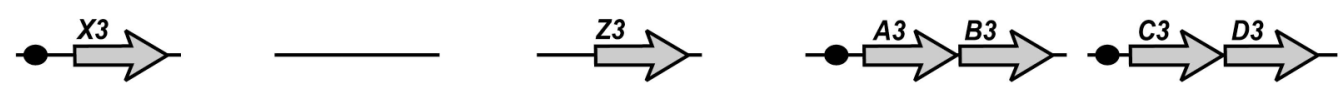

True sites (conserved in related genomes)

False positive sites (non-conserved)

\section{B. Phylogenetic footprinting}

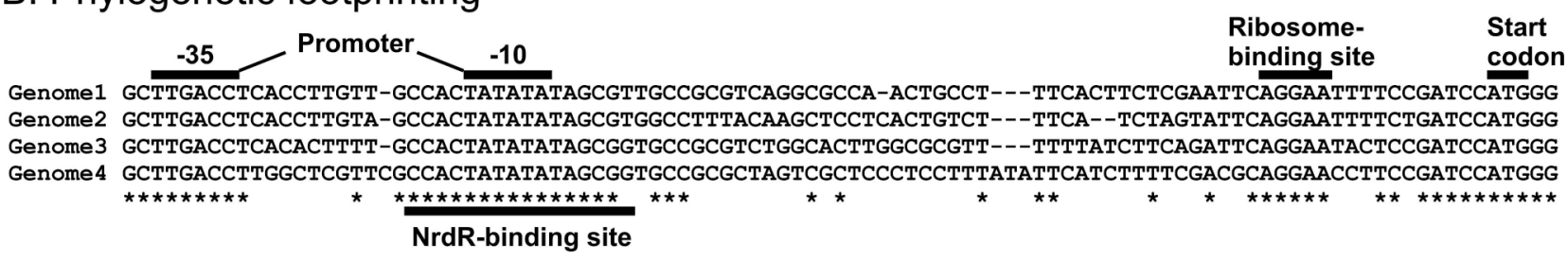

Figure 4. Comparative genomic approaches for TFBSs identification

A. Consistency check of the candidate TFBSs in a group of genomes. First, all UTRs in the genomes are scanned by the constructed PWM to identify candidate TFBSs. Then, the predicted TFBSs are differentiated based on their conservation in other genomes. False positive sites usually are not conserved in related genomes with orthologous TFs. Accounting for changes in operon structure in different genomes (gene loss, split and fusion of operons) increases the rate of predicted true positive sites.

B. Phylogentic footprinting of orthologous UTRs on the example of the $n r d A$ gene in Pseudomonas species. Highly conserved DNA regions that correspond to the NrdR-binding site, candidate -35 and -10 promoter elements, and the ribosomal binding site are shown by thick lines. 


\section{A. Strategy I: Known TFs}

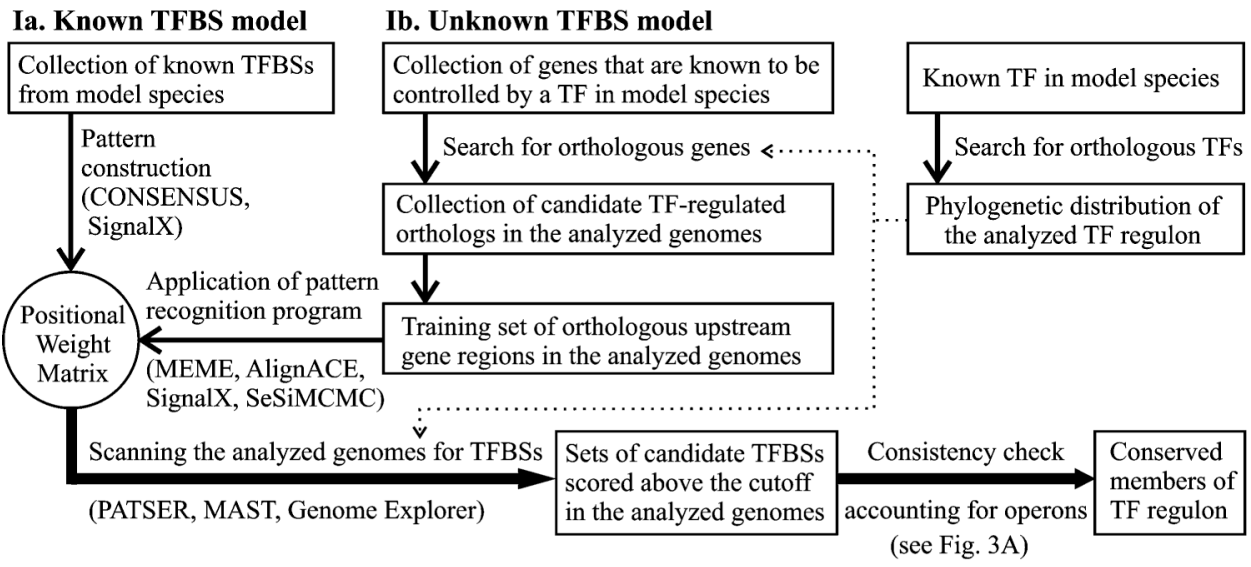

\section{B. Strategy II: Putative TFs}

IIa. Subsystem-oriented approach

Defining of a taxonomic group of species, and a group of genes involved in the metabolic pathway (subsystem) of interest

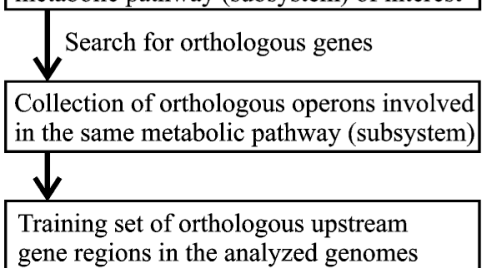

gene regions in the analyzed genomes

\section{IIb. Phylogenetic footprinting}

Collection of orthologous upstream regions Genome-wide of genes of interest in the taxonomic group analysis: of closely related species Pattern recognition
program (Gibbs $\begin{array}{lll}\text { Analysis of individual genes: } & \begin{array}{l}\text { program (Gibbs } \\ \text { Sampler, MEME } \\ \text { Multiple alignment of }\end{array}\end{array}$ $\downarrow$ upstream regions(see Fig. 3B)

Selection of highly conserved regions with intrinsic symmetry Grouping of cross-species motifs into regulons (Bayesian motif clustering)

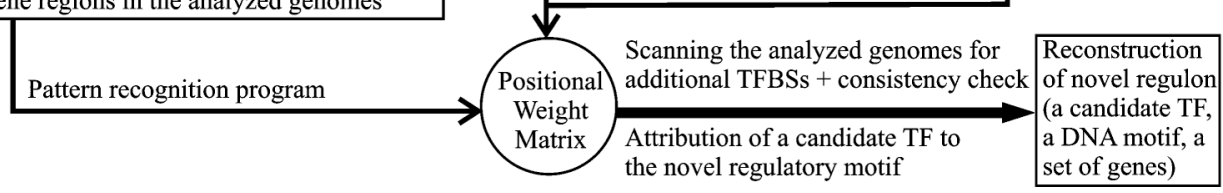

Figure 5. Schematic representation of two strategies for comparative genomic reconstruction of regulons

A. Strategy I for analysis of known regulons with experimentally determined TFs. Known TFBSs are collected to construct a PWM, which is used to scan the genomes for additional sites. If TFBS model is unknown, the set of upstream regions of known TF-regulated genes and their orthologs in other genomes is collected and used as an input for TFBS pattern recognition programs and a PWM construction.

B. Strategy II for discovery of novel regulons operating by previously unknown TFs. In the subsystem-oriented approach, the training set for TFBS recognition program includes upstream regions of genes from the same metabolic pathway in the defined taxonomic group of bacteria. Phylogenetic footprinting identifies highly conserved regions in multiple alignments of upstream gene regions across the closely related species that are used to construct a PWM to search for additional TFBSs in the genomes. 


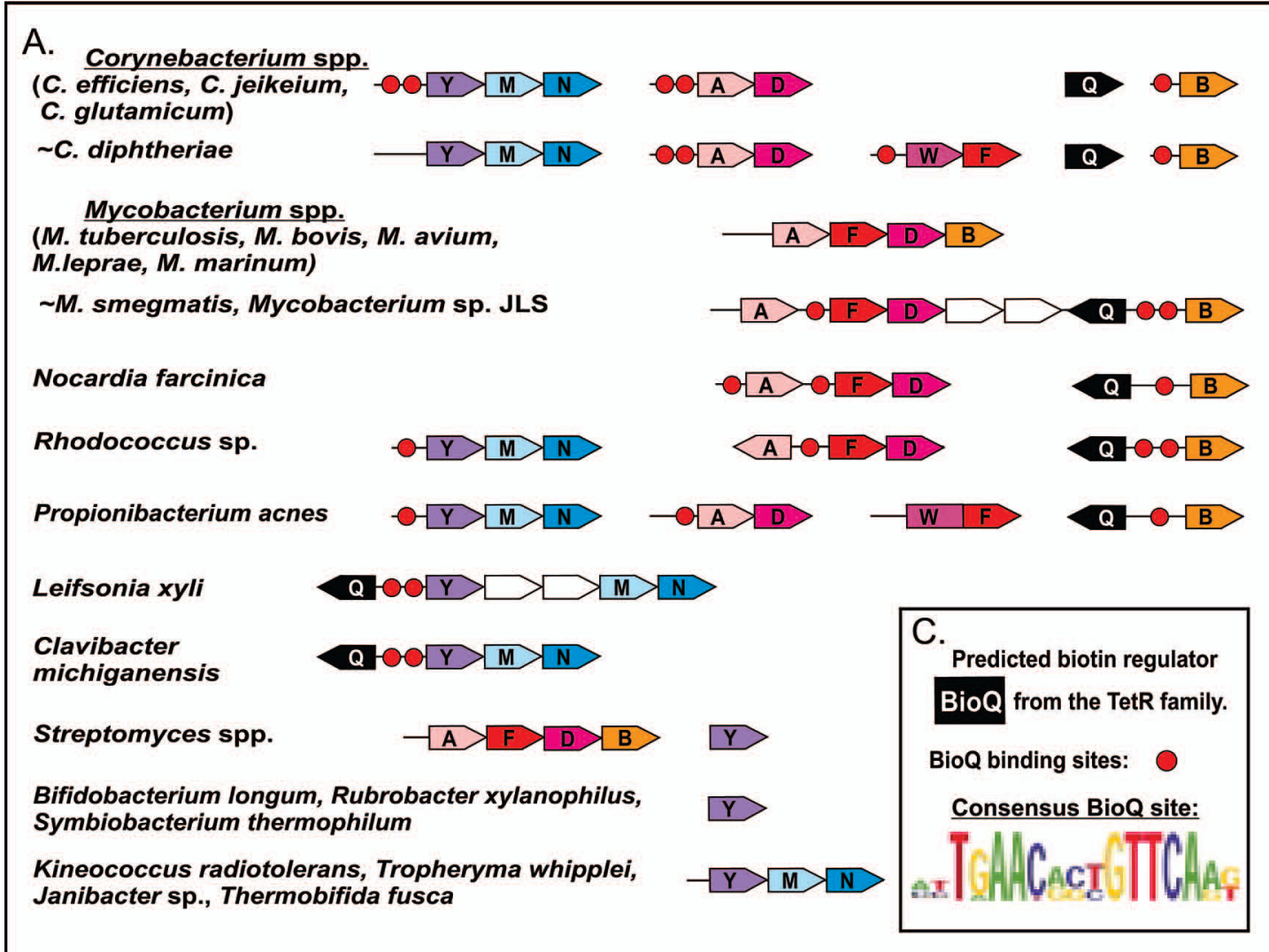

B. (C. efficiens, C. jeikeium,
C. glutamicum)
$\sim$ C. diphtheriae

Figure 6. Novel biotin regulon BioQ in Actinobacteria tentatively predicted by Strategy IIa A. Chromosomal clusters of biotin synthesis and transport genes (shown by arrows) and localization of candidate BioQ-binding sites (red circles). Homologous genes are marked by matching colors.

B. Biotin biosynthesis and uptake pathway.

C. Consensus sequence logo for the predicted BioQ-binding sites. 


\begin{tabular}{|c|c|c|c|c|c|c|c|c|c|c|c|c|c|c|c|c|c|c|c|c|}
\hline \multirow{3}{*}{ 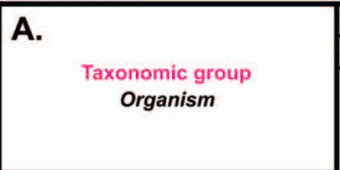 } & \multicolumn{10}{|c|}{ L-Rhamnose catabolic pathway } & \multirow{2}{*}{\multicolumn{3}{|c|}{$\begin{array}{l}\text { L-Rhamnose } \\
\text { transport }\end{array}$}} & \multirow{2}{*}{\multicolumn{4}{|c|}{$\begin{array}{l}\text { Transcriptional } \\
\text { regulators }\end{array}$}} & \multirow{2}{*}{\multicolumn{3}{|c|}{$\begin{array}{c}\text { Rha-GA } \\
\text { utilization }\end{array}$}} \\
\hline & \multicolumn{2}{|c|}{ Isomerase } & \multirow[b]{2}{*}{\begin{tabular}{|l|}
$\frac{m}{0}$ \\
$\frac{w}{\alpha}$ \\
$\frac{w}{\alpha}$
\end{tabular}} & \multicolumn{2}{|c|}{ Aldolase } & \multirow[b]{2}{*}{ 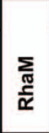 } & \multicolumn{4}{|c|}{ Lactaladehyde util. } & & & & & & & & & & \\
\hline & & 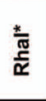 & & $\begin{array}{l}\frac{0}{\tilde{\frac{\sigma}{\alpha}}} \\
\frac{\alpha}{\alpha}\end{array}$ & 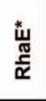 & & $\begin{array}{l}\text { N్ } \\
\frac{\pi}{\alpha}\end{array}$ & 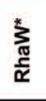 & $\frac{\pi}{4}$ & 怘 & 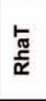 & $\begin{array}{l}\frac{*}{T} \\
\frac{0}{0} \\
\frac{u}{\pi} \\
\frac{\pi}{\alpha}\end{array}$ & 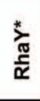 & 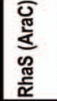 & $\begin{array}{l}\bar{\sigma} \\
\frac{\pi}{\Delta} \\
\bar{\alpha}\end{array}$ & $\begin{array}{l}\overline{\bar{J}} \\
\underset{\widetilde{N}}{\tilde{\Sigma}}\end{array}$ & 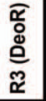 & 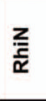 & 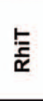 & 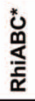 \\
\hline$\gamma$-proteobacteria & & & & & & & & & & & & & & & & & & & & \\
\hline Escherichia coli & s & & s & s & & s & & & u & u & $s$ & & & s & & & & & & \\
\hline Salmonella typhimurium & $\mathbf{s}$ & & $\mathbf{s}$ & $\mathbf{s}$ & & $\mathbf{s}$ & $\mathbf{s}$ & & & $u$ & $\mathbf{s}$ & & & $\mathbf{s}$ & & & & $\mathbf{s}$ & & $\mathbf{s}$ \\
\hline Klebsiella pneumoniae & $\mathbf{s}$ & & $\mathbf{s}$ & $\mathbf{s}$ & & $\mathbf{s}$ & s & & u & u & $\mathbf{s}$ & $\mathbf{s}$ & & s & & & & & & \\
\hline Erwinia carotovora & s & & $\mathbf{s}$ & s & & s & & & $\mathbf{s}$ & u & $\mathbf{s}$ & & & $\mathbf{s}$ & & & & & & $\mathbf{s}$ \\
\hline Erwinia chrysanthemi & $\mathbf{s}$ & & $\mathbf{s}$ & $\mathbf{s}$ & & $\mathbf{s}$ & & & & $\mathbf{s}$ & & & & s & & & & & & \\
\hline Mannheimia succiniciproducens & $\mathrm{s}$ & & s & s & & s & & & & s & s & & & s & & & & & & \\
\hline Bacillus/Clostridium group & & & & & & & & & & & & & & & & & & & & \\
\hline Bacillus subtilis, B. halodurans & R3 & & R3 & & $\underline{\mathbf{R} 3}$ & R3 & & $\underline{\mathbf{R} 3}$ & & & & & & & & & R3 & u & & $u$ \\
\hline Bacillus clausii & R1 & & R1 & & $\underline{\mathrm{R}}$ & R1 & & $\underline{\mathrm{R}}$ & & & & & R1 & & R1 & & & & & \\
\hline Bacillus licheniformis & & R3 & R3 & & $\overline{\mathrm{R} 3}$ & & & $\overline{\mathrm{R} 3}$ & & & & & u & & & & R3 & u & & u \\
\hline Oceanobacillus iheyensis & R3 & & R3 & R3 & & R3 & & & R3 & & & & R3 & & & & R3 & & & \\
\hline Enterococcus faecium & $\begin{array}{l}\text { R1 } \\
\text { R1 }\end{array}$ & & $\begin{array}{l}\text { R1 } \\
\text { R1 }\end{array}$ & $\begin{array}{l}\text { R1 } \\
\text { R1 }\end{array}$ & & $\begin{array}{l}\text { R1 } \\
\text { R1 }\end{array}$ & & & & R1 & & & R1 & & R1 & & & R1 & & R1 \\
\hline \begin{tabular}{|l} 
Listerla monocylogenes \\
\end{tabular} & & & & & & & & & & & & & & & & & & & & \\
\hline $\begin{array}{c}\text { a-proteobacteria } \\
\text { Rhizobiaceae (ML } R L, S M, A T \text { ) }\end{array}$ & & R3' & & & R3' & & & R3' & & & & R3' & & & & & R3' & & & \\
\hline Rhizobiaceae (ML, RL, SM, AT) & R3' & & Ro & & $\frac{\mathrm{KJ}}{\mathrm{R}^{\prime}}$ & $R_{3}$ & & $\frac{R^{\prime}}{R^{\prime}}$ & & & & R3. & & & & & (3) & & & \\
\hline Actinobacteria & & & & & & & & & & & & & & & & & & & & \\
\hline Streptomyces coelicolor & & R2 & R2 & & R2 & R2 & & R2 & u & & & R2 & & & & R2 & & & & \\
\hline Mycobacterium smegmatis & & R2 & R2 & & $\underline{\text { R2 }}$ & R2 & & $\underline{\mathrm{R} 2}$ & & & & & R2 & & & R2 & & & & \\
\hline Nocardia farcinica & & R2 & R2 & & $\overline{\mathrm{R} 2}$ & R2 & & $\overline{\mathrm{R2}}$ & & & & & R2 & & & R2 & & & & \\
\hline
\end{tabular}

B. L-rhamnose Rhamnogalacturonides

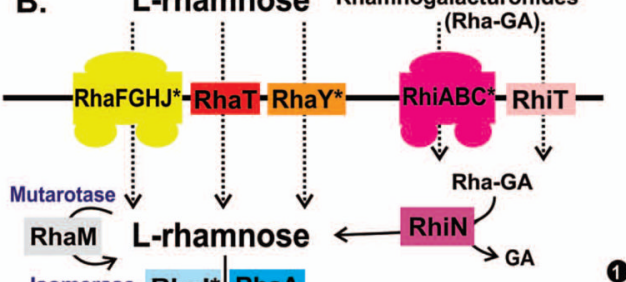

D. Rhas (AraC)

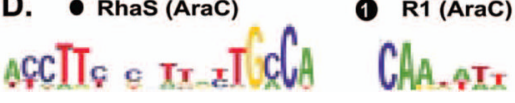

C. Bacillus subtilis (33) $\mathrm{W}^{*} \mathrm{E}^{*}>\mathrm{R} 3 \mathrm{~B} \rightarrow \mathrm{M}$ Bacillus licheniformis 3.3 $-W^{*} E^{*}>\square I^{*}>B>R$ RhiN $>$ RhiA

Oceanobacillus iheyensis 33 $\sqrt{Y^{*}}>3 \times 3>A>D>R 3$

Enterococcus faecium

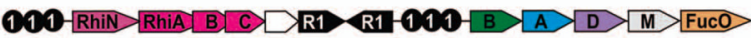
Erwinia carotovora

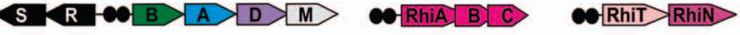
Erwinia chrysanthemi

S R R eolB $>$ A $>D>M>$

RhiT RhiN

Klebsiella pneumoniae

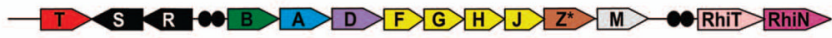

Salmonella typhimurium

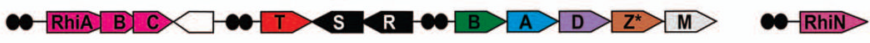

Rhizobiaceae (ML, RL, SM, ATU)

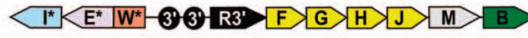

Streptomyces coelicolor $\left\langle B<E^{*}\right| W^{*}<I^{*}-2-F>G>H>J>M>\square-R 2$

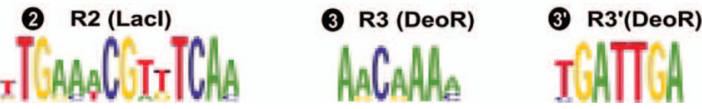

Figure 7. Reconstruction of L-rhamnose utilization system in bacteria

A. Occurence and features of genes involved in L-rhamnose utilization. Species in several taxonomic groups of bacteria are shown as rows. the presence of genes for the respective functional roles (columns) is shown by capital letters corresponding to the four identified rhamnose regulons: S, RahS regulon (as in E. coli); R1, R2, R3, and R3' correspond to the novel regulons of the same names. Other genes that were not identified within the above rhamnose regulons are marked by ' $U$ '. Genes clustered on the chromosome (operons) are outlined by matching background colors. Tentatively predicted functional roles are marked by asterisks. Functional roles corresponding to the predicted bifunctional enzymes RhaE-RhaW are underlined. The four Rhizobiaceae genomes that have the same set of genes and genome 
context are Mesorhizobium loti (ML), Agrobacterium tumefaciens (AT), Rhizobium leguminosarum (RL), and Sinorhizobium meliloti (SM).

B. The reconstructed L-rhamnose utilization pathway.

C. Chromosomal clusters of L-rhamnose utilization genes (arrows) and localization of candidate binding sites (circles) for rhamnose-specific TFs. The genes corresponding to the rhamnose-specific regulators RhaS, RhaR, R1, R2, and R3 are shown by black arrows with S, $\mathrm{R}, \mathrm{R} 1, \mathrm{R} 2$, and R3 letters, respectively. Other homologous genes are marked by matching colors.

D. Consensus sequence logos for predicted binding sites of rhamnose-specific TFs. The corresponding TF protein family name is given in parenthesis. 
Table 1

Symmetry of some bacterial transcription factor binding sites.

\begin{tabular}{|c|c|c|c|c|}
\hline Transcription factor & Consensus half site ${ }^{a}$ & Type $^{b}$ & Site size, nt & Site structure ${ }^{c}$ \\
\hline Biotin repressor BirA ${ }^{72}$ & WTGTAAACC & IR & $32-34$ & $-->14-16 \mathrm{nt}<-$ \\
\hline cAMP receptor protein $\mathrm{Crp}^{149}$ & WWWTGTGA & IR & 22 & $-->6<--$ \\
\hline $\begin{array}{l}\text { Catabolic control protein } \\
\text { CcpA } A^{151}\end{array}$ & WTGWAASC & IR & 16 & $-->0<--$ \\
\hline Arabinose activator $\mathrm{AraC}^{66}$ & YAGCNKNWNWRTCCATA & $\mathrm{DR}$ & 38 & $-->4-->$ \\
\hline Gluconate repressor GntR $\mathrm{R}^{65}$ & SWATGTTACC & IR & 20 & $-->0<--$ \\
\hline Xylose repressor XylR 67 & GTTWGTTWWW & IR & 21 & $-->3<--$ \\
\hline Heat shock repressor HrcA ${ }^{68}$ & TTAGCACTC & IR & 27 & $-->9<--$ \\
\hline NAD repressor NadR ${ }^{71}$ & TGTTTA & IR & 18 & $-->6<--$ \\
\hline Nickel repressor NikR 199 & GTATGA & IR & $27-28$ & $-->15-16 \mathrm{nt}<-$ \\
\hline Methionine repressor MetJ ${ }^{226}$ & RRACRTMY & $\mathrm{DR}$ & 24 & $-->0$--> 0 --> \\
\hline Iron repressor RirA ${ }^{205}$ & SWTGA & IR & 19 & $-->9<--$ \\
\hline
\end{tabular}

${ }^{a}$ Degenerate nucleotides designations are M (A or C), W (A or T), R (A or G), K ( $\mathrm{T}$ or G), S (G or C), Y (T or C), and N stands for any nucleotide.

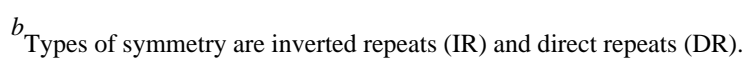

${ }^{c}$ Arrows and numbers show respective orientation of the half sites and distance between them. 


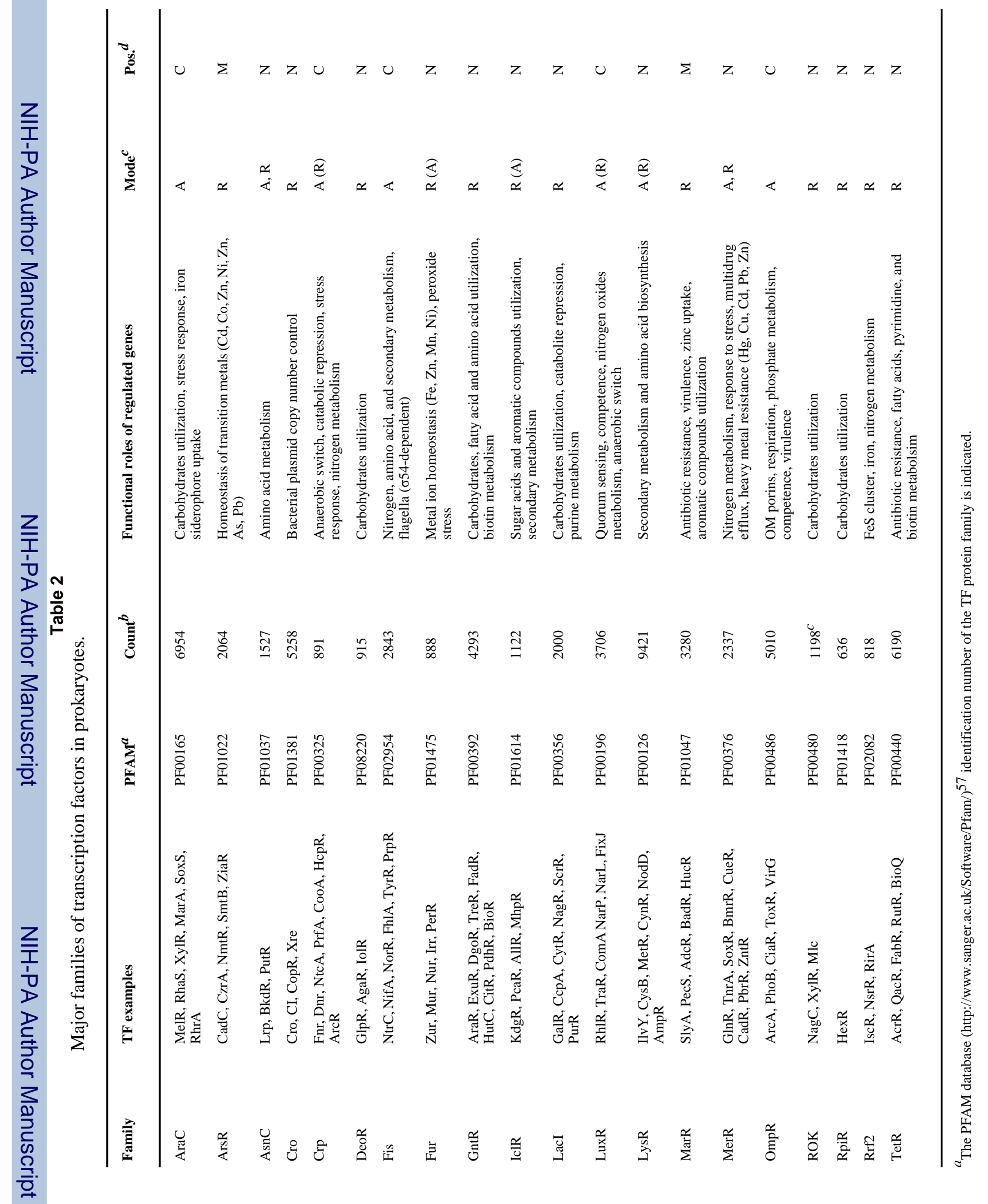

Chem Rev. Author manuscript; available in PMC 2009 February 16. 


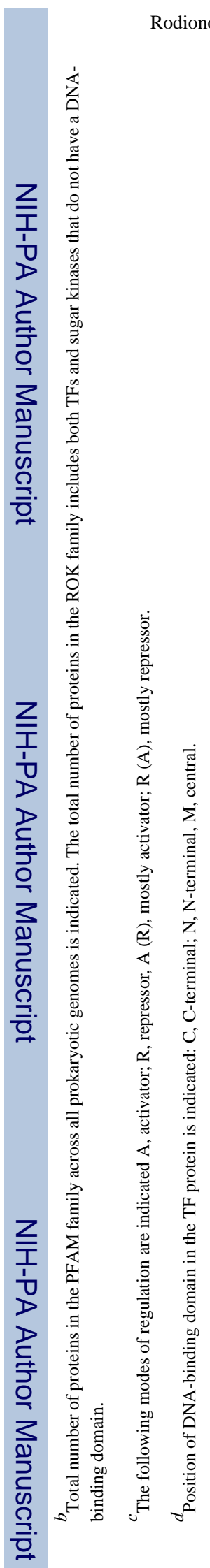

Chem Rev. Author manuscript; available in PMC 2009 February 16. 
Table 3

Databases for microbial TFs and TFBSs.

\begin{tabular}{|c|c|c|c|}
\hline Name & URL & Description & Ref. \\
\hline RegulonDB & http://regulondb.ccg.unam.mx/ & $\begin{array}{l}\text { DB of transcriptional } \\
\text { regulation (TFs, TFBSs) } \\
\text { in } E \text {. coli (literature data } \\
\text { and predictions) }\end{array}$ & 78 \\
\hline DBTBS & http://dbtbs.hgc.jp & $\begin{array}{l}\text { DB of transcriptional } \\
\text { regulation (TFs, TFBSs) } \\
\text { in B. subtilis (literature } \\
\text { data and predictions) }\end{array}$ & 79 \\
\hline CoryneRegNet & https://www.cebitec.uni-bielefeld.de/groups/gi/software/coryneregnet/ & $\begin{array}{l}\text { DB of TFs and TRNs in } \\
\text { Corynebacteria }\end{array}$ & 80 \\
\hline MtbRegList & http://mtbreglist.dyndns.org/MtbRegList/ & $\begin{array}{l}\text { DB for analysis of gene } \\
\text { expression and regulation } \\
\text { data in Mycobacterium } \\
\text { tuberculosis }\end{array}$ & 81 \\
\hline cTFbase & http://cegwz.com/ & $\begin{array}{l}\text { DB for compararative } \\
\text { genomics of TFs in } \\
\text { Cyanobacteria }\end{array}$ & 88 \\
\hline DBD & http://transcriptionfactor.org & $\begin{array}{l}\mathrm{DB} \text { of TF and families } \\
\text { prediction (all genomes) }\end{array}$ & 56 \\
\hline ExtraTrain & http://www.era7.com/ExtraTrain & $\begin{array}{l}\text { DB of extragenic regions } \\
\text { and TFs in prokaryotes }\end{array}$ & 82 \\
\hline BacTregulators & http://www.bactregulators.org/ & $\begin{array}{l}\text { DB of TFs in prokaryotes } \\
\text { (specific TF families) }\end{array}$ & 86 \\
\hline Sentra & http://compbio.mcs.anl.gov/sentra & $\begin{array}{l}\text { DB of sensory signal } \\
\text { transduction proteins }\end{array}$ & 87 \\
\hline PRODORIC & http://prodoric.tu-bs.de & $\begin{array}{l}\text { DB of prokaryotic gene } \\
\text { regulation (several } \\
\text { specific organisms) }\end{array}$ & 89 \\
\hline RegTransBase & http://regtransbase.lbl.gov & $\begin{array}{l}\text { DB of TFBSs and } \\
\text { regulatory interactions in } \\
\text { prokaryotes (literature } \\
\text { data and predictions) }\end{array}$ & 90 \\
\hline TRACTOR & http://www.tractor.lncc.br/ & $\begin{array}{l}\text { DB of TRNs and TFBSs in } \\
\gamma \text {-proteobacteria }\end{array}$ & 91 \\
\hline
\end{tabular}


Table 4

Transcription factors and regulons analyzed by comparative genomics methods.

\begin{tabular}{|c|c|c|c|}
\hline Regulated metabolic pathway & Regulon $^{m}$ & Phylogenetic distribution ${ }^{n}$ & Strategy ${ }^{o}$ \\
\hline \multicolumn{4}{|l|}{ Sugar utilization pathways } \\
\hline Pectin 119,206 & $\mathrm{KdgR}$ & $\gamma($ Ent, Vib) & Ia \\
\hline \multirow[t]{3}{*}{ Chitin $^{203}$} & $\mathrm{NagC}$ & $\gamma($ Ent, Vib) & Ia \\
\hline & $\mathrm{NagR}^{*}$ & $\gamma($ Alt, Xan) & IIa \\
\hline & NagQ* & $\gamma($ Pse $), \beta, \alpha$ & IIa \\
\hline Glucuronate $^{119}$ & UxuR & $\gamma($ Ent, Pas) & $\mathrm{Ib}$ \\
\hline Gluconate $^{119}$ & GntR & $\gamma($ Ent, Vib) & $\mathrm{Ib}$ \\
\hline Arabinose $^{120121}$ & AraC, AraR & $\gamma($ Ent), $\mathrm{BCl}$ & Ia \\
\hline Xylose $^{120,121}$ & XylR & $\gamma$ (Ent, Pas), BCl & $\mathrm{Ib}$ \\
\hline Ribose $^{120,121}$ & RbsR & $\gamma, \mathrm{BCl}$ & $\mathrm{Ib}$ \\
\hline Rhamnose $^{a}$ & $\mathrm{RhaS}, \mathrm{R} 1 *, \mathrm{R} 2 *, \mathrm{R} 3 *$ & $\gamma, \alpha, \mathrm{BCl}, \mathrm{Act}$ & Ia, IIa \\
\hline Glycerol $^{b}$ & GlpR & $\gamma($ Ent, Vib, Pse) & $\mathrm{Ib}$ \\
\hline \multicolumn{4}{|l|}{ Metal homeostasis } \\
\hline \multirow[t]{3}{*}{ Iron $123,240,241, c$} & Fur & $\gamma($ Ent, Vib, Pse) $, \delta, \alpha$ & $\mathrm{Ia}, \mathrm{Ib}$ \\
\hline & Irr, RirA & $\alpha$ & $\mathrm{Ib}$ \\
\hline & IdeR & Act & Ia \\
\hline Zinc $^{124}$ & Zur & $\gamma($ Ent, Vib), $\alpha$ & $\mathrm{Ib}$ \\
\hline Manganese $^{240}$ & Mur, MntR & $\alpha$ & $\mathrm{Ib}$ \\
\hline Nickel $^{234,241}$ & NikR & $\gamma, \beta, \alpha, \delta, \varepsilon, \mathrm{BCl}, \mathrm{Arc}$ & $\mathrm{Ia}, \mathrm{Ib}$ \\
\hline Molybdenum $^{d}, 241$ & ModE & $\gamma, \delta, \mathrm{CFB}, \mathrm{Arc}$ & Ia \\
\hline Heavy metal resistance 260 & $\begin{array}{l}\text { CueR, CadR, HmrR, } \\
\text { PbrR }\end{array}$ & $\gamma, \beta, \alpha, \mathrm{BCl}$ & Ia \\
\hline \multicolumn{4}{|c|}{ Co-factors and amino acid metabolism } \\
\hline \multirow[t]{4}{*}{$\mathrm{NAD}^{69} e$} & $\mathrm{NadR}$ & $\gamma($ Ent $)$ & Ia \\
\hline & YrxA & $\mathrm{BCl}$ & IIa \\
\hline & NadQ* & $\alpha, \beta$ & IIa \\
\hline & $\mathrm{NrtR}^{* *}$ & Cya, Act & IIa \\
\hline \multirow[t]{3}{*}{ Biotin $^{70,208}, a$} & BirA & $\gamma, \beta, \varepsilon, \mathrm{BCl}, \mathrm{Arc}$ & $\mathrm{Ia}, \mathrm{Ib}$ \\
\hline & BioR* & $\alpha$ & IIa \\
\hline & BioQ* & Act & IIa \\
\hline Aromatic amino acids 125,129 & TyrR, TrpR & $\gamma($ Ent, Vib, Pas) & Ia \\
\hline Arginine 9,129 & $\operatorname{ArgR}$ & $\gamma, \mathrm{BCl}, \mathrm{TM}$ & Ia \\
\hline \multicolumn{4}{|l|}{ Nitrogen metabolism } \\
\hline \multirow[t]{3}{*}{ Nitrogen assimilation $127, f, g$} & $\mathrm{NtcA}$ & Cya & Ia \\
\hline & TnrA, GlnR & $\mathrm{BCl}$ & Ia \\
\hline & $\mathrm{NtrC}$ & $\gamma($ Ent, Vib, Pse $), \alpha$ & Ia \\
\hline \multirow[t]{2}{*}{ Nitrogen fixation ${ }^{g}, 103,215$} & NifA & $\alpha$ & Ia \\
\hline & NrpR & Arc & IIa \\
\hline Denitrification $^{216}$ & Dnr, NnrR & $\gamma, \beta, \alpha$ & $\mathrm{Ib}$ \\
\hline
\end{tabular}




\begin{tabular}{|c|c|c|c|}
\hline Regulated metabolic pathway & Regulon $^{m}$ & Phylogenetic distribution $^{n}$ & Strategy ${ }^{o}$ \\
\hline Nitrogen oxides respiration 126 & NarP & $\gamma($ Ent, Pas, Vib) & $\mathrm{Ib}$ \\
\hline \multirow[t]{3}{*}{ Nitrogen oxides detoxification ${ }^{216}$} & NsrR & $\gamma, \beta, \alpha, \mathrm{BCl}, \mathrm{Act}$ & $\mathrm{IIb}$ \\
\hline & $\mathrm{HcpR}^{*}$ & $\delta, \mathrm{BCl}, \mathrm{CFB}, \mathrm{Cya}, \mathrm{TM}$ & $\mathrm{Ilb}$ \\
\hline & NorR & $\gamma, \beta$ & $\mathrm{Ib}$ \\
\hline \multicolumn{4}{|l|}{ Other metabolic pathways } \\
\hline Heat shock ${ }^{122}$ & HrcA, sigma-32 & $\gamma, \beta, \varepsilon$ & Ia \\
\hline DNA damage (SOS system) $h, j$ & LexA & $\gamma, \beta, \alpha$, Суа, ВCl & Ia \\
\hline Ribonucleotides metabolism 147,148 & $\mathrm{NrdR}^{* *}$ & Bacteria & IIa, IIb \\
\hline Purine biosynthesis ${ }^{129} i$ & PurR & $\gamma($ Ent, Vib, Pas) & Ia \\
\hline Anaerobic respiration 197 & Fnr & $\gamma($ Ent, Vib, Pas) & Ia \\
\hline Global catabolic regulation ${ }^{27}$ & Crp & $\gamma($ Ent, Vib, Pas) & Ia \\
\hline Fatty acid biosynthesis 129 & $\mathrm{FabR}^{* *}$ & $\gamma($ Ent) & $\mathrm{IIb}$ \\
\hline Phosphate metabolism $^{k}$ & PhoB & $\gamma, \alpha$ & Ia \\
\hline Sporulation $^{l}$ & Spo0A & $\mathrm{BCl}$ & $\mathrm{Ib}$ \\
\hline
\end{tabular}

${ }^{a}$ Analyzed in this study regulons

${ }^{b}$ Reference 277

${ }^{c}$ Reference 278

$d_{\text {Reference } 279}$

$e^{e}$ D.A.R., manuscript in preparation

$f_{\text {Reference } 280}$

${ }^{g}$ D.A.R. and Natalia Doroshchuk, unpublished observation

$h_{\text {Reference }} 281$

$j_{\text {Reference }} 282$

${ }^{i}$ Reference 283

$k_{\text {Reference } 284}$

${ }^{l}$ Reference 285

$m$ Novel regulons tentatively predicted by comparative genome analysis and those of them that were experimentally confirmed are marked by one and two asterisks, respectively.

${ }^{n} \mathrm{~A}$ Vibrionales; Alt, Altermonadales; Xan, Xanthomonadales; Pse, Pseudomonadales; Pas, Pasteurellales; BCl, Bacillus/Clostridium group; Act, actinobacteria; Arc, Archaea; CFB, Chlorobium/Bacteroides group; Cya, Cyanobacteria; TM, Thermotogales.

${ }^{o}$ Strategies for regulon analysis are described in Figure 5 
Table 5

Binding motif details for microbial TFs analyzed by comparative genomics.

\begin{tabular}{|c|c|c|c|c|}
\hline Metabolic pathway & Regulon & Phylogenetic distribution & Binding site consensus $\log 0^{a}$ & TF family \\
\hline \multirow{3}{*}{$\begin{array}{l}\text { Chitin and N-acetyl- } \\
\text { glucosamine utlization }\end{array}$} & $\mathrm{NagC}$ & $\gamma$-proteobacteria (Enterobacteriales, Vibrionales) & & ROK \\
\hline & NagR & $\gamma$ (Alteromonadales, Xanthomonadales) & & LacI \\
\hline & NagQ & $\begin{array}{l}\gamma \text { (Pseudomonadales), } \\
\beta \text { (Burkholderiales), } \\
\alpha(\text { Rhizobiales, Caulobacter) }\end{array}$ & & GntR \\
\hline Pectin utilization & $\operatorname{KdgR}$ & $\gamma$ (Enterobacteriales, Vibrionales) & & IclR \\
\hline Glucuronate utilization & UxuR & $\gamma($ Enterobacteriales, Pasteurellales) & & GntR \\
\hline Gluconate utilization & GntR & $\gamma($ Enterobacteriales, Vibrionales) & & LacI \\
\hline \multirow[t]{2}{*}{ Nitrogen assimilation } & NtcA & Cyanobacteria & & Fnr \\
\hline & TnrA & Bacillus/Clostridium group & & MerR \\
\hline \multirow[t]{2}{*}{ Nitrogen fixation } & NifA & $\alpha$-proteobacteria & & Fis \\
\hline & NrpR & Methanogenic archaea & & COG1693 \\
\hline \multirow[t]{4}{*}{ Biotin metabolism } & BirA & $\gamma$ - and $\beta$-proteobacteria & & BirA \\
\hline & BirA & Bacillus/Clostridium group, Archaea & & BirA \\
\hline & BioR & $\alpha$-proteobacteria & & GntR \\
\hline & BioQ & Actinobacteria & & TetR \\
\hline \multirow[t]{3}{*}{ NAD metabolism } & $\mathrm{NadR}$ & $\gamma($ Enterobacteriales $)$ & & NadR \\
\hline & YrxA & Bacillus/Clostridium group, TM & & COG1654 \\
\hline & NrtR & Cyanobacteria, Actinobacteria & & COG1051 \\
\hline
\end{tabular}




\begin{tabular}{llll}
\hline Metabolic pathway & Regulon & Phylogenetic distribution & Binding site consensus logo ${ }^{a}$ \\
\hline NadQ & $\alpha$ - and $\beta$-proteobacteria &
\end{tabular}

${ }^{a}$ Sequence logos were generated by the WebLogo tool (http://weblogo.berkeley.edu). 
Table 6

Cross-talk in transcriptional regulation of isozymes with different cofactor requirement.

\begin{tabular}{|c|c|c|}
\hline Isozyme $^{a}$ & Cofactor & Regulon and its effector $b$ \\
\hline \multicolumn{3}{|c|}{$\underline{\text { Ribonucleotide reductase: }}(\alpha, \mathrm{BCl}, \mathrm{Act}, \mathrm{CFB})$} \\
\hline NrdJ & {$\left[\mathrm{B}_{12}\right]$} & - \\
\hline NrdAB or NrdDG & - & {$\left[\mathrm{B}_{12}\right]$-riboswitch (represses) } \\
\hline \multicolumn{3}{|c|}{ Methionine synthase: $(\alpha, \mathrm{BCl}, \mathrm{Act}, \mathrm{CFB})$} \\
\hline MetH & {$\left[\mathrm{B}_{12}\right]$} & - \\
\hline MetE & - & {$\left[\mathrm{B}_{12}\right]$-riboswitch (represses) } \\
\hline \multicolumn{3}{|c|}{ Fumarate hydratase: $(\gamma)$} \\
\hline FumA & {$[\mathrm{Fe}]$} & [Fe]-Fur (activates) \\
\hline FumC & - & {$[\mathrm{Fe}]-F u r$ (represses) } \\
\hline \multicolumn{3}{|c|}{ Fumarate hydratase: $(\alpha)$} \\
\hline FumA & {$[\mathrm{Fe}]$} & - \\
\hline FumC & - & [Fe]-RirA (represses) \\
\hline \multicolumn{3}{|c|}{$\underline{\text { Superoxide dismutases: }}(\gamma)$} \\
\hline SodB & {$[\mathrm{Fe}]$} & [Fe]-Fur (activates) \\
\hline SodA & {$[\mathrm{Mn}]$} & {$[\mathrm{Fe}]-$ Fur (represses) } \\
\hline \multicolumn{3}{|c|}{ Electron transfer proteins: $(\delta)$} \\
\hline ferredoxin & {$[\mathrm{Fe}]$} & - \\
\hline flavodoxin & - & [Fe]-Fur (represses) \\
\hline \multicolumn{3}{|l|}{ Hydrogenases: $(\delta)$} \\
\hline$[\mathrm{Ni}-\mathrm{Fe}] \mathrm{Hyd}$ & {$[\mathrm{Ni}-\mathrm{Fe}]$} & - \\
\hline$[\mathrm{Fe}] \mathrm{Hyd}$ & {$[\mathrm{Fe}]$} & [Ni]-NikR (represses) \\
\hline \multicolumn{3}{|c|}{ GTP cyclohydrolase I: $(\mathrm{BCl}, \gamma, \beta)$} \\
\hline FolE & {$[\mathrm{Zn}]$} & - \\
\hline YciA & [?] & [Zn]-Zur (represses) \\
\hline
\end{tabular}

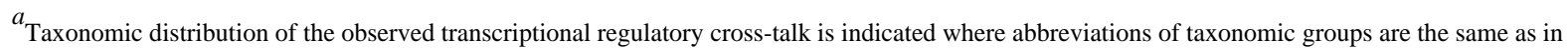
Table 4.

${ }^{b}$ Regulatory effector molecules are shown in square brackets. Positive or negative mechanism of regulation is indicated in parenthesis. 
Table 7

Regulatory systems for methionine and aromatic amino acid metabolism in bacteria.

\begin{tabular}{|c|c|c|c|c|}
\hline System & Type $^{a}$ & Effector $b$ & Phylogenetic distribution $c$ & Regulated genes $^{d}$ \\
\hline \multicolumn{5}{|l|}{ A. Methionine } \\
\hline MetJ & TF (MetJ) & SAM & $\gamma($ Ent, Pas, Vib, Alt) & $\begin{array}{l}\text { metK (SAM synthesis); } \\
\text { metABCFEHY (Met } \\
\text { synthesis); } \\
\text { metNPQ, met } T \text { (Met } \\
\text { transport) } \\
\text { metJ (autoregulation) }\end{array}$ \\
\hline MetR & TF (LysR) & Homo-cysteine & $\begin{array}{l}\gamma \text { (Ent, Vib, Alt, Pse), } \\
\beta \text { (Bor, Bur, Ral) }\end{array}$ & $\begin{array}{l}\text { In Ent: metAEFH (Met } \\
\text { synthesis); } \\
\text { metR (autoregulation) }\end{array}$ \\
\hline McbR & TF (TetR) & $\mathrm{SAH}$ & Act (Corynebacteria) & $\begin{array}{l}\text { metK (SAM synthesis); } \\
\text { metBFEHXY (Met } \\
\text { synthesis); } \\
\text { cysNDHIJEK (sulfur } \\
\text { assimilation) }\end{array}$ \\
\hline SAM-I (S-box) & riboswitch & SAM & $\begin{array}{l}\mathrm{BCl}(\mathrm{Bac}, \mathrm{Clost}), \gamma \text { (Xan), } \delta \\
(\mathrm{Geo}), \mathrm{TM}, \mathrm{DR}, \mathrm{FN}, \mathrm{CT}\end{array}$ & $\begin{array}{l}\text { met } K \text { (SAM synthesis); } \\
\text { metBCFEHIXY (Met } \\
\text { synthesis); } \\
\text { metNPQ, met } T \text { (Met } \\
\text { transport) }\end{array}$ \\
\hline SAM-II & riboswitch & SAM & $\alpha, \beta$ (Bor), CFB & $\begin{array}{l}\text { metK (SAM synthesis); } \\
\text { metACHXY (Met } \\
\text { synthesis); }\end{array}$ \\
\hline \multirow[t]{2}{*}{ MtaR / MET-box } & TF (LysR) & Met & $\mathrm{BCl}$ (Strep, LL) & $\begin{array}{l}\text { In Strep: metNPQ (Met } \\
\text { transport); } \\
\text { metBEFIY (Met } \\
\text { synthesis). }\end{array}$ \\
\hline & & & & $\underline{\text { In LL: }}$ metEF only \\
\hline CmbR / CYS-box & TF (LysR) & O-acetyl-serine & $\mathrm{BCl}$ (LL, Strep) & $\begin{array}{l}\text { Experimental data in LL } \\
\text { only: } \\
\text { cysM, tcy (Cys } \\
\text { synthesis, transport); } \\
\text { yrhBA (Met to Cys } \\
\text { synthesis); } \\
\text { met } N P Q \text {, (Met } \\
\text { transport); } \\
\text { metBIY (Met synthesis) }\end{array}$ \\
\hline Met-T-box & antiterminator & Met-tRNA & $\mathrm{BCl}$ (LB, Bac, Clost) & $\begin{array}{l}\text { In LB: } m e t B C F E I Y \\
\text { (Met synthesis); } \\
\text { metNPQ (Met } \\
\text { transport). }\end{array}$ \\
\hline SAM-III & riboswitch & SAM & BCl (LB, Strep, LL) & $\begin{array}{l}\text { In Bac, Clost: met } S \\
\text { (tRNA synthesis) } \\
\text { metK (SAM synthesis) }\end{array}$ \\
\hline \multicolumn{5}{|c|}{ B. Aromatic amino acids } \\
\hline TrpR & $\mathrm{TF}$ (TrpR) & $\operatorname{Trp}$ & $\begin{array}{l}\gamma(\text { Ent, Pas, Vib, Alt), } \\
\text { Chlamydia }\end{array}$ & $\begin{array}{l}\text { In Ent, Pas, Vib: aro, } \\
\operatorname{trp} \text { (Trp synthesis); } m t r \\
\text { (Trp transport); } \\
\text { trpR (autoregulation). } \\
\text { In Alt: aro, tyr (Tyr } \\
\text { synthesis); } \\
\text { tyrP (Tyr transport); } \\
\text { trpR. } \\
\text { In Chlamydia: } \operatorname{trp} \text { (Trp } \\
\text { synthesis) }\end{array}$ \\
\hline TyrR & TF (TyrR) & Tyr, Phe & $\gamma($ Ent, Pas, Vib, Alt, Pse $)$ & $\begin{array}{l}\text { In Ent, Pas, Vib: aro, } \\
\text { tyr, tyrP, aroP } \\
\text { (Tyr, Phe synthesis and } \\
\text { transport); } \\
\text { tyrR (autoregulation). }\end{array}$ \\
\hline
\end{tabular}

Chem Rev. Author manuscript; available in PMC 2009 February 16. 


\begin{tabular}{|c|c|c|c|c|}
\hline System & Type $^{a}$ & Effector $^{b}$ & Phylogenetic distribution $c$ & Regulated genes $^{d}$ \\
\hline & & & & $\begin{array}{l}\text { In Pse: Phe and Tyr } \\
\text { catabolism. }\end{array}$ \\
\hline Phe-atten. & attenuator & Phe-tRNA & $\gamma($ Ent, Vib, Alt $)$ & $\begin{array}{l}\text { In Alt: amino acid } \\
\text { catabolism; tyrR } \\
\text { pheA (Phe synthesis) }\end{array}$ \\
\hline Trp-atten. & attenuator & Trp-tRNA & $\gamma($ Ent, Vib, Alt, Pse), $\alpha$ & $\operatorname{trp}$ (Trp synthesis) \\
\hline TRAP & RNA-binding protein & $\operatorname{Trp}$ & $\mathrm{BCl}$ (Bac - except Bcer) & $\begin{array}{l}\operatorname{trp} \text { (Trp synthesis); } \\
\operatorname{trp} P \text { (Trp transport) }\end{array}$ \\
\hline Trp-T-box & antiterminator & Trp-tRNA & $\begin{array}{l}\text { BCl (Bcer, LB, LL, Strep, } \\
\text { Clost) }\end{array}$ & $\begin{array}{l}\operatorname{trp} \text { (Trp synthesis); } \\
\text { trpP, trpXYZ (Trp } \\
\text { transport) }\end{array}$ \\
\hline Tyr-T-box & antiterminator & Tyr-tRNA & $\mathrm{BCl}$ (LB, Bcer) & $\begin{array}{l}\text { aro, tyr (Tyr synthesis) } \\
\text { tyrT (Tyr transport) }\end{array}$ \\
\hline PCE-box & uncertain $\mathrm{TF}$ & uncertain & $\mathrm{BCl}$ (Bac - except Bcer) & aro (Tyr, Phe synthesis) \\
\hline ARO-box & uncertain $\mathrm{TF}$ & uncertain & $\mathrm{BCl}$ (LL, Strep) & aro (Tyr, Phe synthesis) \\
\hline
\end{tabular}

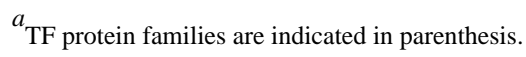

${ }^{b}$ Abbreviations for effectors: Met, methionine; Trp, tryptophan; Tyr, tyrosine; Phe, phenylalanine; SAM, S-adenosylmethionine; SAH, Sadenosylhomocysteine.

\footnotetext{
${ }^{c}$ Abbreviations for taxonomic groups are the same as in Table 3; additional abbreviations are: Bac, Bacillales; Bcer, Bacillis cereus group; LB, Lactobacilli; Strep, Streptococci; LL, Lactococcus lactis; Clost, Clostridiales; Bor, Bordetella spp.; Bur, Burkholderia spp.; Ral, Ralstonia spp.; Geo, Geobacter spp..; DR, Deinococcus radiodurans; FN, Fusobacterium nucleatum; CT, Chlorobium tepidum.

$d_{\text {Functional roles of genes and operons from the amino acid regulons are indicated in parenthesis. }}$
} 
Table 8

Major TF regulons for iron and manganese homeostasis in bacteria.

\begin{tabular}{|c|c|c|}
\hline Taxonomic group & Iron regulons $^{a}$ & Manganese regulons ${ }^{a}$ \\
\hline Cyanobacteria & Fur & - \\
\hline Actinobacteria & IdeR (DtxR family) & - \\
\hline Firmicutes & Fur & MntR (DtxR family) \\
\hline$\gamma$ (Enterobacteriales, Xanthomonadales) & Fur & MntR \\
\hline$\alpha$ (Rhizobiales) & Irr (Fur family), RirA (Rrf2 family) & Mur (Fur family) \\
\hline exception: Bradyrhizobiaceae group & Irr & Mur \\
\hline exception: Mesorhizobium loti & Irr, RirA & MntR \\
\hline$\alpha$ (Rhodobacterales) & Irr, Iron-Rhodo-box (uncertain TF) & Mur \\
\hline exception: Rhodobacter capsulatus & Irr, Iron-Rhodo-box & MntR \\
\hline$\alpha$ (other groups), $\beta, \delta, \varepsilon, \gamma$ (other groups) & Fur & - \\
\hline
\end{tabular}

$a_{\mathrm{TF}}$ protein families are indicated in parenthesis. 